\title{
The Time-varying Relationship between Liquidity and Stock Returns: Evidence from Germany
}

\author{
Thomas Paul ${ }^{\mathrm{a}}$, Abdullah Aryoubi ${ }^{\mathrm{b}}$, and Thomas Walther ${ }^{\mathrm{r}, \mathrm{d} *}$ \\ a Department of Economics, UHH University of Hamburg, Hamburg, Germany \\ ${ }^{b}$ Hamburg School of Business Administration (HSBA), Hamburg, Germany \\ ${ }^{c}$ Utrecht School of Economics, Utrecht University, Utrecht, the Netherlands \\ ${ }^{d}$ Faculty of Business and Economics, Technische Universität Dresden, Dresden, Germany
}

This study investigates the structural relationship between illiquidity and excess returns in the German stock market over time. The idea of illiquidity's impact on asset prices has been challenged in more recent research and we provide further insight into the comprehensive picture of it. We show that illiquidity is still a significant factor when periods of financial turmoil are excluded, and longer expectation formations are considered. Departing from previous studies, we do not examine the relationship between illiquidity and excess returns in exogenously fixed observation periods but rather identify the observation periods endogenously and find the structure that illiquidity is still priced but not in times of financial turmoil. We furthermore apply different variations of Amihud's illiquidity measure with various adjustments, including a control for Fama-French factors, and our results are robust. When investors incorporate the insight in portfolio decisions by interpreting a structural break of the relation between illiquidity and excess returns as a trading signal significantly better portfolio returns result.

Keywords: Illiquidity, Excess Return, Structural Breaks, Financial turmoil, Asset Pricing, Portfolio Management

Subject classification codes: E32, G12

\section{This Version: October 2021}

\section{Paul, Thomas}

Department of Economics, UHH University of Hamburg, ORCID: 0000-0002-9635-6305

Aryoubi, Abdullah

Hamburg School of Business Administration (HSBA), Hamburg, Germany, ORCID: 0000-0003-33416670

*Walther, Thomas (Corresponding Author)

Utrecht School of Economics, Utrecht University, the Netherlands, and Faculty of Business and Economics, Technische Universität Dresden, Germany, e-mail: t.walther@uu.nl, ORCID: 0000-00034359-987X

\section{Acknowledgments}

We are thankful to Nick Nguyen Hoang and Barbara Będowska-Sójka for helpful comments and suggestions. We are solely responsible for any errors. 


\section{Introduction}

According to Amihud and Mendelson (1986), illiquid assets yield higher expected returns to investors' net of transaction costs, a relationship that other authors have also confirmed (Eleswarapu 1997, Chalmers and Kadlec 1998, Hasbrouck 2009). However, while most studies formerly agreed that illiquidity is priced in expected stock returns, the idea has been challenged in more recent research. The main criticism stems from the fact that the previous results are not robust across different time periods and countries, and can only be found during the in-sample periods (Drienko, Smith, and Reibnitz 2019, Harris and Amato 2019, Ben-Rephael, Kadan, and Wohl 2015). Others criticize the finding that micro-caps largely drive the liquidity effects ${ }^{1}$. For example, Hou, Xue, and Zhang (2020) show that within portfolios, less weight from micro-caps leads to insignificant liquidity measures. $^{2}$

Controlling for the former criticisms and further aspects, we examine whether the relationship between illiquidity and excess returns in the German stock market varies over time. Thereby we do not simply fix the time periods exogenously and examine the relationship but rather identify them endogenously by applying Bai and Perron's (2003) multiple structural break point test. We additionally consider in our examination that investors base their expectation formation on different time periods in the past and therefore integrate Amihud's (2002) illiquidity measure (ILLIQ) with different rolling averages and time lags. This study has practical implications for investors and market participants as we find that the relation varies over time and that illiquidity's impact is only lost in periods of financial turmoil. Hence, when periods of financial turmoil are excluded, illiquidity still plays a significant role and investors taking structural breaks as a trading signal generate higher returns than investors solely buying and holding their portfolio. Our findings are robust to different variations of $I L L I Q$, including a control for 
Fama-French factors. We additionally quantify the magnitude of illiquidity's impact in non-crisis and crisis phases and examine how accurate our model works to ex-ante estimate returns.

The remainder of this paper is organized as follows. Section 2 provides a literature review of liquidity measures and their relationship with stock market returns. Section 3 presents the data, Section 4 offers our results for the entire sample period, and Section 5 investigates whether the relationship between excess returns and illiquidity varies over time. Section 6 conducts different robustness analyses with respect to the modified ILLIQ measures and whether our results hold after controlling for Fama and French (2015) factors. Additionally, this section analyses whether a flight-to-liquidity effect occurs, quantifies illiquidity's impact on returns and examines the estimation accuracy of ex-ante return. Finally, Section 7 presents our main conclusions.

\section{Literature Review}

\subsection{Nature of illiquidity measures and proxies}

Liquidity is present in many different financial and economic contexts, and depends on several factors as well as the asset's features, such as outstanding amount, issue status, economic activity cycle, interest rate volatility, or investor risk aversion. Therefore, liquidity is an elusive concept that is subjective in nature and difficult to measure (Díaz and Escribano 2020). Although a wide range of definitions and measures exist, none capture all of its aspects (Amihud, Mendelson, and Pedersen 2005). In this regard, Lybek and Sarr (2002), and Bervas (2006) specify five dimensions, namely tightness, immediacy, depth, breadth, and resiliency. ${ }^{3}$ As all these dimensions are different in nature, with some being interrelated, the existing literature has developed and implemented different measures to assess them, some of which can simultaneously 
capture multiple dimensions. ${ }^{4}$ For example, while bid-ask spread and trade volume measure only tightness or depth, the auto-covariance in price changes covers resilience and tightness (Bao, Pan, and Wang 2011), and the Amihud (2002) measure assesses depth, immediacy, and tightness.

Díaz and Escribano (2020) highlight that all liquidity measures can be differentiated into direct and indirect measures, latter also called proxies, and the difference between them basically results from the frequency and type of employed data. Direct measures are based on high-frequency, trade, and/or quote data, and are usually accurately computed, further processed, and difficult to obtain. On the other hand, proxies are based on low-frequency data (e.g., daily or monthly), are usually less sophisticated and complex to compute, and have higher availability and accessibility. The latter factor is a major reason why the bulk of the literature employs liquidity proxies (Fong, Holden, and Trzcinka 2017).

The Amihud (2002) ILLIQ is one of the most widely used proxies for analysis in the stock and fixed-income markets ${ }^{5}$. It is defined, for each security, as a ratio of the daily absolute stock return to its dollar-traded volume on that day and averaged over a period, showing the price change required to move a unit of dollar trading volume. Then, a market's illiquidity can be computed using the average across all stocks. According to Fong, Holden, and Trzcinka (2017), ILLIQ is the best cost-per-dollar-volume proxy on a daily and monthly basis, when compared to high-frequency liquidity benchmarks. Similarly, after examining the dependencies between monthly liquidity, spreads, and volatility in the German and Polish stock markets, from 2001 to 2016, Bedowska-Sojka (2019) confirms the strong interaction between ILLIQ and high-low spreads within the whole sample. Thus, due to ILLIQ's prevalence, explanatory power, and availability, we use it as the illiquidity proxy in this study. 


\subsection{Illiquidity and its impact on asset pricing}

According to Bank, Larch, and Peter (2012), the empirical findings related to illiquidity's influence on stock returns seem rather mixed, especially when studies employ the bid-ask spread as an illiquidity measure. They argue that the results seem to be more consistent when illiquidity measures, other than the bid-ask spread, are employed, and that although studies generally indicate that illiquidity impacts expected returns, some still fail to confirm this relationship. Highlighting this association, Amihud (2002) analyses the expected market illiquidity's time-series effects on expected excess stock returns in the U.S. stock market from 1964 to 1996 . The results reveal that expected market illiquidity has a positive and significant effect on expected excess stock returns, while unexpected market illiquidity has a negative and significant effect on contemporaneous excess stock returns. Furthermore, he demonstrates that these effects are more pronounced for small stocks, showing a substitution from less liquid to more liquid, in times of constrained market trading, which he termed "flight to liquidity." After replicating Amihud's (2002) paper Harris and Amato (2019), as well as Drienko, Smith, and Reibnitz (2019) find essentially the same results, but their application on more recent data shows a much weaker relationship between liquidity and asset pricing. Both show that only unexpected illiquidity is significant, with expected illiquidity losing its significance, and that the flight-to-liquidity effect cannot be observed. They attribute this loss of significance to a decline in investors' sensitivity to illiquidity risks over the last few years, with Drienko, Smith, and Reibnitz (2019) arguing that the last two decades were a period during which technological innovations and decimalization have markedly reduced transaction costs and increased stock liquidity.

Unfortunately, the majority of studies on the liquidity of financial markets focus on the U.S., with only a few comparable works tackling the German stock market. For 
example, approximating illiquidity with four different measures and covering a period of 32 years until 2006, Koch (2010) provides evidence that illiquidity drives stock returns and furthermore entails a significant risk premium independent of the chosen measure. Also, Bank, Larch, and Peter (2012) approximate illiquidity using five different measures, covering the period between 1999 and 2009. In line with Amihud (2002), they show that average market and individual stock returns are a positive function of expected illiquidity, while unexpected illiquidity has a negative impact on contemporaneous returns. Additionally, Hagemeister and Kempf (2010) analyse the period between 1996 and 2006, testing CAPM based on analysts' expectations, thereby controlling for liquidity, and identify the latter as the main determinant of expected returns.

Studies dealing with the time-varying relationship between illiquidity and stock returns are rare and mostly focus on liquidity risk and liquidity premiums but not on liquidity level. In almost all cases the respective papers compare the relationships between periods of financial turmoil and non-financial turmoil. For periods of financial turmoil it is well documented that risk is stronger priced (Watanabe and Watanabe 2008; Lou and Sadka 2011; Amihud and Mendelson 2015) and that liquidity premiums are higher (Hagströmer, Hansson, and Nilsson 2013; Jang, Kang, and Lee 2017). For liquidity level, only a few studies exist, which provide an ambiguous picture. For example, while Lou and Sadka (2011) use ILLIQ as the illiquidity measure of their choice and state that liquidity level has no impact in times of crises but liquidity risk has, Al-Haji (2020) states, replicating Lou and Sadka's (2011) study with an adjusted ILLIQ measure, that illiquidity level also has an impact. Hartian and Sitorus (2015) in turn confirm for ILLIQ having a significant impact on returns in crises periods. However, to the best of our knowledge all papers exogenously fixed or in a few cases identified under the consideration of a Markov 
regime switching model the crises periods but none has determined them by using an endogenous procedure, like Bai and Perron's (2003) multiple structural break point test.

For the German stock market, we are only aware of two articles dealing with the time-varying relationship between illiquidity and returns. Weigerding and Hanke (2018) approach this relationship and find that market liquidity is the main driver of return seasonality. Liu, Gregoriou, and Bo (2020) examine this relationship before (2002-2006), during (2007-2009), and after (2010-2013) the global financial crisis, apart from the UK, the U.S., and Chinese stock markets, concluding that the German stock market consistently exhibit a positive liquidity pattern in relation to the returns across the three examined time periods. Other studies deal with the time-varying structure of illiquidity itself but not with its impact on returns. Rösch and Kaserer (2014) analyse the dynamics and drivers of market liquidity during a financial crisis using a unique volume-weighted spread measure called the XETRA liquidity measure. The authors show, inter alia, that market liquidity is impaired when stock markets decline and that liquidity commonalities vary over time, increasing during market downturns and peaking at major crisis events. Johann et al. (2019) employ a relatively new and publicly available dataset called Market Microstructure Database XETRA, finding that for the German market, from 1999 to 2013, liquidity has generally increased over time and is lower in times of crisis. However, they also reveal a significant commonality between liquidity in the U.S. and the German equity markets that is especially pronounced in times of crisis. Paul, Walther, and Kuester Simic (2021) confirm these results for German real estate securities.

In summary, the literature shows that illiquidity has an impact on stock returns in the German stock market, but not in the U.S. market in more recent times. However, when it comes to the time-varying impact of illiquidity on returns on the U.S. market, only a few studies exist with ambiguous results and for the German stock market there is hardly 
any research. Furthermore, to the best of our knowledge the periods of structural change of illiquidity's impact over time have never been identified endogenously. Thus, based on previous findings, we examine (1) whether illiquidity effects can be measured in the German stock market using a more recent dataset, (2) whether illiquidity' impact varies over time measured with an endogenous procedure, (3) whether a flight-to-liquidity effect can be observed, and (4) whether illiquidity has an impact on stock returns when controlling for other factors including, among others, Fama and French (2015) factors.

\section{Data}

We use monthly German stock market data stemming from Thomson Reuters Datastream, covering all CDAX ${ }^{6}$ constituents, dead or alive, between July 1999 and June 2019. The total sample comprises 1,075 individual stocks, with an average of 613 stocks per month, but we reduced this average to 407 stocks per month after applying the following filters: excluding financial institutions, including stocks that have more than 12 trading days per month, and ensuring a minimum trading price of $1 €$, a positive book-to-market ratio, and a market capitalization amounting to at least Mio. 1€. Following Söderberg (2008), we only consider stocks' monthly observations if they are available for two consecutive months, further reducing the average sample size to 382 stocks per month. Furthermore, ILLIQ is winsorized each month by the highest and lowest $5 \%$ to account for erroneous data and outliers. ${ }^{7}$ To calculate the stock excess return, we use EURIBOR ${ }^{8}$ as the riskfree yield.

\section{Illiquidity over the total period}

\subsection{Estimation procedure}

As noted above, we use Amihud's (2002) ILLIQ as the illiquidity proxy in this study and 
follow his estimation procedure but extent his procedure with further adjustments. The monthly illiquidity of stock $i$ in month $m$ is defined as:

$$
I L L I Q_{i m}=\frac{1}{D_{i m}} \sum_{t=1}^{D_{i m}} \frac{\left|R_{i m d}\right|}{D V O L_{i m d}}
$$

where $R_{\text {imd }}$ is the return of security $i$ on day $d$ of month $m, D V O L_{i m d}$ is the relevant trading volume (EUR) of security $i$ on day $d$ of month $m$ and $D_{i m}$ refers to the number of days with available trading activities for security $i$ in month $m$. The average across all stock's $I L L I Q$ in month $m$ is the resulting market illiquidity $A I L L I Q_{m}$ and to reduce its high kurtosis (Table 1) a log-transformation $\ln A I L L I Q=\ln \left(1+10^{6} \cdot A I L L I Q\right)$ is employed.

\section{[Table 1 about here]}

Following Amihud (2002), we test whether expected and unexpected market illiquidity affects aggregated stock excess returns. Based on the propositions that investors require compensation for expected illiquidity and that the future illiquidity level is based on its current level, the hypotheses are that expected excess return is an increasing function of expected illiquidity (H1) and unexpected illiquidity has a negative effect on contemporaneous unexpected excess returns (H2). Expected market illiquidity is estimated by using an autoregressive model.

$$
L I Q_{m}=c_{0}+c_{1} L I Q_{m-z}+v_{m}
$$

where $c_{0}$ and $c_{1}$ are coefficients, $v_{m}$ is the residual, and $\mathrm{z}=1,2,3$. Investors determine the expected illiquidity $L I Q_{m}^{E}$ of month $m$ based on information from month $m-z$. 


$$
L I Q_{m}^{E}=c_{0}+c_{1} L I Q_{m-z}
$$

For a clear reference to our usage of Amihud's (2002) ILLIQ, but extended by further adjustments, we abbreviate $\ln A I L L I Q$ to $L I Q$ for the remainder of this paper. Taking into consideration that fundamental information of stock exchange listed corporates are not published on a monthly basis but rather on a quarterly or yearly basis, that information is not always immediately available to investors and that investors not consider only the latest information but also older information for their portfolio construction, we extend Amihud's (2002) procedure by including three different time lags, instead of only applying a one month time lag $(z=1)$. Additionally, we extend Amihud's (2002) procedure by considering for the calculation of $I L L I Q_{i m}$ up to previous twelve months of data of return and trading volume and not only the corresponding return and trading volume of the respective month. This approach results in twelve different rolling averages reducing the noise in $L I Q_{m}^{E}$ and is in line with different studies, which have adopted different measurement periods (Bali, Engle, and Murray 2016). Both extensions (3 x 12) result in a total of 36 different variations for $L I Q_{m}^{E}$ and increase the robustness of our results.

Based on the expected illiquidity, investors set their prices at month $m-z$ to generate the expected excess return for month $m$ :

$$
(R M-R f)_{m}=f_{0}+f_{1} L I Q_{m}^{E}+u_{m}=g_{0}+g_{1} L I Q_{m-z}+u_{m} .
$$

Within this formulation, $R M$ is the market return, $R f$ is the risk-free yield, $g_{0}=f_{0}+f_{1} c_{0}$, $g_{1}=f_{1} c_{1}$, and the residual $u_{m}$ represents the contemporaneous unexpected excess return. The latter should have a negative relation with unexpected illiquidity, because if higher expected illiquidity causes expected excess stock returns to rise (it is reasonable to 
expect that $c_{1}>0$, in (3)), then stock prices should fall when illiquidity unexpectedly rises. We test both hypotheses using the following model.

$$
(R M-R f)_{m}=g_{0}+g_{1} L I Q_{m-z}+g_{2} L I Q_{m}^{U}+w_{m}
$$

where $L I Q_{m}^{U}$ is the unexpected illiquidity in month $m$, and $L I Q_{m}^{U}=v_{m}$, the residual from model (2). The hypotheses consequently have two implications:

$$
\begin{array}{ll}
\mathrm{H} 1: & g_{1}>0, \text { and } \\
\mathrm{H} 2: & g_{2}<0 .
\end{array}
$$

\subsection{Results}

After testing whether illiquidity has an impact over the total sample period, the estimation results of model (5), presented in Table 2, show that expected and unexpected illiquidity have the hypothesized signs. However, the levels of significance run counter to each other, and lead to a non-significance of the respective expected and unexpected $L I Q$ at a certain level of rolling averages. While, unexpected $L I Q$ is highly significant at shorter rolling periods and less significant for longer rolling periods and lags, expected $L I Q$ becomes increasingly significant for longer rolling periods and lags. This contrasting development characterizes the short- and long-term characteristics of expectation formation in regard of unexpected and expected illiquidity's impact on expected returns, which are usually based on shorter and longer periods, respectively. Furthermore, we observe that the adjusted $\mathrm{R}^{2}$ decreases when more months are included in the rolling averaged $L I Q$.

\section{[Table 2 about here]}


Amihud (2002) only applies an average across one month with a one-month lag and finds strong support for H1 and H2. However, in line with Harris and Amato (2019), who also applicate the procedure to more recent data, we only find support for $\mathrm{H} 2$ when looking at the same setup, as only an unexpected $L I Q$ is significant. In addition, we cannot find support for Bank, Larch, and Peter (2012), who confirm Amihud's (2002) findings in their analysis of the German stock market in an earlier period (1999 to 2009). However, when considering the rolling averages of five to seven periods, both the expected and unexpected LIQs become significant. Hou, Xue, and Zhang's (2020) US stock market study, as well as Cakici and Zaremba's (2021) study, which covers 45 developed and emerging stock markets, claim that illiquidity has no impact on excess returns when the data sample is controlled for micro-caps, but our results show that this is not the case for the German stock market, as illiquidity is priced. Due to the high adjusted $\mathrm{R}^{2}$ and the plausible assumption that information is not always immediately available to investors, we use a time lag of three months in the following sections if not otherwise explicitly stated. Our subsequent analyses, based on a time lag of one or two months, did not significantly change the results (available upon request).Figure 1 illustrates the $L I Q$ for 10 size portfolios (decentiles) and the total market revealing that for most portfolios, a clear increase in illiquidity in times of market turmoil is visible (e.g., around the dotcom bubble and the global financial crisis). The aim of this study is to understand whether an increase of illiquidity has an impact on the level of excess returns and how the relation between both might change in sub-periods that are endogenously, and not exogenously, identified.

\section{[Figure 1 about here]}




\section{$5 \quad$ Illiquidity in sub-periods}

\subsection{Estimation procedure}

Following the prior analysis in which expected and unexpected illiquidity both have a significant impact on stock returns over the total period between 1999 and 2019, we now analyse whether this relationship is stable over time. We hypothesize that liquidity in the aggregated German stock market is prone to structural changes and that the impact on excess returns changes over time.

To account for the structural breaks in the time series, Amihud (2002) applies Chow's (1960) test, noting that "estimated parameters of the model are found to be stable over time" (p. 44). However, as the test procedure only allows one exogenously determined break point, we employ Bai and Perron's (2003) test that can identify multiple structural breaks endogenously. We follow Bai and Perron's (2003) practical recommendations and first check whether the $\sup F_{\mathrm{T}}(\mathrm{k})$ tests indicate the presence of at least one structural break, based on global minimizers. ${ }^{9}$ After testing all rolling periods (12), the results of the double maximum statistics (UDmax and WDmax) far exceed the critical value. Hence, we reject the null hypothesis of no breaks (Panel A, Table 3).

\section{[Table 3 about here]}

As the global minimizer indicates that at least one structural break point exists, we begin the sequential procedure $\operatorname{Sup} F_{T}(1+1 \mid 1)$ with $F(2 \mid 1)$. Panel B of Table 3 reports the results. We stop at $F(5 \mid 4)$, which does not indicate more than four breakpoints, and analyse the statistical significance at the $5 \%$ level using a trimming percentage of $\varepsilon=$ $10 \%{ }^{10}$. Given our $\mathrm{T}=240$ sample size, it seems appropriate to consider serial correlation and/or heterogeneity in the data. Furthermore, as Bai and Perron (2003) highlight, the 
information criteria are biased downward and the sequential $\sup F_{T}(1+1 \mid 1)$ test performs better when error distributions are allowed to differ across periods. As we are directly interested in the estimated break points, we apply the sequential procedure to all rolling periods, following Bai and Perron (2003) and ignoring the $\sup F(1 \mid 0)$ test. The vast majority of regressions, except for very short rolling periods, indicate four structural breaks at the time points of April 2003, April 2007, March 2009, and December 2016 (Panel C, Table 3). Finally, we apply likewise these identified break points to all regressions to ensure the trends are comprehensible for further analysis.

\subsection{Results}

After repeating the regressions from Section 4.2 and fixing the structural breaks to the dates determined in Section 5.1 (Table 4), the significance of illiquidity's impact on excess returns varies substantially from period to period. In periods two (April 2003 to March 2007), four (March 2009 to November 2016), and five (December 2016 to June 2019), expected illiquidity is a significant explanatory factor for the excess returns, but not in periods one (July 1999 to March 2003) and three (April 2007 to February 2009) that historically correspond to times of financial turmoil, and cover the dotcom bubble and global financial crisis. In the non-financial turmoil periods (two, four, and five), expected illiquidity's impact on excess returns is approximately twice as strong and more significant than when we consider the total sample period (Section 4.2). In the post-crisis phases, covering periods two and four, expected illiquidity is especially significant for all rolling periods, contrasting our earlier total sample results. The consideration of subperiods shows that the effect of expected illiquidity on excess returns still plays a significant role and is more sustainable when excluding periods of financial turmoil.

On the other hand, unexpected illiquidity in the post-crisis phases has a much lower impact on returns, compared to the regression results over the total sample period. 
In addition, it is only significant for longer rolling periods, which again contrasts the total period's regression results. Unexpected illiquidity's positive coefficients in the post-crisis period are a result of its construction. According to Amihud (2002), unexpected illiquidity represents the residual of expected illiquidity's AR process over time. Consequently, the unexpected component will increase during periods of rising market illiquidity, and vice versa, when illiquidity levels peak in crisis periods.

Compared to longer periods (e.g., the total sample), the crisis and post-crisis periods only represent a fraction. Hence, we cannot depict differences in these effects when looking at the entire period at once. Overall, our results provide important insights into long-term investors' illiquidity effects and the market environment's impact on a shorter time line.

For portfolio decision reasons, investors must first determine which parameters are good indicators of potential structural breaks as structural breaks are only evident with a certain time lag. At best, the parameters are the leading economic indicators and the relating literature on time-varying economic uncertainty's role in macroeconomic variables is growing rapidly. For instance, Bloom (2009) identifies 17 crisis periods between 1962 and 2008 based on stock market volatility, and Opitz and Szimayer (2018) identify the Treasury bill rate of return as the most significant factor for differentiating extreme situations in financial markets. Other models integrate further macroeconomic variables that reduce the number of identified crisis periods (Klose 2014; Jurado, Ludvigson, and Ng 2015). For example, Eross, Urquhart, and Wolfe (2019) use a regimeswitching model to identify spillover effects in the interbank market and eventually find a significant impact on the economy, illustrating that this occurs via a nonlinear framework. 


\section{[Table 4 about here]}

\section{Additional analyses}

\subsection{Robustness tests}

First, we first employ the turnover-based Amihud measure, proposed by Brennan, Huh, and Subrahmanyam (2013), that uses the absolute return-to-turnover ratio instead of the absolute return-to-volume ratio. Second, we follow Barardehi et al. (2020) and use opento-close returns instead of close-to-close returns. Third, we use a value weighted $L I Q$ that considers the stock's market capitalization for the market ILLIQ calculation, instead of simply taking the average across all stocks' ILLIQ. Fourth, we follow Hou, Xue, and Zhang (2020) and control the micro-caps by applying various winsorizing levels. Lastly, we adjust the $L I Q$ by inflation. None of the aforementioned variations in our original analysis qualitatively change the results and the previous sections' results hold for various robustness test applications (available upon request).

\subsection{Illiquidity controlled for Fama-French factors}

As a further robustness test to control for other well-known factors having an impact on excess returns, we risk-adjust the illiquidity measure using the Fama and French (2015) factors. ${ }^{11}$ Following Fama and French (1993), and Amihud et al. (2015), we estimate the following regression to obtain the risk-adjusted illiquidity premium $C_{t}$ and the orthogonalized illiquidity measure $O L I Q_{t} .^{12}$

$$
\begin{gathered}
L I Q_{t}=C+a \times S M B_{t}+b \times H M L_{t}+c \times C M A_{t}+d \times R M W_{t}+\epsilon_{t}, \\
O L I Q_{t}=C+\epsilon_{t} .
\end{gathered}
$$


We find a positive significant relationship between the size-factor $S M B$ and illiquidity for longer rolling periods: the correlation between $S M B$ and illiquidity with a 12 months rolling average is 0.1525 . The remaining Fama-French factors are not significant at the $10 \%$ level, but the intercept is highly significant in all cases, indicating that the FamaFrench factors cannot fully explain the measured illiquidity, with the Durbin-Watson statistics supporting this assumption. Hence, the orthogonalized $L I Q$ is similar to the original illiquidity measure.

To test the robustness of our analyses in the previous sections, we replicate the regressions from Sections 4 and 5 with orthogonalized illiquidity measures, OLIQ. Table 5 lists the results. First, we repeat the regressions of model (5) with orthogonalized LIQs, and find higher coefficients and t-statistics for expected illiquidity, compared to the results in Section 4.2, with all rolling periods being significant at $10 \%$ or higher. Again, unexpected illiquidity's significance declines with increasing observation periods and time lags, corresponding to the developments in Section 4.2. However, expected illiquidity's increased significance leads to an increased adjusted $\mathrm{R}^{2}$ and Schwarz information criteria. Thus, the overall explanatory power of the relationship between illiquidity and excess returns increases. Second, we consider the break dates of April 2003, April 2007, March 2009, and December 2016, and find similar results as those in Section 5.2. The only exception is period 4, in which the significance levels are partially lower after orthogonalization. However, it is possible that the Fama-French factors partially explain unexpected illiquidity's effects and reduce their impact. By contrast, the effects of expected illiquidity are amplified.

\section{[Table 5 about here]}




\subsection{Illiquidity in size-based portfolios - flight to liquidity}

When overall illiquidity rises unexpectedly, all stocks should decrease in value, resulting in a substitution from less liquid to more liquid stocks (flight to liquidity). However, stocks perceived as more illiquid, usually those with lower market capitalization, should decrease more in value than less illiquid stocks. This is because the flight-to-liquidity effect counteracts the overall decreasing value trend in favour of less illiquid stocks, due to the increase in investors' demands (see Amihud 2002). To test this relation, we divide all stocks by their market capitalization value into 10 size-based portfolios. As a result, we adjust model (5) as follows:

$$
\left(R S Z_{i}-R f\right)_{m}=g_{0}^{i}+g_{1}^{i} L I Q_{m-3}+g_{2}^{i} L I Q_{m}^{U}+w_{m}
$$

where $R S Z_{i}$ is the return on the portfolio of size decile $i$. He estimates size portfolios $i=$ $2,4,6,8$, and 10 , and hypothesizes that the coefficients $g_{1}^{i}$ and $g_{2}^{i}$, being respectively positive and negative, should have magnitudes that decrease and increase monotonically in size as value $i$ increases:

$$
\begin{aligned}
& \text { SZ1: } g_{1}^{2}>g_{1}^{4}>g_{1}^{6}>g_{1}^{8}>g_{1}^{10}>0, \text { and } \\
& \text { SZ2: } g_{2}^{2}<g_{2}^{4}<g_{2}^{6}<g_{2}^{8}<g_{2}^{10}<0,
\end{aligned}
$$

Amihud (2002) finds support for both hypotheses, and his results suggest that market illiquidity's effects, both expected and unexpected, are stronger for small firm stocks than for larger firms, implying that the former have a higher illiquidity risk. After replicating Amihud (2002) to more recent data, Harris and Amato (2019), and Drienko, Smith, and Reibnitz (2019) only find $g_{2}^{i}$ to be significant with a lose of monotonic 
increase, which Drienko, Smith, and Reibnitz (2019) argue is an indication of investors' declining sensitivity to illiquidity risks. When no sub-periods are considered, we find for $g_{1}^{i}$ and $g_{2}^{i}$ the declining and increasing development but it is not monotonical in size, and again expected illiquidity is only significant at longer rolling periods, while unexpected illiquidity is only significant at shorter rolling periods (Table 6). However, for portfolio 10 that comprises the largest companies in the CDAX in terms of market capitalization, expected illiquidity has no significant effect on excess stock returns.

When considering the sub-periods, the already known pattern emerge: expected and unexpected illiquidity are not significant in periods of financial turmoil, but outside of those periods, especially in the post-crisis phases, expected illiquidity's impact on excess returns is highly significant for all rolling averages and nearly all portfolio sizes, while unexpected illiquidity' impact is prevailing at higher rolling averages for all portfolio sizes. However, comparing period two and four with each other shows while in period two a declining and increasing development of $g_{1}^{i}$ and $g_{2}^{i}$ can be observed this development dissipates in the more recent period four.

\section{[Table 6 about here]}

\subsection{Economic value of illiquidity}

Finally, we quantify illiquidity's impact on excess returns in non-crisis and crisis periods and examine the ex-ante estimation accuracy of excess returns. In this context, we demonstrate the economic value of our study and show that it is more advantageous for investors to take structural breaks as a trading signal, being periods of financial turmoil, and not to ignore them. Being self-evident that a buy and hold investor generates lower total returns than investors selling their portfolios in times of crises and holding them in 
non-crisis periods, we want to turn the gaze towards the need of further research to identify possible exogenous variables that can serve as early indicators of such structural breaks and financial turmoil periods. Table 7 summarizes the results.

In the left panel we show the ex-ante estimated excess returns. They are derived by regressing the relationship between illiquidity and excess return over rolling 24 months periods, corresponding to the minimum length of a period within our structural break analysis (trimming level), and considering the applied 3-month lag. Therefore, this sample considers monthly returns in the period from October 2001 to October 2018 (205 months). Finally, based on these regressions, the respective monthly returns are estimated ex-ante and averaged over the crisis and non-crisis periods. In a further step, we regress the excess returns on the ex-ante estimated returns of the respective periods to examine the explanatory power. Over the total period, the estimation accuracy increases with increasing the rolling average window. For crisis or non-crisis periods, the estimates are less effective and we find them tounderestimated in non-crisis periods and overestimated in crisis periods. The reason for the under- and overestimation in the respective periods is that for example in crisis periods the expected returns are estimated to a certain extend with $L I Q$ parameters from non-crisis periods and vice versa. Hence, when periods of crisis and non-crisis alternate at shorter intervals a persistent time lag distorts the estimation accuracy for the respective periods. However, as already shown in the previous sections, longer $L I Q$ time series are better estimators of expected returns and investors could improve their returns if structural breakpoints could be adequately estimated.

The middle panel presents the ex-post excess returns of the different size portfolios. For the total period (buy and hold investors), we find that all portfolios generate positive excess returns with a total market's monthly average return of $0.71 \%$. If investors are only investing during non-crisis periods, the average return for these 
periods increases to $1.65 \%$. Considering the crisis periods when the investor remained in cash hold with a return of $0 \%$ per month, this corresponds to an average return of $1.13 \%$ extrapolated on the total period and thus higher than that of the buy and hold investors. Hence, the return premium of not being invested in crisis periods averages to $3.07 \%$.

In the right panel, we consider the return contribution of the total market illiquidity. Based on the regression results without structural breaks (Section 4.2), we find that for the total period, the return contribution of market illiquidity with rolling onemonth LIQs is $1.78 \%$ at the total market level. As the explanatory contribution of illiquidity is higher than the excess return $(0.71 \%)$, other effects have a negative impact, but we do not explore these further in the analyses.

The inclusion of a structural break analysis increases the accuracy of the regression and increase the results to $2.71 \%$, compared to $1.78 \%$ in the regression without structural breaks. In the non-crisis (crisis) period, the return contribution of illiquidity for the total market increases (decreases) to $3.27 \%(0.44 \%)$. When comparing the explanatory contribution of market illiquidity in the non-crisis periods between the model with and without structural breaks, the contribution increases by $1.22 \%$. Considering the non-crisis and crisis periods reveals evident size effects. In non-crisis periods, portfolios of stocks with smaller value generate stronger effects than those with larger value, although the trend is not monotonic. In crisis periods, where the relation between illiquidity and excess returns is not significant, we can find flight-to-liquidity effects when observing the return contributions (Amihud, Mendelson, and Wood 1990). Smallcapitalization stocks generate negative contributions from market illiquidity (portfolio 1, 1m rolling: $-0.27 \%$ ) and large capitalization stocks deliver positive return contributions (portfolio 10: $+1,00 \%$ ). However, as the larger portfolios' excess returns are nevertheless more negative in times of crisis (-2.91\%), compared to that of smaller portfolios $(-1.51 \%)$, 
further contrary effects have an impact here as well. As the illiquidity parameters' roll period increases, these portfolio effects become more pronounced.

In conclusion, the analysis of market illiquidity shows that the identification of structural breaks for an investment strategy can significantly increase portfolio returns. Obviously, this results from the significantly higher explanatory power of illiquidity, even after the Fama-French factors' risk adjustments.

\section{[Table 7 about here]}

\section{Conclusion}

This study contributes to the literature on the structural relation between market illiquidity and excess stock returns over time. We set our focus on the following central issue: Within the German stock market, does illiquidity still have an impact on excess stock returns and is that relation hampered over time?

After replicating Amihud's (2002) estimation procedure in the German stock market for more recent times, we, like other authors also, only find support for unexpected illiquidity being priced by investors, while expected illiquidity is not. This result deviates from Amihud's (2002) findings, and might be a result of increased equity trading and illiquidity's overall lower level in more recent times, compared to the period between 1964 and 1997. However, since expectation formation is usually based on a certain time period, we adjust the illiquidity measure and calculate $L I Q$ over longer periods (rolling averages), finding expected illiquidity being significant and unexpected illiquidity's significance decreasing until it vanishes. 
Examining the time series for structural breaks using the Bai and Perron (2003) procedure provides significant evidence of instabilities in the relation between illiquidity and excess return over time: while neither expected nor unexpected illiquidity provides significant explanatory power for excess returns in the crisis phases, expected illiquidity in particular has a significant positive effect on portfolio returns across all rolling periods in the post-crisis phases. Additionally, we find support for the flight-to-liquidity effect in expected and unexpected illiquidity, but their size development is not strictly monotonic and even becomes blurry when sub-periods are considered. As demonstrated in the subperiod analysis, the flight-to-liquidity effect is also only significant in periods outside of financial market turmoil. In one of the various robustness tests, we risk-adjust the illiquidity parameters by the four Fama-French factors, and the regressions with these orthogonalized LIQs confirm the results presented above. Hence, against the increasing perception in recent times illiquidity not having an impact on stock excess returns, this study shows that illiquidity still had a relevant explanatory contribution on excess returns over the past two decades, when controlling for periods of longer expectation formations (rolling averages) and financial turmoil.

Finally, we consider these econometric insights with practical implications. Contrary to our initial belief that illiquidity is especially priced in times of financial turmoil, our paper shows that this is not the case. Illiquidity is priced in times outside of financial turmoil, and a business cycle-based strategy outperforms a buy-and-hold investment strategy. Structural breakpoints are valuable decision support tools for the investment process. As they are only detectable in ex-post analyses, further research is needed to identify possible exogenous variables that can serve as early indicators of such structural breaks. The literature addressing time-varying economic uncertainty's role in macroeconomic variables is growing rapidly, but the transmission channels and 
mechanisms require deeper insights. To develop a complete picture of the degree of explanatory illiquidity in the sub-periods, further studies are required to identify other relevant influencing factors. Moreover, as our study only focuses on the German market, future research should test whether the same observations hold for other regions, such as Anglo-Saxon countries and others. 


\section{References}

Acharya, Viral V., and Lasse H. Pedersen. 2005. "Asset Pricing with Liquidity Risk." Journal of Financial Economics 77 (2): 375-410.

Al-Haji, Ahmad. 2020. "Liquidity Level or Liquidity Risk? A fresh look with new measures." Spanish Journal of Finance and Accounting. doi:10.1080/02102412.2020.1863126.

Amihud, Yakov. 2002. "Illiquidity and Stock Returns: Cross-Section and Time-Series Effects.” Journal of Financial Markets 5 (1): 31-56.

Amihud, Yakov, Allaudeen S. Hameed, Wenjin Kang, and Huiping Zhang. 2015. "The Illiquidity Premium: International Evidence.” Journal of Financial Economics 117 (2): $350-68$.

Amihud, Yakov, and Haim Mendelson. 1986. "Asset Pricing and the Bid-Ask Spread." Journal of Financial Economics 17 (2): 223-49.

Amihud, Yakov, and Haim Mendelson. 2015. "The Pricing of Illiquidity as a Characteristic and as Risk.” Multinational Finance Journal 19 (3/4): 149-68.

Amihud, Yakov, Haim Mendelson, and Lasse H. Pedersen. 2005. "Liquidity and Asset Prices." Foundations and Trends in Finance 1 (4): 269-364.

Amihud, Yakov, Haim Mendelson, and Robert A. Wood. 1990. "Liquidity and the 1987 Stock Market Crash.” Journal of Portfolio Management 16 (3): 65-69.

Andrews, Donald W. K. 1991. "Heteroskedasticity and Autocorrelation Consistent Covariance Matrix Estimation.” Econometrica 59 (3): 817-58.

Andrews, Donald W. K., and J. C. Monahan. 1992. “An Improved Heteroskedasticity and Autocorrelation Consistent Covariance Matrix Estimator.” Econometrica 60 (4): 953-66. 
Bai, Jushan, and Pierre Perron. 2003. "Computation and Analysis of Multiple Structural Change Models." Journal of Applied Econometrics 18 (1): 1-22.

Bali, Turan G., Robert F. Engle, and Scott Murray. 2016. Empirical Asset Pricing: The Cross Section of Stock Returns. Hoboken, NJ: John Wiley \& Sons, Inc.

Bank, Matthias, Martin Larch, and Georg Peter. 2012. 'Investors' Compensation for Illiquidity: Evidence from the German Stock Market." International Journal of Economic Research 9 (2): 341-68.

Bao, Jack, and Jun Pan. 2013. "Bond Illiquidity and Excess Volatility." The Review of Financial Studies 26 (12): 3068-3103.

Bao, Jack, Jun Pan, and Jiang Wang. 2011. "The Illiquidity of Corporate Bonds.” The Journal of Finance 66 (3): 911-46.

Barardehi, Yashar H., Dan Bernhardt, Thomas G. Ruchti, and Marc Weidenmier. 2020. “The Night and Day of Amihud's (2002) Liquidity Measure." The Review of Asset Pricing Studies. doi:10.1093/rapstu/raaa022.

Bedowska-Sojka, Barbara. 2019. “The Dynamics of Low-frequency Liquidity Measures: The Developed versus the Emerging Market.” Journal of Financial Stability 42: 136-42.

Ben-Rephael, Azi, Ohad Kadan, and Avi Wohl. 2015. “The Diminishing Liquidity Premium.” Journal of Financial and Quantitative Analysis 50 (1/2): 197-229.

Bervas, Arnaud. 2006. "Market Liquidity and Its Incorporation into Risk Management." Financial Stability Review 8 (2006): 63-79.

Black, Fischer. 1971. “Toward a Fully Automated Stock Exchange.” Financial Analysts' Journal 27 (4): 28-35.

Bloom, Nicholas. 2009. "The Impact of Uncertainty Shocks.” Econometrica 77 (3): $623-85$. 
Brennan, Michael J., Sahn-wook Huh, and Avanidhar Subrahmanyam. 2013. “An Analysis of the Amihud Illiquidity Premium." The Review of Asset Pricing Studies 3 (1): $133-76$.

Cakici, Nusret, and Adam Zaremba. 2021. "Liquidity and the Cross-Section of International Stock Returns.” Journal of Banking \& Finance 127.

Chalmers, John M. R., and Gregory B. Kadlec. 1998. “An Empirical Examination of Amortized Spread.” Journal of Financial Economics 48 (2): 159-88.

Chow, Gregory C. 1960. "Tests of Equality Between Sets of Coefficients in Two Linear Regressions.” Econometrica 28 (3): 591-605.

Díaz, Antonio, and Ana Escribano. 2020. "Measuring the Multi-faceted Dimension of Liquidity in Financial Markets: A Literature Review.” Research in International Business and Finance 51.

Drienko, Jozef, Tom Smith, and Anna von Reibnitz. 2019. "A Review of the ReturnIlliquidity Relationship." Critical Finance Review 8 (1-2): 127-71.

Eleswarapu, Venkat R. 1997. "Cost of Transacting and Expected Returns in the Nasdaq Market.” The Journal of Finance 52 (5): 2113-27.

Eross, Andrea, Andrew Urquhart, and Simon Wolfe. 2019. "Investigating Risk Contagion Initiated by Endogenous Liquidity Shocks: Evidence from the US and Eurozone Interbank Markets.” The European Journal of Finance 25 (1): 35-53.

Fama, Eugene F., and Kenneth R. French. 1993. "Common Risk Factors in the Returns on Stocks and Bonds." Journal of Financial Economics 33 (1): 3-56.

Fama, Eugene F., and Kenneth R. French. 2008. "Dissecting Anomalies.” The Journal of Finance 63 (4): 1653-78.

Fama, Eugene F., and Kenneth R. French. 2015. “A Five-Factor Asset Pricing Model.” Journal of Financial Economics 116 (1): 1-22. 
Fong, Kingsley Y. L., Craig W. Holden, and Charles Trzcinka. 2017. "What Are the Best Liquidity Proxies for Global Research?” Review of Finance 21 (4): 1355-1401. Goyenko, Ruslan Y., Craig W. Holden, and Charles Trzcinka. 2009. "Do Liquidity Measures Measure Liquidity?” Journal of Financial Economics 92 (2): 153-81. Grossman, Sanford J., and Merton H. Miller. 1988. "Liquidity and Market Structure." The Journal of Finance 43 (3): 617-33.

Hagemeister, Meike, and Alexander Kempf. 2010. "CAPM und erwartete Renditen: Eine Untersuchung auf Basis der Erwartung von Marktteilnehmern.” DBW Die Betriebswirtschaft - Business Administration Review 2: 145-64.

Hagströmer, Björn, Björn A. Hansson, and Birger Nilsson. 2013. "The Components of the Illiquidity Premium: An Empirical Analysis of US Stocks ; 1927 - 2010.” Journal of Banking \& Finance 37 (11): 4476-87.

Han, Song, and Hao Zhou. 2016. "Effects of Liquidity on the Non-Default Component of Corporate Yield Spreads: Evidence from Intraday Transactions Data.” The Quarterly Journal of Finance 6 (3): 1650012.

Harris, Larry, and Andrea Amato. 2019. "Illiquidity and Stock Returns: Cross-Section and Time-Series Effects: A Replication.” Critical Finance Review 8 (1/2): 173-202. Hartian, Kenas R., and Romora E. Sitorus. 2015. "Liquidity and Returns: Evidences from Stock Indexes around the World." Asian Economic and Financial Review 5 (1): $33-45$.

Hasbrouck, Joel. 2009. “Trading Costs and Returns for US Equities: Estimating Effective Costs from Daily Data." The Journal of Finance 64 (3): 1445-77. Hou, Kewei, Chen Xue, and Lu Zhang. 2020. "Replicating Anomalies.” The Review of Financial Studies 33 (5): 2019-2133. 
Jang, Jeewon, Jangkoo Kang, and Changjun Lee. 2017. "State-Dependent Variations in the Expected Illiquidity Premium." Review of Finance 21 (6): 2277-2314.

Jankowitsch, Rainer, Florian Nagler, and Marti G. Subrahmanyam. 2014. "The

Determinants of Recovery Rates in the US Corporate Bond Market.” Journal of Financial Economics 114 (1): 155-77.

Jankowitsch, Rainer, Amrut Nashikkar, and Marti G. Subrahmanyam. 2011. "Price Dispersion in OTC Markets: A New Measure of Liquidity." Journal of Banking \& Finance 35 (2): 343-57.

Johann, Thomas, Stefan Scharnowski, Erik Theissen, Christian Westheide, and Lukas Zimmermann. 2019. "Liquidity in the German Stock Market.” Schmalenbach Business Review 71: 443-73.

Jurado, Kyle, Sydney C. Ludvigson, and Serena Ng. 2015. "Measuring Uncertainty." American Economic Review 105 (3): 1177-1216.

Klose, Jens. 2014. "Determining Structural Breaks in Central Bank Reaction Functions of the Financial Crisis.” The Journal of Economic Asymmetries 11: 78-90.

Koch, Stefan. 2010. "Illiquidity and Stock Returns: Evidence from the German Stock Market.” Working Paper. doi:10.2139/ssrn.1646859.

Kyle, Albert S. 1985. "Continuous Auctions and Insider Trading." Econometrica 53 (6): $1315-35$.

Lin, Hai, Junbo Wang, and Chunchi Wu. 2011. "Liquidity Risk and Expected Corporate Bond Returns.” Journal of Financial Economics 99 (3): 628-50.

Liu, Guy, Andros Gregoriou, and Yibo Bo. 2020. "How Do Markets Value Stock Liquidity? Comparative Evidence from the UK, the US, Germany and China.” Economics Letters 186. doi:10.1016/j.econlet.2019.06.006. 
Lou, Xiaoxia, and Ronnie Sadka. 2011. "Liquidity Level or Liquidity Risk? Evidence from the Financial Crisis.” Financial Analysts Journal 67 (3): 51-62.

Lybek, Tonny, and Abdourahmane Sarr. 2002. Measuring Liquidity in Financial Markets IMF Working Paper No. 02/232.

https://www.imf.org/external/pubs/ft/wp/2002/wp02232.pdf.

Mahanti, Sriketan, Amrut Nashikkar, Marti Subrahmanyam, George Chacko, and Gaurav Mallik. 2008. "Latent Liquidity: A New Measure of Liquidity, with an Application to Corporate Bonds.” Journal of Financial Economics 88 (2): 272-98.

Opitz, Sebastian, and Alexander Szimayer. 2018. "What Drives Flight to Quality?" Account Finance 58: 529-71.

Paul, Thomas, Thomas Walther, and André Kuester Simic. 2021. "Empirical Analysis of the Illiquidity Premia of German Real Estate Securities." Financial Markets and Portfolio Management, forthcoming. doi:10.1007/s11408-021-00398-0.

Pu, Xiaoling. 2009. "Liquidity Commonality Across the Bond and CDS Markets.” The Journal of Fixed Income 19 (1): 26-39.

Rösch, Chistoph G., and Christoph Kaserer. 2014. "Reprint of: Market Liquidity in the Financial Crisis: The Role of Liquidity Commonality and Flight-to-Quality.” Journal of Banking \& Finance 45: 152-70.

Sadka, Ronnie. 2006. "Momentum and Post-Earnings-Announcement Drift Anomalies: The Role of Liquidity Risk.” Journal of Financial Economics 80 (2): 309-49.

Schestag, Raphael, Philipp Schuster, and Marliese Uhrig-Homburg. 2016. "Measuring Liquidity in Bond Markets.” The Review of Financial Studies 29 (5): 1170-1219.

Söderberg, Jonas. 2008. "Liquidity on the Scandinavian Order-driven Stock Exchanges." CAFO Working Paper. doi:10.5089/9781451860252.001. 
Watanabe, Akiko, and Masahiro Watanabe. 2008. "Time-Varying Liquidity Risk and the Cross Section of Stock Returns." The Review of Financial Studies 21 (6): 244986.

Weigerding, Michael, and Michael Hanke. 2018. "Drivers of Seasonal Return Patterns in German Stocks.” Business Research 11 (1): 173-96.

\section{Notes}

1 According to Fama and French (2008), micro-caps account for only 3\% of the NYSE-AmexNASDAQ universe's market cap, but they account for about $60 \%$ of the total number of stocks. 2 Hou, Xue, and Zhang (2020) replicate the bulk of the anomalies literature by compiling an extensive data library of 452 anomalies. They find that 102 of the 106 variables that are in the category containing liquidity, market micro-structure, and other trading friction variables become insignificant when they control for micro-caps.

3 Díaz and Escribano (2020) define the five dimensions as follows: tightness (the amount of transaction costs), immediacy (the speed with which orders are executed), depth (the number of orders around equilibrium prices), breadth (the number of orders and their volumes around equilibrium prices), and resiliency (the market's capacity to recover from unexpected events). Some prior literature specifies four (Black 1971; Grossman and Miller 1988) or three (Kyle 1985) of these dimensions.

4 For a detailed description of the dimensions' interrelations, please refer to Díaz and Escribano (2020). Goyenko, Holden, and Trzcinka (2009) also provide an overview of a close association between many dimensions and their respective measures.

5 Our list of papers using ILLIQ (Acharya and Pedersen 2005; Sadka 2006 ; Mahanti et al. 2008; Pu 2009; Lin, Wang, and Wu 2011; Jankowitsch, Nagler, and Subrahmanyam 2014; Bao and Pan 2013; Jankowitsch, Nashikkar, and Subrahmanyam (2011); Ben-Rephael, Kadan, and Wohl 2015; Han and Zhou 2016; Drienko, Smith, and Reibnitz 2019; Harris and Amato 2019) or an extension of it (Goyenko, Holden, and Trzcinka 2009; Schestag, Schuster, and Uhrig-Homburg 2016; Han 
and Zhou 2016; Fong, Holden, and Trzcinka 2017) is not complete. It simply represents a small fraction of available research papers.

6 "CDAX" is a registered trademark of Deutsche Börse AG, representing an index containing all German stocks listed on the Frankfurt Stock Exchange in the General Standard and Prime Standard. Foreign stocks are not included.

7 To account for the findings of Hou, Xue, and Zhang (2020), as well as Cakici and Zaremba (2021) we control for the effects of micro-caps by computing different winsorizing levels $(0.5 \% / 99.5 \%, 5 \% / 95 \%$, and $10 \% / 90 \%)$ and weighting types (equal and value weighted). Our results are robust with respect to these variations.

8 “EURIBOR” ${ }^{\circledR}$ is a registered trademark of EMMI a.i.s.b.l.

$9 \mathrm{We}$ analyse the $\sup F_{T}(\mathrm{k})$ tests, based on global minimizers. We follow the literature and allow for the possibility of serial correlations in the disturbances for the $\sup F_{T}(\mathrm{k})$ tests and reported standard errors. The heteroscedasticity and autocorrelation consistent covariance matrix is based on a quadratic kernel with automatic bandwidth selection with an $\mathrm{AR}(1)$ approximation, as suggested by Andrews (1991), and Andrews and Monahan (1992).

10 According to Bai and Perron (2003) using any value of the trimming $\varepsilon$ will lead to tests with adequate sizes if serial correlation and/or heterogeneity in the data or errors across segments are not allowed in the estimated regression model. However, if such features are allowed, which we do, a higher trimming is needed. Bai and Perron (2003) recommend for a sample of $T=120$ to use $\varepsilon=15 \%$ when allowing for heterogeneity in the errors or data and to use $\varepsilon=20 \%$ when allowing for serial correlations. Hence, each segment has at least 18 to 24 observations. However, the trimming levels can be reduced if larger sample sizes are available, which is the case in our paper $(T=240)$. Hence, we reduced our trimming level to $10 \%$, imposing a minimum length of 24 observations per segment. A trimming level of $15 \%$ imposes a minimum length of 36 observations per segment and thus cannot separate crises, which are often shorter and substantial for the impact. A trimming level of 5\% imposes a relatively small minimum length of 12 observations and does not change our results. 
11 The Fama-French factors were gratefully provided by M. Hanauer, TU Munich. They are available for the German market until October 2018 and determine the OLIQs observation period. 12 In our regressions, the German stock market's excess return is the variable to be explained. Therefore, we only consider the four Fama-French factors (size, value, investment factors, and profitability) in the orthogonalization. 
Figure 1: LIQs over time

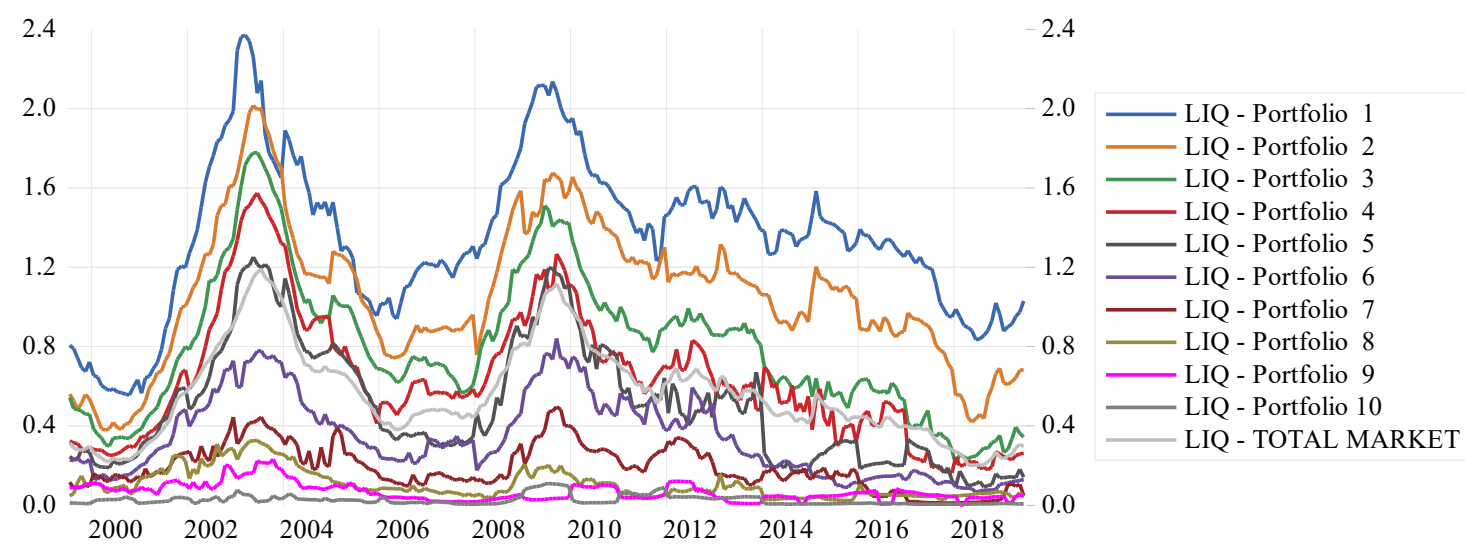

Note: This figure shows the LIQs of 10 size portfolios and the total market over the entire sample period. All stocks in the sample are sorted at the year-end into one of 10 equal-weighted portfolios, based on their respective value. For $L I Q$ 's calculation, we use a 12-month rolling average. The illiquidity measures are winsorized at the 5\% and 95\% levels for each month. The data include CDAX stocks from July 1999 to June 2019. 
Table 1: Statistical parameters (monthly)

\begin{tabular}{|l|r|r|r|}
\hline Parameters & Excess Returns & AILLIQ & InAILLIQ \\
\hline Mean & -0.03 & 0.8048 & 11.7037 \\
SD & 5.49 & 1.2240 & 2.8529 \\
Skew & -0.96 & 2.05 & -0.78 \\
Kurt & 2.05 & 3.80 & 0.36 \\
Min & -21.43 & 0.0002 & 0.0000 \\
Median & -10.35 & 0.2172 & 12.2266 \\
Max & -2.64 & 5.8604 & 15.8344 \\
$n$ & 396 & 382 & 382 \\
\hline
\end{tabular}

Note: This table presents the summary statistics of the monthly excess returns and the illiquidity measures, $A I L L I Q$ and $\ln A I L L I Q$, for the stocks in the sample. ILLIQ $Q_{i}$ is the average daily ratio of absolute returns to the EUR stock volume $i$ in month $m$. AILLIQ represents the average market illiquidity across stocks' ILLIQ in each month. The ILLIQs are winsorized at the 5\% and 95\% levels, and the distribution of AILLIQ is highly skewed and leptokurtic. Thus, we log-transform the AILLIQ (natural log of one plus the AILLIQ values, which is then multiplied by $10^{6}$ ). Hence, the $\ln A I L L I Q$ can be interpreted as the percentage price impact of trading one million EUR (impact is measured as a decimal), and the results are nearly normally distributed. To examine the illiquidity effects, we use the work of Bali et al. (2016) as a guide to calculate the variables for different rolling periods. The values in the table are based on a 12 months period. $n$ indicates the average number of stocks for which a given variable is available. The data include CDAX stocks from July 1999 to June 2019. 
Table 2: Regression results without breaks

\begin{tabular}{|c|c|c|c|c|c|c|c|c|c|c|}
\hline \multirow{3}{*}{$\begin{array}{c}\text { averaged } \\
\text { across } m \\
\text { months }\end{array}$} & \multicolumn{3}{|c|}{ Lag 1} & \multicolumn{3}{|c|}{ Lag 2} & \multicolumn{4}{|c|}{ Lag 3} \\
\hline & \multirow[b]{2}{*}{ Adj. $R^{2}$} & \multicolumn{2}{|c|}{ Illiquidity } & \multirow[b]{2}{*}{ Adj. $R^{2}$} & \multicolumn{2}{|c|}{ Illiquidity } & \multirow[b]{2}{*}{ Adj. $R^{2}$} & \multicolumn{3}{|c|}{ Illiquidity } \\
\hline & & Exp. & Unexp. & & Exp. & Unexp. & & Exp. & & Unexp. \\
\hline 1 & 0.1357 & 0.50 & $-20.77 * * *$ & 0.1218 & 1.24 & $-15.32 * * *$ & 0.1435 & 1.92 & & $-14.58 * * *$ \\
\hline 2 & 0.1287 & 0.88 & $-30.60 * * *$ & 0.0861 & 1.77 & $-15.36 * * *$ & 0.0841 & 2.21 & & $-12.36 * * *$ \\
\hline 3 & 0.1252 & 1.30 & $-36.77 * * *$ & 0.0709 & 2.04 & $-16.36 * * *$ & 0.0715 & 2.59 & & $-12.13 * * *$ \\
\hline 4 & 0.0920 & 1.65 & $-35.67 * * *$ & 0.0646 & 2.43 & $-16.98 * *$ & 0.0692 & 2.99 & & $-12.56 * * *$ \\
\hline 5 & 0.0997 & 1.97 & $-40.18 * * *$ & 0.0729 & 2.80 & $-18.99 * * *$ & 0.0665 & 3.23 & & $-12.78 * *$ \\
\hline 6 & 0.0952 & 2.38 & $-40.24 * * *$ & 0.0629 & $3.09 *$ & $-17.85 * *$ & 0.0594 & 3.48 & & $-12.01 * *$ \\
\hline 7 & 0.0802 & 2.69 & $-38.35 * * *$ & 0.0538 & $3.35 *$ & $-16.18 * *$ & 0.0524 & 3.70 & $* *$ & $-10.89 *$ \\
\hline 8 & 0.0721 & 2.98 & $-36.18 * * *$ & 0.0516 & $3.59 *$ & $-15.54 *$ & 0.0506 & 3.92 & $* *$ & -10.36 \\
\hline 9 & 0.0666 & $3.25 *$ & $-34.40 * *$ & 0.0495 & $3.83 *$ & -14.57 & 0.0446 & 4.04 & $* *$ & -9.01 \\
\hline 10 & 0.0633 & $3.52 *$ & $-32.72 * *$ & 0.0430 & $3.99 *$ & -12.30 & 0.0409 & 4.18 & $* *$ & -7.79 \\
\hline 11 & 0.0494 & $3.75 *$ & -26.38 & 0.0385 & $4.15 *$ & -10.00 & 0.0380 & 4.31 & $* *$ & -6.43 \\
\hline 12 & 0.0460 & $3.92 * *$ & -23.81 & 0.0378 & $4.28 *$ & -9.02 & 0.0365 & 4.40 & $* *$ & -5.49 \\
\hline
\end{tabular}

Note: This table presents the results of model (5)'s time-series regressions on equal-weighted excess returns and illiquidity measures for different time lags and rolling averages (3x12). It includes the coefficients of expected and unexpected illiquidity, with their respective significance levels, and an adjusted R-square, based on market excess returns (dependent variable). However, the intercept is not reported. ***, ** and * denote the test statistics of the coefficients at the $1 \%, 5 \%$, and $10 \%$ levels, respectively. The illiquidity measures are winsorized at the 5\% and $95 \%$ levels for each month $\mathrm{m}$. The data include CDAX stocks from July 1999 to June 2019. 
Table 3: Results of the stability tests

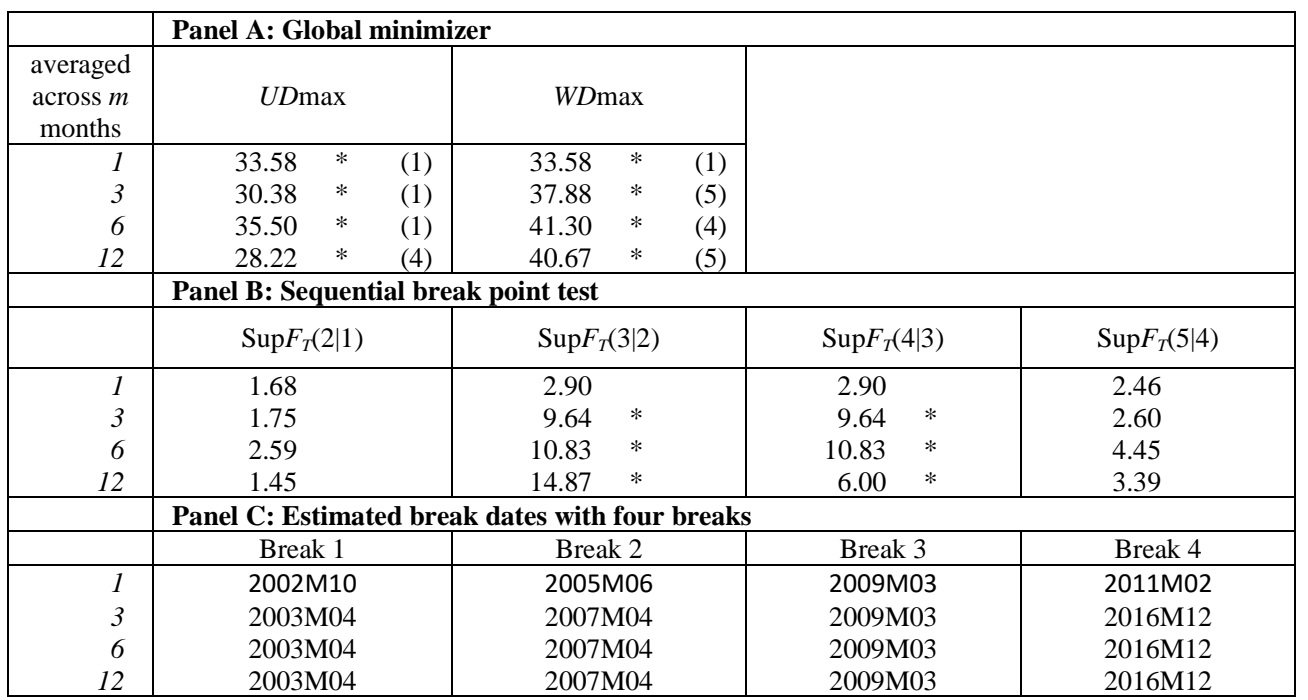

Note: The table shows the stability test results of model (5) on equal-weighted excess returns and illiquidity measures, following the Bai and Perron (2003) stability test procedure for a time lag of three months and rolling averages across one, three, six, and 12 months. In Panel A, we report the results of the $\sup F_{\mathrm{T}}(\mathrm{k})$ test statistics, based on global minimizers. We show the maxima of the UDmax and WDmax values, and their significance at the $5 \%$ level $(*)$. The number of associated breakpoints is in parentheses. In panel B, we present the results of the sequential test, $\sup F_{T}(1+1 \mid 1)$. Panel $\mathrm{C}$ shows the structural break points, based on the four breaks. The $\sup F_{T}(\mathrm{k})$ tests and reported standard errors allow for the possibility of serial correlations in the disturbances. The heteroscedasticity and autocorrelation consistent covariance matrix is based on a quadratic kernel with automatic bandwidth selection with an AR(1) approximation, as suggested by Andrews (1991), and Andrews and Monahan (1992). The residuals are pre-whitened using VAR(1). We use a $10 \%$ trimming size for the sequential test, $\sup F_{T}(1+1 \mid 1)$. The illiquidity measures are winsorized at the 5\% and 95\% levels for each month m. The data include CDAX stocks from July 1999 to June 2019. 
Table 4: Regression results with fix breaks

\begin{tabular}{|c|c|c|c|c|c|c|c|c|c|c|c|c|c|c|c|c|c|c|}
\hline & & & \multicolumn{2}{|c|}{ Period 1} & \multicolumn{4}{|c|}{ Period 2} & \multicolumn{2}{|r|}{ Period 3} & \multicolumn{4}{|c|}{ Period 4} & \multicolumn{4}{|c|}{ Period 5} \\
\hline \multirow{2}{*}{$\begin{array}{c}\text { averaged } \\
\text { across } m \\
\text { months } \\
\end{array}$} & \multirow[b]{2}{*}{ Adj. $R^{2}$} & \multirow[b]{2}{*}{ SIC } & \multicolumn{2}{|c|}{ Illiquidity } & \multicolumn{4}{|c|}{ Illiquidity } & \multicolumn{2}{|r|}{ Illiquidity } & \multicolumn{4}{|c|}{ Illiquidity } & \multicolumn{4}{|c|}{ Illiquidity } \\
\hline & & & Exp. & Unexp. & $\mathrm{Ex}_{1}$ & & Un & & Exp. & Unexp. & Exp. & & Unex & & Exp. & & Unex & \\
\hline 1 & 0.2342 & -2.9940 & -0.94 & -9.09 & 6.84 & $* * *$ & -6.58 & * & -7.42 & -16.65 & 5.98 & $* *$ & -3.44 & & 10.31 & & -19.21 & \\
\hline 2 & 0.2098 & -2.9626 & -0.87 & -9.33 & 7.68 & $* * *$ & -1.73 & & -9.46 & -5.46 & 6.63 & $* * *$ & 3.03 & & 6.50 & & -31.64 & $*$ \\
\hline 3 & 0.2191 & -2.9745 & -0.71 & -11.42 & 7.90 & $* * *$ & 0.11 & & -10.96 & -1.61 & 6.83 & $* * *$ & 5.63 & & 10.97 & & -40.70 & $* * *$ \\
\hline 4 & 0.2212 & -2.9772 & -0.50 & -12.99 & 8.02 & $* * *$ & 2.22 & & -10.45 & -8.15 & 6.97 & $* * *$ & 7.49 & & 12.40 & * & -44.32 & $* * *$ \\
\hline 5 & 0.2188 & -2.9741 & -0.31 & -13.34 & 7.84 & $* * *$ & 3.75 & & -11.88 & -5.57 & 6.72 & $* * *$ & 8.18 & & 13.23 & * & -49.95 & $* * *$ \\
\hline 6 & 0.2125 & -2.9661 & -0.26 & -13.19 & 7.76 & $* * *$ & 5.15 & & -11.00 & -12.75 & 6.45 & $* * *$ & 10.74 & $*$ & 20.05 & $* * *$ & -32.95 & $*$ \\
\hline 7 & 0.2183 & -2.9734 & -0.07 & -14.04 & 7.64 & $* * *$ & 8.32 & & -8.84 & -23.57 & 6.16 & $* * *$ & 13.55 & $* *$ & 22.59 & $* * *$ & -30.32 & \\
\hline 8 & 0.2187 & -2.9739 & 0.41 & -16.26 & 7.41 & $* * *$ & 10.47 & $*$ & -7.84 & -29.42 & 5.86 & $* * *$ & 14.94 & $* * *$ & 23.26 & $* * *$ & -20.52 & \\
\hline 9 & 0.2212 & -2.9772 & 0.85 & -18.77 & 7.19 & $* * *$ & 15.36 & $* *$ & -7.66 & -31.60 & 5.44 & $* * *$ & 16.64 & $* * *$ & 23.26 & $* * *$ & -15.63 & \\
\hline 10 & 0.2175 & -2.9724 & 1.60 & -22.73 & 6.78 & $* * *$ & 17.96 & $* * *$ & -9.22 & -27.94 & 5.13 & $* * *$ & 17.91 & $* * *$ & 23.99 & $* * *$ & -8.86 & \\
\hline 11 & 0.2183 & -2.9734 & 2.56 & -27.74 & 6.30 & $* * *$ & 21.38 & $* * *$ & -11.81 & -22.30 & 4.87 & $* * *$ & 19.09 & $* * *$ & 23.73 & $* * *$ & -8.19 & \\
\hline 12 & 0.2144 & -2.9685 & 2.62 & -29.11 & 5.67 & $* *$ & 22.64 & $* * *$ & -14.15 & -18.65 & 4.58 & $* * *$ & 19.47 & $* * *$ & 23.44 & $* * *$ & -5.60 & \\
\hline
\end{tabular}

Note: This table presents the results of model (5)'s time-series regressions on equal-weighted excess returns and illiquidity measures for a time lag of three months and 12 rolling averages for the identified sub-periods. It includes the coefficients of expected and unexpected illiquidity with their respective significance levels, the adjusted R-squares, and the Schwarz information criteria (SIC), based on the market's excess returns (dependent variable). However, the intercept is not reported. ***,** and * denote the test statistics of the coefficients at the $1 \%, 5 \%$ and $10 \%$ levels, respectively. The heteroscedasticity and autocorrelation consistent covariance matrix is based on a quadratic kernel with automatic bandwidth selection with an AR(1) approximation, as suggested by Andrews (1991), and Andrews and Monahan (1992). The residuals are pre-whitened using VAR(1). The sub-periods are defined as follows: (1) July 1999 to March 2003; (2) April 2003 to March 2007; (3) April 2007 to February 2009; (4) March 2009 to November 2016; and

(5) December 2016 to June 2019. The illiquidity measures are winsorized at the 5\% and 95\% levels for each month. The data include CDAX stocks from July 1999 to June 2019. 
Table 5: Regression results with orthogonalized LIQ and Fama-French factors without breaks and with fix breaks

\begin{tabular}{|c|c|c|c|c|c|c|c|c|c|c|c|c|c|c|c|c|c|c|c|c|c|}
\hline \multirow{4}{*}{$\begin{array}{l}\text { averaged } \\
\text { across } m \\
\text { months }\end{array}$} & \multirow{2}{*}{\multicolumn{5}{|c|}{ Total Sample }} & \multicolumn{16}{|c|}{ Subsamples with breakpoints } \\
\hline & & & & & & \multirow{2}{*}{\multicolumn{3}{|c|}{$\frac{\text { Period 1 }}{\text { Illiquidity }}$}} & \multirow{2}{*}{\multicolumn{4}{|c|}{$\begin{array}{c}\text { Period } 2 \\
\text { Illiquidity }\end{array}$}} & \multicolumn{2}{|c|}{ Period 3} & \multicolumn{4}{|c|}{ Period 4} & \multicolumn{3}{|c|}{ Period 5} \\
\hline & \multirow[b]{2}{*}{ Adj. $\mathrm{R}^{2}$} & \multicolumn{4}{|c|}{ Illiquidity } & & & & \multicolumn{2}{|c|}{ Illiquidity } & & & \multicolumn{2}{|c|}{ Illiquidity } & \multicolumn{4}{|c|}{ Illiquidity } & \multicolumn{3}{|c|}{ Illiquidity } \\
\hline & & \multicolumn{2}{|c|}{ Exp. } & \multicolumn{2}{|c|}{ Unexp. } & Adj. $R^{2}$ & Exp. & Unexp. & Ex & p. & Une & exp. & Exp. & Unexp. & Ex & & Une & exp. & Ex & p. & Unexp. \\
\hline 1 & 0.3867 & 2.89 & $*$ & -11.26 & $* * *$ & 0.6402 & -2.02 & -1.60 & 8.10 & $* * *$ & -5.34 & * & $-12.98 *$ & -0.26 & 2.35 & & -6.03 & & 13.96 & & -28.42 \\
\hline 2 & 0.3562 & 3.21 & $*$ & -9.84 & $* * *$ & 0.6272 & -1.90 & -2.42 & 8.90 & $* * *$ & -0.84 & & -13.18 & 0.32 & 2.71 & & -2.77 & & 13.84 & & -35.90 \\
\hline 3 & 0.3593 & 3.80 & ** & -10.30 & $* * *$ & 0.6308 & -1.53 & -4.96 & 9.06 & $* * *$ & 0.30 & & -13.23 & -0.23 & 3.26 & * & 0.24 & & 13.08 & & $-48.14 *$ \\
\hline 4 & 0.3658 & 4.34 & $* * *$ & -11.12 & $* * *$ & 0.6338 & -0.92 & $-7.63 *$ & 9.18 & $* * *$ & 1.19 & & -13.45 & -5.71 & 3.60 & $*$ & 2.55 & & 12.09 & & $-55.89 *$ \\
\hline 5 & 0.3745 & 4.81 & $* * *$ & -12.16 & $* * *$ & 0.6321 & -0.30 & $-9.52 * *$ & 9.02 & $* * *$ & 1.90 & & -14.81 & -3.07 & 3.72 & $* *$ & 2.18 & & 16.00 & * & $-51.20 *$ \\
\hline 6 & 0.3696 & 5.07 & $* * *$ & -11.45 & $* * *$ & 0.6277 & -0.19 & $-9.66 * *$ & 8.98 & $* * *$ & 1.91 & & -14.71 & -4.13 & 3.62 & $* *$ & 4.18 & & 22.69 & $* * *$ & -31.34 \\
\hline 7 & 0.3609 & 5.23 & $* * *$ & -9.98 & $* *$ & 0.6262 & -0.18 & $-9.44 * *$ & 8.73 & $* * *$ & 6.35 & & -14.11 & -7.97 & 3.41 & $* *$ & 7.20 & & 25.22 & $* * *$ & -27.22 \\
\hline 8 & 0.3547 & 5.42 & $* * *$ & -8.36 & $* *$ & 0.6253 & -0.13 & $-9.15 *$ & 8.50 & $* * *$ & 8.05 & $*$ & -13.70 & -10.88 & 3.28 & $* *$ & 9.20 & $* *$ & 26.63 & $* * *$ & -17.05 \\
\hline 9 & 0.3453 & 5.42 & $* * *$ & -6.23 & & 0.6252 & -0.36 & $-8.66 *$ & 8.18 & $* * *$ & 11.35 & $* *$ & -13.20 & -11.89 & 3.02 & $*$ & 10.16 & $* * *$ & 27.70 & $* * *$ & -15.29 \\
\hline 10 & 0.3392 & 5.39 & $* * *$ & -4.33 & & 0.6216 & -0.80 & -7.74 & 7.83 & $* * *$ & 12.00 & $* *$ & -13.52 & -9.72 & 2.89 & $*$ & 10.30 & $* * *$ & 28.76 & $* * *$ & -15.11 \\
\hline 11 & 0.3343 & 5.34 & $* * *$ & -2.06 & & 0.6225 & -0.93 & -7.75 & 7.49 & $* * *$ & 13.85 & $* * *$ & -13.43 & -5.48 & 2.79 & $*$ & 11.21 & $* * *$ & 29.91 & $* * *$ & -19.14 \\
\hline 12 & 0.3316 & 5.27 & $* * *$ & -0.54 & & 0.6209 & -1.07 & -8.12 & 7.10 & $* * *$ & 14.71 & $* *$ & -13.35 & -1.08 & 2.66 & $*$ & 11.65 & $* * *$ & 30.47 & $* * *$ & -12.71 \\
\hline
\end{tabular}

Note: This table presents the results of model (5)'s time-series regressions on equal-weighted excess returns and illiquidity measures for a time lag of three months, and 12 rolling averages for the total period, without breaks, and identified sub-periods. It includes the coefficients of expected and unexpected illiquidity with their respective

significance levels, and the adjusted R-squares, based on the market's excess returns (dependent variable). However, the intercept is not reported. $* * *, * *$ and $*$ denote the test statistics of the coefficients at the $1 \%, 5 \%$, and $10 \%$ levels, respectively. The $O L I Q$, which represents the orthogonalized $L I Q$, is the illiquidity measure. This orthogonalized $L I Q$ is risk-adjusted for the four Fama-French factors. The heteroscedasticity and autocorrelation consistent covariance matrix is based on a quadratic kernel with automatic bandwidth selection with an AR(1) approximation, as suggested by Andrews (1991), and Andrews and Monahan (1992). The residuals are pre-whitened using VAR(1). The sub-periods are defined as follows: (1) July 1999 to March 2003; (2) April 2003 to March 2007; (3) April 2007 to February 2009; (4) March 2009 to November 2016; and (5) December 2016 to October 2018. The illiquidity measures are winsorized at the 5\% and 95\% levels for each month m. The data include CDAX stocks from July 1999 to October 2018 . 
Table 6: Regression results without breaks and with fix breaks on size-based portfolios

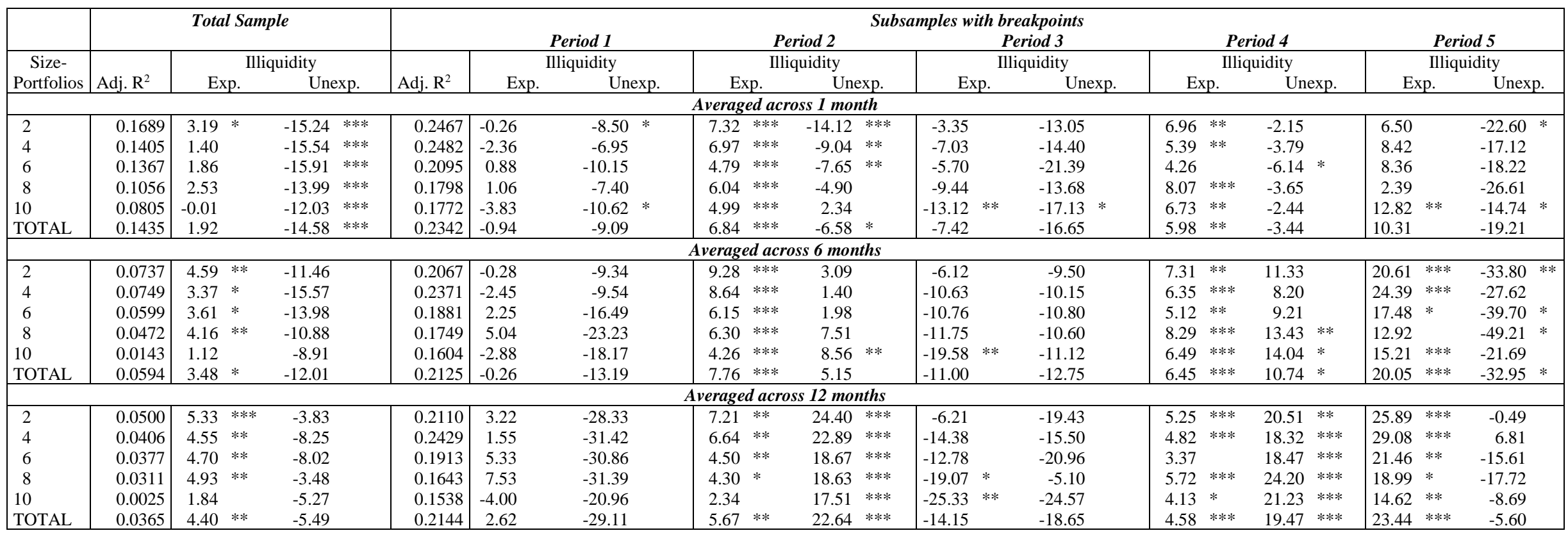

Note: This table presents the results of model (5)'s time-series regressions on equal-weighted excess returns and illiquidity measures for a time lag of three months and different rolling averages of the selected size portfolios, as well as the total market for the total period, without breaks, and the identified sub-periods. It includes the coefficients of expected and unexpected illiquidity with their respective significance levels and the adjusted R-squares, based on the market's excess returns (dependent variable). However, the intercept is not reported. $* * *, * *$ and $*$ denote the test statistics of the coefficients at the $1 \%, 5 \%$, and $10 \%$ levels, respectively. The heteroscedasticity and autocorrelation consistent covariance matrix is based on a quadratic kernel with automatic bandwidth selection with an AR(1) approximation, as suggested by Andrews (1991), and Andrews and Monahan (1992). The residuals are pre-whitened using VAR(1). All stocks in the sample are sorted at the year-end into one of 10 portfolios, based on their respective value. The sub-periods are defined as follows: (1) July 1999 to March 2003; (2) April 2003 to March 2007; (3) April 2007 to February 2009; (4) March 2009 to November 2016; and (5) December 2016 to June 2019. The illiquidity measures are winsorized at the 5\% and 95\% levels for each month. The data include CDAX stocks from July 1999 to June 2019. 
Table 7: Economic value of illiquidity

\begin{tabular}{|c|c|c|c|c|c|c|c|c|c|c|c|c|c|c|c|c|}
\hline \multirow[b]{3}{*}{$\begin{array}{c}\text { Size- } \\
\text { Portfolio }\end{array}$} & \multirow{2}{*}{\multicolumn{6}{|c|}{$\begin{array}{c}\text { ex-ante analysis } \\
\text { Return }\end{array}$}} & \multicolumn{10}{|c|}{ ex-post analysis } \\
\hline & & & & & & & \multicolumn{4}{|c|}{ Return } & \multicolumn{6}{|c|}{ Return contribution of market illiquidity } \\
\hline & \multicolumn{2}{|c|}{ Total period } & \multicolumn{2}{|c|}{ Non-crisis period } & \multicolumn{2}{|c|}{ Crisis-period } & \multirow{2}{*}{$\begin{array}{l}\begin{array}{l}\text { Total } \\
\text { period }\end{array} \\
\text { Ave }\end{array}$} & $\begin{array}{l}\text { Non- } \\
\text { crisis } \\
\text { period }\end{array}$ & \multicolumn{2}{|c|}{ Crisis period } & \multirow[t]{2}{*}{$\begin{array}{c}\text { Total } \\
\text { period }\end{array}$} & \multirow[t]{2}{*}{$\begin{array}{l}\text { Total } \\
\text { period }\end{array}$} & \multirow{2}{*}{\multicolumn{2}{|c|}{$\begin{array}{l}\text { Crisis } \\
\text { period }\end{array}$}} & \multicolumn{2}{|c|}{$\begin{array}{l}\text { Difference between } \\
\text { non-crisis periods } \\
\text { (with vs. w/o breaks) }\end{array}$} \\
\hline \multicolumn{12}{|c|}{ Averaged across 1 month } & & & & & \\
\hline 1 & 0.71 & & 1.49 & & -2.38 & & 1.34 & 2.05 & -1.51 & * & 2.98 & 4.28 & 5.41 & -0.27 & 2.25 & **** \\
\hline 2 & 0.09 & & 0.72 & & -2.41 & & 0.64 & 1.57 & -3.08 & $* * *$ & 2.26 & 2.86 & 3.77 & -0.77 & 1.24 & $* * *$ \\
\hline 4 & 0.05 & & 0.71 & $* *$ & -2.57 & & 0.52 & 1.64 & -3.93 & $* * *$ & 1.42 & 2.51 & 3.29 & -0.61 & 1.55 & $* * *$ \\
\hline 6 & -0.08 & & 0.64 & $* * *$ & -2.96 & & 0.58 & 1.62 & -3.55 & $* * *$ & 1.65 & 1.95 & 2.36 & 0.30 & 0.41 & $* *$ \\
\hline 8 & 0.17 & & 0.76 & $* * *$ & -2.15 & & 0.84 & 1.72 & -2.67 & ** & 2.30 & 3.20 & 3.47 & 2.11 & 0.96 & $* * *$ \\
\hline 10 & -0.25 & & 0.05 & $* * *$ & -1.46 & $* * *$ & 0.53 & 1.39 & -2.91 & $* *$ & 1.18 & 1.90 & 2.13 & 1.00 & 0.70 & $* * *$ \\
\hline TOTAL & 0.10 & & 0.70 & & -2.26 & & 0.71 & 1.65 & -3.07 & $* * *$ & 1.78 & 2.71 & 3.27 & 0.44 & 1.22 & $* * *$ \\
\hline \multicolumn{17}{|c|}{ Averaged across 6 months } \\
\hline 1 & 0.74 & ** & 1.51 & & -2.32 & & 1.34 & 2.05 & -1.51 & $*$ & 3.96 & 4.85 & 6.16 & -0.42 & 2.11 & **** \\
\hline 2 & 0.10 & ** & 0.73 & & -2.43 & & 0.64 & 1.57 & -3.08 & **** & 3.36 & 3.94 & 4.94 & -0.09 & 1.40 & $* * *$ \\
\hline 4 & 0.13 & * & 0.67 & & -2.01 & & 0.52 & 1.64 & -3.93 & **** & 3.04 & 3.51 & 4.39 & 0.00 & 1.07 & $* * *$ \\
\hline 6 & 0.30 & & 0.84 & & -1.85 & & 0.58 & 1.62 & -3.55 & $* * *$ & 2.99 & 2.68 & 3.16 & 0.79 & -0.06 & \\
\hline 8 & 0.03 & & 0.60 & & -2.27 & & 0.84 & 1.72 & -2.67 & $* *$ & 3.65 & 3.72 & 4.01 & 2.56 & 0.18 & \\
\hline 10 & 0.01 & & 0.27 & & -1.04 & & 0.53 & 1.39 & -2.91 & $* *$ & 2.23 & 2.59 & 2.86 & 1.54 & 0.44 & $* *$ \\
\hline TOTAL & 0.28 & & 0.82 & & -1.87 & & 0.71 & 1.65 & -3.07 & $* * *$ & 3.07 & 3.46 & 4.11 & 0.86 & 0.84 & $* * *$ \\
\hline \multicolumn{17}{|c|}{ Averaged across 12 months } \\
\hline 1 & 0.97 & **** & 1.77 & & -2.22 & & 1.34 & 2.05 & -1.51 & * & 3.90 & 4.26 & 5.55 & -0.91 & 1.66 & **** \\
\hline 2 & 0.20 & $* * *$ & 1.02 & & -3.06 & & 0.64 & 1.57 & -3.08 & $* * *$ & 3.35 & 3.60 & 4.57 & -0.24 & 1.16 & $* * *$ \\
\hline 4 & 0.43 & $* *$ & 1.14 & & -2.40 & & 0.52 & 1.64 & -3.93 & $* * *$ & 3.28 & 3.22 & 4.03 & -0.02 & 0.63 & $* *$ \\
\hline 6 & 0.97 & & 1.53 & & -1.28 & & 0.58 & 1.62 & -3.55 & $* * *$ & 3.14 & 2.22 & 2.73 & 0.18 & -0.49 & \\
\hline 8 & 0.44 & $*$ & 1.01 & & -1.85 & & 0.84 & 1.72 & -2.67 & $* *$ & 3.59 & 3.27 & 3.54 & 2.16 & -0.09 & \\
\hline 10 & 0.53 & & 0.68 & & -0.07 & ** & 0.53 & 1.39 & -2.91 & $* *$ & 2.26 & 2.27 & 2.56 & 1.12 & 0.26 & \\
\hline TOTAL & 0.68 & $* *$ & 1.44 & & -2.34 & & 0.71 & 1.65 & -3.07 & $* * *$ & 3.15 & 3.02 & 3.68 & 0.41 & 0.47 & \\
\hline
\end{tabular}

Note: This table presents in the left panel the means of the ex-ante estimated excess returns and the explanatory power of the excess returns by the estimated ex-ante returns.

The ex-ante estimated excess-returns are derived by model (5)'s time-series regressions on equal-weighted excess returns and illiquidity measures over rolling 24 months periods, corresponding to the minimum length of a period within our structural break analysis (trimming level), and a lag of 3 month. The means of the ex-post excess returns are presented in the middle panel, and the return impact of orthogonalized market illiquidity in the right panel. All these data are shown for the total period (205 months), noncrisis periods (140 months), and crisis periods (65 months). These are presented in percentage points per month for portfolios of different sizes, with a time lag of three months, and rolling averaged across one, six, and 12 months. In addition, we compare the difference between illiquidity's impact in non-crisis periods from the model with and without structural breaks by testing a t-statistic to determine whether the difference is equal to zero. ***, ** and $*$ denote the test statistics of the coefficients at the $1 \%, 5 \%$, and $10 \%$ levels, respectively. The illiquidity measures are winsorized at the 5\% and 95\% levels for each month. The data include CDAX stocks from October 2001 to October 2018. 


\section{Supplementary Material for}

'The Time-varying Relationship between Liquidity and Stock Returns:

Evidence from Germany' 
Table 1: Regression results without breaks - equal-weighted, adjusted for inflation

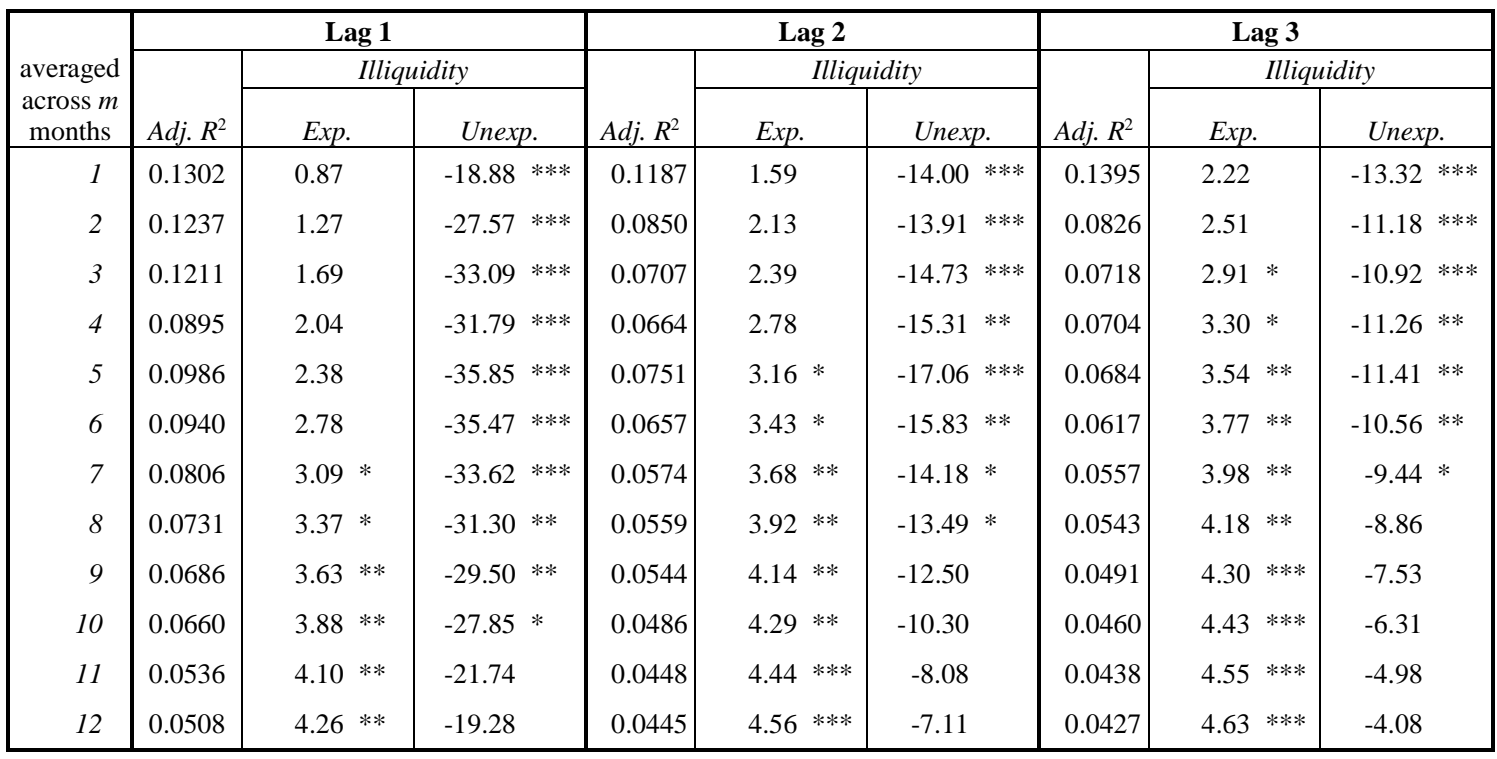

Note: This table presents the results of model (5)'s time-series regressions on equal-weighted excess returns and illiquidity measures for different time lags and rolling averages $(3 \times 12)$. The illiquidity measures are adjusted for inflation (EUR-turnover adjusted by consumer price index, Germany). It includes the coefficients of expected and unexpected illiquidity, with their respective significance levels, and an adjusted $\mathrm{R}$-square, based on market excess returns (dependent variable). However, the intercept is not reported. ***, $* *$ and $*$ denote the test statistics of the coefficients at the $1 \%, 5 \%$, and $10 \%$ levels, respectively. The illiquidity measures are winsorized at the 5\% and 95\% levels for each month. The data include CDAX stocks from July 1999 to June 2019.

Table 2: Regression results without breaks - equal-weighted, lag 3 months, different winsorizing levels

\begin{tabular}{|c|c|c|c|c|c|c|c|c|c|c|}
\hline \multirow{3}{*}{\begin{tabular}{|c|} 
win-level \\
averaged \\
across $m$ \\
months \\
\end{tabular}} & \multicolumn{4}{|c|}{$0.5 \% / 99.5 \%$} & \multicolumn{3}{|c|}{$5.0 \% / 95.0 \%$} & \multicolumn{3}{|c|}{$10.0 \% / 90.0 \%$} \\
\hline & \multirow[b]{2}{*}{ Adj. $R^{2}$} & \multicolumn{3}{|c|}{ Illiquidity } & \multirow[b]{2}{*}{$\operatorname{Adj.} R^{2}$} & \multicolumn{2}{|c|}{ Illiquidity } & \multirow[b]{2}{*}{ Adj. $R^{2}$} & \multicolumn{2}{|c|}{ Illiquidity } \\
\hline & & Exp. & & Unexp. & & Exp. & Unexp. & & Exp. & Unexp. \\
\hline 1 & 0.1230 & 2.23 & & $-12.35 * * *$ & 0.1435 & 1.92 & $-14.58 * * *$ & 0.1713 & 1.90 & $-17.09 * * *$ \\
\hline 2 & 0.0669 & 2.51 & & $-10.09 * * *$ & 0.0841 & 2.21 & $-12.36 * * *$ & 0.0994 & 2.20 & $-14.37 * * *$ \\
\hline 3 & 0.0496 & $2.90 *$ & & $-8.59 * *$ & 0.0715 & 2.59 & $-12.13 * * *$ & 0.0869 & 2.59 & $-14.56 * * *$ \\
\hline 4 & 0.0437 & $3.30 *$ & & $-7.60 *$ & 0.0692 & $2.99 *$ & $-12.56 * * *$ & 0.0862 & $3.02 *$ & $-15.62 * * *$ \\
\hline 5 & 0.0451 & $3.58 *$ & & $-7.43 *$ & 0.0665 & $3.23 *$ & $-12.78 * *$ & 0.0838 & $3.27 *$ & $-16.31 * * *$ \\
\hline 6 & 0.0430 & $3.85 *$ & $* *$ & -6.38 & 0.0594 & $3.48 *$ & $-12.01 * *$ & 0.0766 & $3.53 *$ & $-15.98 * * *$ \\
\hline 7 & 0.0400 & $4.05 *$ & *** & -5.03 & 0.0524 & $3.70 *$ & $-10.89 *$ & 0.0661 & 3.76 ** & $-14.81 * *$ \\
\hline 8 & 0.0406 & $4.25 *$ & *** & -4.28 & 0.0506 & $3.92 *$ & -10.36 & 0.0625 & $3.97 * *$ & $-14.40 * *$ \\
\hline 9 & 0.0390 & $4.38 *$ & $* * *$ & -2.92 & 0.0446 & $4.04 *$ & -9.01 & 0.0541 & 4.11 ** & $-13.02 *$ \\
\hline 10 & 0.0380 & $4.46 *$ & $* * *$ & -1.65 & 0.0409 & $4.18 *$ & -7.79 & 0.0478 & $4.23 * *$ & -11.75 \\
\hline 11 & 0.0381 & $4.55 *$ & **** & -0.07 & 0.0380 & $4.31 *$ & -6.43 & 0.0431 & 4.36 ** & -10.44 \\
\hline 12 & 0.0389 & $4.61 *$ & *** & 0.98 & 0.0365 & $4.40 *:$ & -5.49 & 0.0405 & $4.46 * *$ & -9.58 \\
\hline
\end{tabular}

Note: This table presents the results of model (5)'s time-series regressions on equal-weighted excess returns and illiquidity measures for a time lag of three months and different and rolling averages (1 to 12 months). It includes the coefficients of expected and unexpected illiquidity, with their respective significance levels, and an adjusted R-square, based on market excess returns (dependent variable). However, the intercept is not reported. $* * *, * *$ and $*$ denote the test statistics of the coefficients at the $1 \%, 5 \%$, and $10 \%$ levels, respectively. The illiquidity measures are winsorized at the $0.5 \%$ and $99.5 \%$, the $5 \%$ and $95 \%$, and the $10 \%$ and $90 \%$ levels for each month, respectively. The data include CDAX stocks from July 1999 to June 2019. 
Table 3: Regression results without breaks - value-weighted

\begin{tabular}{|c|c|c|c|c|c|c|c|c|c|}
\hline \multirow{3}{*}{$\begin{array}{c}\text { averaged } \\
\text { across } m \\
\text { months }\end{array}$} & \multicolumn{3}{|c|}{ Lag 1} & \multicolumn{3}{|c|}{ Lag 2} & \multicolumn{3}{|c|}{ Lag 3} \\
\hline & \multirow[b]{2}{*}{ Adj. $R^{2}$} & \multicolumn{2}{|c|}{ Illiquidity } & \multirow[b]{2}{*}{$\operatorname{Adj} . R^{2}$} & \multicolumn{2}{|c|}{ Illiquidity } & \multirow[b]{2}{*}{ Adj. $R^{2}$} & \multicolumn{2}{|c|}{ Illiquidity } \\
\hline & & Exp. & Unexp. & & Exp. & Unexp. & & Exp. & Unexp. \\
\hline 1 & 0.0811 & -1.57 & $-153.26 * * *$ & 0.0738 & 3.72 & $-132.18 * * *$ & 0.0909 & 21.74 & $-125.12 * * *$ \\
\hline 2 & 0.0521 & 0.62 & $-203.22 * *$ & 0.0401 & 14.31 & $-119.60 * *$ & 0.0463 & 25.97 & $-104.08 * * *$ \\
\hline 3 & 0.0489 & 8.00 & $-234.37 * *$ & 0.0358 & 19.27 & $-132.86 * *$ & 0.0419 & $32.79=$ & $-104.58 * *$ \\
\hline 4 & 0.0313 & 13.06 & $-215.57 *$ & 0.0332 & 25.92 & $-139.28 * *$ & 0.0418 & 39.10 & $-110.47 * *$ \\
\hline 5 & 0.0370 & 19.67 & $-251.91 * *$ & 0.0393 & 33.15 & $-157.34 * *$ & 0.0333 & 40.09 & $-104.25 * *$ \\
\hline 6 & 0.0244 & 26.45 & -205.65 & 0.0215 & 34.89 & -118.09 & 0.0298 & 45.19 & $-96.09 *$ \\
\hline 7 & 0.0071 & 28.72 & -121.02 & 0.0182 & $39.40 *$ & -103.66 & 0.0236 & 47.10 & -82.35 \\
\hline 8 & 0.0122 & 32.42 & -149.38 & 0.0205 & $42.14 *$ & -112.03 & 0.0248 & $49.30=$ & -85.89 \\
\hline 9 & 0.0075 & 35.70 & -104.33 & 0.0166 & $44.62 * *$ & -91.87 & 0.0219 & 51.24 & -75.60 \\
\hline 10 & 0.0053 & $37.90 *$ & -71.66 & 0.0142 & $46.19 * *$ & -77.25 & 0.0171 & $50.68=$ & -61.71 \\
\hline 11 & 0.0038 & $39.56 *$ & -34.69 & 0.0108 & $46.44 * *$ & -57.77 & 0.0162 & $52.07 *$ & -55.86 \\
\hline 12 & 0.0028 & $39.70 *$ & 10.40 & 0.0106 & $47.63 * *$ & -52.89 & 0.0177 & $54.06 *$ & -59.81 \\
\hline
\end{tabular}

Note: This table presents the results of model (5)'s time-series regressions on value-weighted excess returns and illiquidity measures for different time lags and rolling averages (3x12). It includes the coefficients of expected and unexpected illiquidity, with their respective significance levels, and an adjusted R-square, based on market excess returns (dependent variable). However, the intercept is not reported. ***, ** and * denote the test statistics of the coefficients at the $1 \%, 5 \%$, and $10 \%$ levels, respectively. The illiquidity measures are winsorized at the 5\% and $95 \%$ levels for each month. The data include CDAX stocks from July 1999 to June 2019. 
Table 4: Results of the stability tests - equal-weighted, adjusted for inflation

\begin{tabular}{|c|c|c|c|c|c|c|c|c|}
\hline & \multicolumn{8}{|c|}{ Panel A: Global minimizer } \\
\hline $\begin{array}{c}\text { averaged } \\
\text { across } m \\
\text { months }\end{array}$ & \multicolumn{3}{|c|}{$U D \max$} & \multicolumn{3}{|c|}{ WDmax } & & \\
\hline 1 & 37.43 & $*$ & & 37.43 & $*$ & & & \\
\hline 3 & 32.44 & $*$ & (1) & 37.49 & $*$ & (5) & & \\
\hline 6 & 36.00 & $*$ & (1) & 40.26 & $*$ & (4) & & \\
\hline \multirow[t]{3}{*}{12} & 28.45 & $*$ & (4) & 41.40 & $*$ & $(5)$ & & \\
\hline & \multicolumn{8}{|c|}{ Panel B: Sequential breakpoint test } \\
\hline & \multicolumn{3}{|c|}{$\operatorname{Sup} F_{T}(2 \mid 1)$} & \multicolumn{3}{|c|}{$\operatorname{Sup} F_{T}(3 \mid 2)$} & $\operatorname{Sup} F_{T}(4 \mid 3)$ & $\operatorname{Sup} F_{T}(5 \mid 4)$ \\
\hline 1 & \multicolumn{3}{|l|}{1.82} & \multicolumn{3}{|l|}{2.89} & 2.89 & 2.35 \\
\hline 3 & \multicolumn{3}{|l|}{1.57} & 9.15 & $*$ & & $9.15 *$ & 2.59 \\
\hline 6 & \multicolumn{3}{|l|}{2.39} & 10.36 & $*$ & & 10.36 & 4.42 \\
\hline \multirow[t]{3}{*}{12} & \multicolumn{3}{|l|}{1.21} & 14.68 & $*$ & & 5.93 & 3.68 \\
\hline & \multicolumn{8}{|c|}{ Panel C: Estimated break dates with four breaks } \\
\hline & \multicolumn{3}{|c|}{ Break 1} & \multicolumn{3}{|c|}{ Break 2} & Break 3 & Break 4 \\
\hline 1 & \multicolumn{3}{|c|}{ 2002M10 } & \multicolumn{3}{|c|}{ 2005M06 } & \multirow{2}{*}{$\begin{array}{l}\text { 2009M0 } \\
\text { 2009M0 }\end{array}$} & $2011 \mathrm{M} 02$ \\
\hline 3 & \multicolumn{3}{|c|}{$2003 \mathrm{M} 04$} & \multicolumn{3}{|c|}{ 2007M04 } & & $2016 \mathrm{M} 12$ \\
\hline 6 & \multicolumn{3}{|c|}{$2003 \mathrm{M} 04$} & \multicolumn{3}{|c|}{ 2007M04 } & 2009M0 & 2016M12 \\
\hline 12 & \multicolumn{3}{|c|}{ 2003M04 } & \multicolumn{3}{|c|}{ 2007M04 } & 2009M0 & 2016M12 \\
\hline
\end{tabular}

Note: The table shows the stability test results of model (5) on equal-weighted excess returns and illiquidity measures, following the Bai and Perron (2003) stability test procedure for a time lag of three months and rolling averages across one, three, six, and 12 months. The illiquidity measures are adjusted for inflation (EUR-turnover adjusted by consumer price index, Germany). In Panel A, we report the results of the $\sup F_{\mathrm{T}}(\mathrm{k})$ test statistics, based on global minimizers. We show the maxima of the UDmax and WDmax values, and their significance at the 5\% level (*). The number of associated breakpoints is in parentheses. In panel $\mathrm{B}$, we present the results of the sequential test, $\sup F_{\mathrm{T}}(1+1 \mid 1)$. Panel $\mathrm{C}$ shows the structural break points, based on the four breaks. The $\sup F_{\mathrm{T}}(\mathrm{k})$ tests and reported standard errors allow for the possibility of serial correlations in the disturbances. The heteroscedasticity and autocorrelation consistent covariance matrix is based on a quadratic kernel with automatic bandwidth selection with an AR(1) approximation, as suggested by Andrews (1991), and Andrews and Monahan (1992). The residuals are pre-whitened using VAR(1). We use a $10 \%$ trimming size for the sequential test, $\sup F_{\mathrm{T}}(1+1 \mid 1)$. The illiquidity measures are winsorized at the 5\% and 95\% levels for each month. The data include CDAX stocks from July 1999 to June 2019. 
Table 5: Results of the stability tests - equal-weighted, winsorizing level $0.5 \%$ and $99.5 \%$

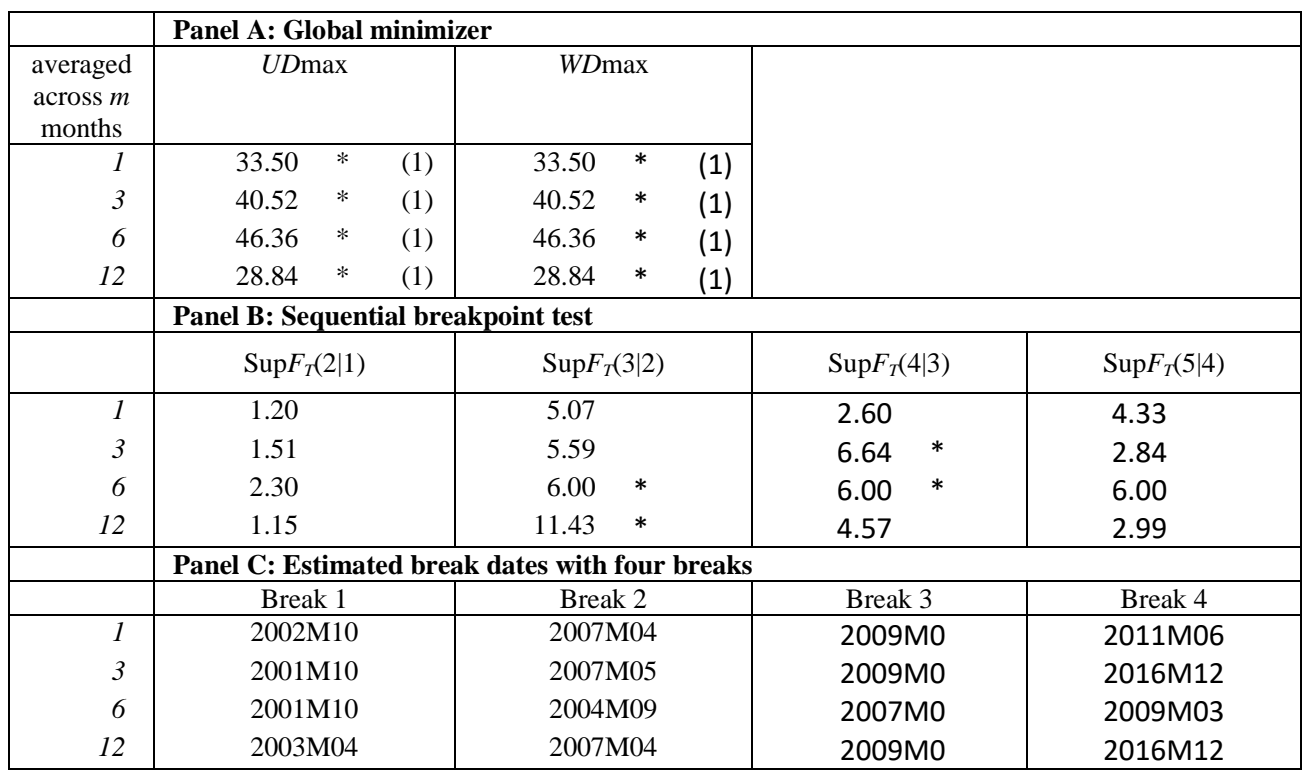

Note: The table shows the stability test results of model (5) on equal-weighted excess returns and illiquidity measures, following the Bai and Perron (2003) stability test procedure for a time lag of three months and rolling averages across one, three, six, and 12 months. In Panel A, we report the results of the $\sup F_{\mathrm{T}}(\mathrm{k})$ test statistics, based on global minimizers. We show the maxima of the UDmax and WDmax values, and their significance at the 5\% level (*). The number of associated breakpoints is in parentheses. In panel B, we present the results of the sequential test, $\sup F_{\mathrm{T}}(1+1 \mid 1)$. Panel $\mathrm{C}$ shows the structural break points, based on the four breaks. The $\sup F_{\mathrm{T}}(\mathrm{k})$ tests and reported standard errors allow for the possibility of serial correlations in the disturbances. The heteroscedasticity and autocorrelation consistent covariance matrix is based on a quadratic kernel with automatic bandwidth selection with an AR(1) approximation, as suggested by Andrews (1991), and Andrews and Monahan (1992). The residuals are pre-whitened using VAR(1). We use a $10 \%$ trimming size for the sequential test, $\sup F_{\mathrm{T}}(1+1 \mid 1)$. The illiquidity measures are winsorized at the $0.5 \%$ and $99.5 \%$ levels for each month. The data include CDAX stocks from July 1999 to June 2019. 
Table 6: Results of the stability tests - equal-weighted, winsorizing level 10\% and 90\%

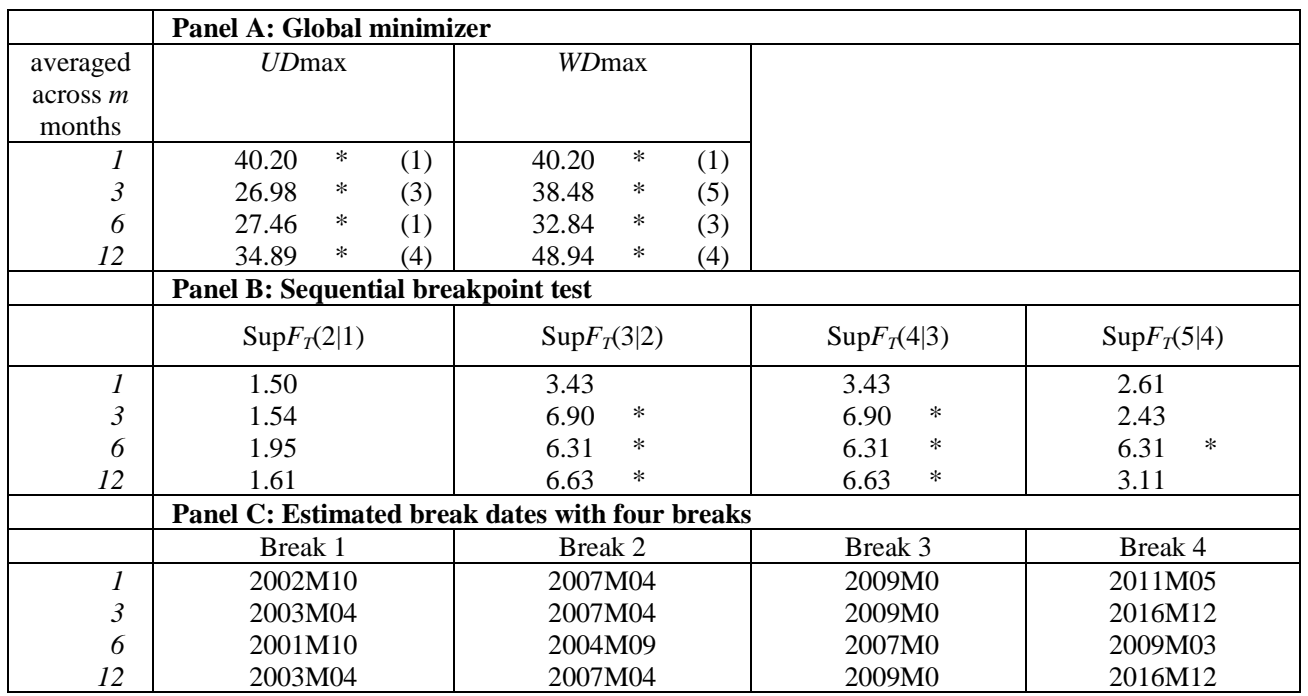

Note: The table shows the stability test results of model (5) on equal-weighted excess returns and illiquidity measures, following the Bai and Perron (2003) stability test procedure for a time lag of three months and rolling averages across one, three, six, and 12 months. In Panel A, we report the results of the $\sup F_{\mathrm{T}}(\mathrm{k})$ test statistics, based on global minimizers. We show the maxima of the UDmax and WDmax values, and their significance at the 5\% level (*). The number of associated breakpoints is in parentheses. In panel B, we present the results of the sequential test, $\sup F_{\mathrm{T}}(1+1 \mid 1)$. Panel $\mathrm{C}$ shows the structural break points, based on the four breaks. The $\sup F_{\mathrm{T}}(\mathrm{k})$ tests and reported standard errors allow for the possibility of serial correlations in the disturbances. The heteroscedasticity and autocorrelation consistent covariance matrix is based on a quadratic kernel with automatic bandwidth selection with an AR(1) approximation, as suggested by Andrews (1991), and Andrews and Monahan (1992). The residuals are pre-whitened using VAR(1). We use a $10 \%$ trimming size for the sequential test, $\sup F_{\mathrm{T}}(1+1 \mid 1)$. The illiquidity measures are winsorized at the $10 \%$ and $90 \%$ levels for each month. The data include CDAX stocks from July 1999 to June 2019. 
Table 7: Results of the stability tests - value-weighted

\begin{tabular}{|c|c|c|c|c|c|}
\hline & \multicolumn{5}{|c|}{ Panel A: Global minimizer } \\
\hline $\begin{array}{c}\text { averaged } \\
\text { across } m \\
\text { months }\end{array}$ & $U D \max$ & \multicolumn{2}{|l|}{ WDmax } & & \\
\hline 1 & 13.20 & $17.95 *$ & & & \\
\hline 3 & 12.11 & 12.30 & (0) & & \\
\hline 6 & 13.56 & $19.02 *$ & & & \\
\hline \multirow[t]{3}{*}{12} & 13.16 & 20.04 & (5) & & \\
\hline & \multicolumn{5}{|c|}{ Panel B: Sequential breakpoint test } \\
\hline & $\operatorname{Sup} F_{T}(2 \mid 1)$ & \multicolumn{2}{|l|}{$\operatorname{Sup} F_{T}(3 \mid 2)$} & $\operatorname{Sup} F_{T}(4 \mid 3)$ & $\operatorname{Sup} F_{T}(5 \mid 4)$ \\
\hline 1 & 3.25 & \multicolumn{2}{|l|}{1.19} & 5.61 & 1.90 \\
\hline 3 & 1.65 & 1.49 & & 1.72 & 2.12 \\
\hline 6 & 2.65 & 2.03 & & 1.56 & 0.75 \\
\hline \multirow[t]{3}{*}{12} & 6.62 & 1.14 & & 6.19 & 6.19 \\
\hline & \multicolumn{5}{|c|}{ Panel C: Estimated break dates with four breaks } \\
\hline & Break 1 & Break 2 & & Break 3 & Break 4 \\
\hline 1 & 2002M10 & 2006M12 & & 2008M11 & 2011M10 \\
\hline 3 & 2001M10 & 2006M12 & & 2008M11 & 2008M11 \\
\hline 6 & 2001M10 & 2006M12 & & 2008M11 & 2009M03 \\
\hline 12 & 2002M04 & 2006M12 & & 2008M11 & 2009M08 \\
\hline
\end{tabular}

Note: The table shows the stability test results of model (5) on value-weighted excess returns and illiquidity measures, following the Bai and Perron (2003) stability test procedure for a time lag of three months and rolling averages across one, three, six, and 12 months. In Panel A, we report the results of the $\sup F_{\mathrm{T}}(\mathrm{k})$ test statistics, based on global minimizers. We show the maxima of the UDmax and WDmax values, and their significance at the 5\% level (*). The number of associated breakpoints is in parentheses. In panel B, we present the results of the sequential test, $\sup F_{\mathrm{T}}(1+1 \mid 1)$. Panel $\mathrm{C}$ shows the structural break points, based on the four breaks. The $\sup F_{\mathrm{T}}(\mathrm{k})$ tests and reported standard errors allow for the possibility of serial correlations in the disturbances. The heteroscedasticity and autocorrelation consistent covariance matrix is based on a quadratic kernel with automatic bandwidth selection with an AR(1) approximation, as suggested by Andrews (1991), and Andrews and Monahan (1992). The residuals are pre-whitened using VAR(1). We use a $10 \%$ trimming size for the sequential test, $\sup F_{\mathrm{T}}(1+1 \mid 1)$. The illiquidity measures are winsorized at the 5\% and 95\% levels for each month. The data include CDAX stocks from July 1999 to June 2019. 
Table 8: Regression results with fix breaks - equal-weighted, adjusted for inflation

\begin{tabular}{|c|c|c|c|c|c|c|c|c|c|c|c|c|c|c|c|c|c|c|}
\hline & & & \multicolumn{2}{|c|}{ Period 1} & \multicolumn{4}{|c|}{ Period 2} & \multicolumn{2}{|r|}{ Period 3} & \multicolumn{4}{|c|}{ Period 4} & \multicolumn{4}{|c|}{ Period 5} \\
\hline \multirow{2}{*}{$\begin{array}{c}\text { averaged } \\
\text { across } m \\
\text { months }\end{array}$} & \multirow[b]{2}{*}{ Adj. $R^{2}$} & \multirow[b]{2}{*}{ SIC } & \multicolumn{2}{|c|}{ Illiquidity } & \multicolumn{4}{|c|}{ Illiquidity } & \multicolumn{2}{|r|}{ Illiquidity } & \multicolumn{4}{|c|}{ Illiquidity } & \multicolumn{4}{|c|}{ Illiquidity } \\
\hline & & & Exp. & Unexp. & Exp. & & Unexp & & Exp. & Unexp. & Exp. & & Unexp. & & Exp. & & Unexp & \\
\hline 1 & 0.2325 & -2.9918 & -0.73 & -8.92 & 6.83 & $* * *$ & -6.12 & $*$ & -6.72 & -15.07 & 5.91 & $* *$ & -2.79 & & 8.40 & & -15.24 & \\
\hline 2 & 0.2095 & -2.9622 & -0.69 & -9.16 & 7.58 & $* * *$ & -1.49 & & -8.77 & -4.41 & 6.57 & $* * *$ & 3.03 & & 5.85 & & -24.74 & $*$ \\
\hline 3 & 0.2193 & -2.9747 & -0.52 & -11.23 & 7.79 & $* * *$ & 0.31 & & -10.21 & -0.55 & 6.80 & $* * *$ & 5.37 & & 10.01 & & -31.50 & $* * *$ \\
\hline 4 & 0.2213 & -2.9773 & -0.32 & -12.71 & 7.90 & $* * *$ & 2.37 & & -9.74 & -6.27 & 6.93 & $* * *$ & 7.03 & & 11.37 & $* *$ & -34.05 & $* * *$ \\
\hline 5 & 0.2188 & -2.9741 & -0.15 & -12.99 & 7.71 & $* * *$ & 3.89 & & -11.11 & -3.66 & 6.67 & $* * *$ & 7.62 & & 12.08 & $* *$ & -38.43 & $* * *$ \\
\hline 6 & 0.2126 & -2.9662 & -0.13 & -12.74 & 7.62 & $* * *$ & 5.27 & & -10.24 & -10.40 & 6.38 & $* * *$ & 9.95 & * & 17.21 & $* * *$ & -25.37 & * \\
\hline 7 & 0.2182 & -2.9733 & 0.05 & -13.54 & 7.48 & $* * *$ & 8.35 & * & -8.09 & -20.86 & 6.06 & $* * *$ & 12.50 & ** & 19.24 & $* * *$ & -23.48 & \\
\hline 8 & 0.2185 & -2.9737 & 0.54 & -15.71 & 7.24 & $* * *$ & 10.47 & $*$ & -7.06 & -26.59 & 5.74 & $* * *$ & 13.81 & $* * *$ & 19.62 & $* * *$ & -15.58 & \\
\hline 9 & 0.2212 & -2.9772 & 0.96 & -18.04 & 6.98 & $* * *$ & 15.20 & $* * *$ & -6.84 & -28.75 & 5.29 & $* * *$ & 15.40 & $* * *$ & 19.56 & $* * *$ & -11.69 & \\
\hline 10 & 0.2177 & -2.9727 & 1.68 & -21.70 & 6.55 & $* * *$ & 17.74 & $* * *$ & -8.39 & -25.00 & 4.95 & $* * *$ & 16.59 & $* * *$ & 20.08 & $* * *$ & -6.31 & \\
\hline 11 & 0.2186 & -2.9738 & 2.63 & -26.41 & 6.05 & $* * *$ & 21.00 & $* * *$ & -10.99 & -19.19 & 4.67 & $* * *$ & 17.64 & $* * *$ & 19.85 & $* * *$ & -5.74 & \\
\hline 12 & 0.2148 & -2.9690 & 2.71 & -27.77 & 5.41 & $* *$ & 22.28 & $* * *$ & -13.34 & -15.22 & 4.36 & $* * *$ & 17.93 & $* * *$ & 19.59 & $* * *$ & -3.51 & \\
\hline
\end{tabular}

Note: This table presents the results of model (5)'s time-series regressions on equal-weighted excess returns and illiquidity measures for a time lag of three months and 12 rolling averages for the identified sub-periods. It includes the coefficients of expected and unexpected illiquidity with their respective significance levels, the adjusted R-squares, and the Schwarz information criteria (SIC), based on the market's excess returns (dependent variable). The illiquidity measures are adjusted for inflation (EUR-turnover adjusted by consumer price index, Germany). However, the intercept is not reported. ***, ** and * denote the test statistics of the coefficients at the $1 \%, 5 \%$ and $10 \%$ levels, respectively. The heteroscedasticity and autocorrelation consistent covariance matrix is based on a quadratic kernel with automatic bandwidth selection with an AR(1) approximation, as suggested by Andrews (1991), and Andrews and Monahan (1992). The residuals are pre-whitened using VAR(1). The sub-periods are defined as follows: (1) July 1999 to March 2003; (2) April 2003 to March 2007; (3) April 2007 to February 2009; (4) March 2009 to November 2016; and (5) December 2016 to June 2019. The illiquidity measures are winsorized at the 5\% and 95\% levels for each month. The data include CDAX stocks from July 1999 to June 2019. 
Table 9: Regression results with fix breaks - equal weighted, winsorizing level 0.5\% and 99.5\%

\begin{tabular}{|c|c|c|c|c|c|c|c|c|c|c|c|c|c|c|c|c|c|c|c|}
\hline & & & \multicolumn{2}{|c|}{ Period 1} & \multicolumn{4}{|c|}{ Period 2} & \multicolumn{3}{|c|}{ Period 3} & \multicolumn{4}{|c|}{ Period 4} & \multicolumn{4}{|c|}{ Period 5} \\
\hline \multirow{2}{*}{$\begin{array}{c}\text { averaged } \\
\text { across } m \\
\text { months }\end{array}$} & \multirow[b]{2}{*}{ Adj. $R^{2}$} & \multirow[b]{2}{*}{ SIC } & \multicolumn{2}{|c|}{ Illiquidity } & \multicolumn{4}{|c|}{ Illiquidity } & \multicolumn{3}{|c|}{ Illiquidity } & \multicolumn{4}{|c|}{ Illiquidity } & \multicolumn{4}{|c|}{ Illiquidity } \\
\hline & & & Exp. & Unexp. & Exp. & & Unex & & Exp. & Unexp. & & Exp. & & Unexp & & Exp. & & Unexp & \\
\hline 1 & 0.2210 & -2.9480 & -0.36 & $-9.59 *$ & 6.98 & $* * *$ & -3.94 & & -12.27 & -0.31 & & 6.35 & $* *$ & -4.37 & & 8.02 & & -8.49 & \\
\hline 2 & 0.1976 & -2.9184 & -1.11 & -6.62 & 7.62 & $* * *$ & -0.32 & & -13.05 & 9.45 & & 7.02 & $* * *$ & 2.71 & & 8.78 & & -17.61 & \\
\hline 3 & 0.2031 & -2.9253 & -1.23 & -6.71 & 7.92 & $* * *$ & 2.55 & & -13.24 & 5.13 & & 7.24 & $* * *$ & 5.91 & & 13.68 & $* * *$ & -18.14 & * \\
\hline 4 & 0.2059 & -2.9288 & -1.41 & -5.71 & 7.97 & $* * *$ & 4.09 & & -12.14 & -8.74 & & 7.27 & $* * *$ & 8.05 & & 14.73 & $* * *$ & -17.62 & * \\
\hline 5 & 0.2046 & -2.9273 & -1.62 & -4.70 & 7.74 & $* * *$ & 3.83 & & -14.27 & -3.35 & & 6.94 & $* * *$ & 8.34 & * & 15.16 & $* * *$ & -17.13 & \\
\hline 6 & 0.2001 & -2.9216 & -2.12 & -2.67 & 7.54 & $* * *$ & 4.96 & & -14.07 & -9.11 & & 6.66 & $* * *$ & 9.18 & * & 16.68 & $* * *$ & -8.71 & \\
\hline 7 & 0.2066 & -2.9297 & -2.79 & -0.50 & 7.37 & $* * *$ & 7.34 & & -12.17 & -21.15 & & 6.22 & $* * *$ & 10.84 & $* *$ & 17.03 & $* * *$ & -10.93 & \\
\hline 8 & 0.2095 & -2.9335 & -2.22 & -3.04 & 7.12 & $* * *$ & 9.51 & $*$ & -10.84 & -31.02 & $*$ & 5.84 & $* * *$ & 11.52 & $* * *$ & 16.79 & $* * *$ & -6.52 & \\
\hline 9 & 0.2122 & -2.9368 & -2.31 & -3.26 & 6.71 & $* * *$ & 13.09 & $* * *$ & -10.19 & -34.02 & & 5.46 & $* * *$ & 12.53 & $* * *$ & 16.55 & $* * *$ & -7.51 & \\
\hline 10 & 0.2063 & -2.9293 & -2.17 & -4.60 & 6.22 & $* * *$ & 15.16 & $* * *$ & -11.59 & -32.87 & & 5.16 & $* * *$ & 12.79 & $* * *$ & 16.85 & $* * *$ & -1.73 & \\
\hline 11 & 0.2009 & -2.9226 & -1.68 & -6.74 & 5.69 & $* * *$ & 17.18 & $* * *$ & -15.21 & -26.10 & & 4.89 & $* * *$ & 13.28 & $* * *$ & 16.55 & $* * *$ & -0.15 & \\
\hline 12 & 0.1957 & -2.9162 & -1.00 & -10.30 & 5.04 & $* *$ & 17.17 & $* * *$ & -17.67 & -23.65 & & 4.59 & $* * *$ & 13.34 & $* * *$ & 16.54 & $* * *$ & 3.35 & \\
\hline
\end{tabular}

Note: This table presents the results of model (5)'s time-series regressions on equal-weighted excess returns and illiquidity measures for a time lag of three months and 12 rolling averages for the identified sub-periods. It includes the coefficients of expected and unexpected illiquidity with their respective significance levels, the adjusted R-squares, and the Schwarz information criteria (SIC), based on the market's excess returns (dependent variable). However, the intercept is not reported. ***, ** and * denote the test statistics of the coefficients at the $1 \%, 5 \%$ and $10 \%$ levels, respectively. The heteroscedasticity and autocorrelation consistent covariance matrix is based on a quadratic kernel with automatic bandwidth selection with an AR(1) approximation, as suggested by Andrews (1991), and Andrews and Monahan (1992). The residuals are pre-whitened using VAR(1). The sub-periods are defined as follows: (1) July 1999 to March 2003; (2) April 2003 to March 2007; (3) April 2007 to February 2009; (4) March 2009 to November 2016; and (5) December 2016 to June 2019. The illiquidity measures are winsorized at the $0.5 \%$ and $99.5 \%$ levels for each month. The data include CDAX stocks from July 1999 to June 2019. 
Table 10: Regression results with fix breaks - equal weighted, winsorizing level 10\% and 90\%

\begin{tabular}{|c|c|c|c|c|c|c|c|c|c|c|c|c|c|c|c|c|c|c|c|}
\hline & & & \multicolumn{2}{|c|}{ Period 1} & \multicolumn{4}{|c|}{ Period 2} & \multicolumn{3}{|c|}{ Period 3} & \multicolumn{4}{|c|}{ Period 4} & \multicolumn{4}{|c|}{ Period 5} \\
\hline \multirow{2}{*}{$\begin{array}{c}\text { averaged } \\
\text { across } m \\
\text { months }\end{array}$} & \multirow[b]{2}{*}{ Adj. $R^{2}$} & \multirow[b]{2}{*}{ SIC } & \multicolumn{2}{|c|}{ Illiquidity } & \multicolumn{4}{|c|}{ Illiquidity } & \multicolumn{3}{|c|}{ Illiquidity } & \multicolumn{4}{|c|}{ Illiquidity } & \multicolumn{4}{|c|}{ Illiquidity } \\
\hline & & & Exp. & Unexp. & $\operatorname{Exp}$ & & Un & & Exp. & & Unexp. & Exp & & Unex & & Exp. & & Unex & \\
\hline 1 & 0.2474 & -3.0572 & -0.76 & -10.37 & 6.93 & $* * *$ & -7.32 & $* *$ & -5.74 & & $-21.37 *$ & 5.59 & $* *$ & -6.24 & & -1.53 & & -39.01 & $* *$ \\
\hline 2 & 0.2119 & -3.0111 & -0.89 & -9.55 & 8.11 & $* * *$ & -1.08 & & -8.76 & $* *$ & -8.79 & 6.31 & $* *$ & 0.16 & & -2.58 & & -53.19 & $* *$ \\
\hline 3 & 0.2165 & -3.0169 & -0.65 & -12.50 & 8.39 & $* * *$ & 0.78 & & -10.62 & $* *$ & -4.90 & 6.53 & $* * *$ & 2.76 & & 3.54 & & -62.18 & $* * *$ \\
\hline 4 & 0.2197 & -3.0210 & -0.45 & -14.21 & 8.53 & $* * *$ & 2.86 & & -9.50 & & -12.05 & 6.79 & $* * *$ & 4.63 & & 5.45 & & -69.70 & $* * *$ \\
\hline 5 & 0.2170 & -3.0175 & -0.18 & -15.03 & 8.36 & $* * *$ & 4.35 & & -10.86 & & -10.61 & 6.60 & $* * *$ & 5.70 & & 9.09 & & -74.07 & $* * *$ \\
\hline 6 & 0.2107 & -3.0095 & 0.11 & -15.97 & 8.31 & $* * *$ & 5.89 & & -9.93 & & -16.79 & 6.41 & $* * *$ & 8.69 & & 19.51 & $* *$ & -50.82 & $*$ \\
\hline 7 & 0.2148 & -3.0147 & 0.29 & -16.77 & 8.24 & $* * *$ & 8.79 & $*$ & -7.15 & & -27.42 & 6.19 & $* * *$ & 12.88 & & 24.24 & $* * *$ & -43.62 & \\
\hline 8 & 0.2162 & -3.0165 & 0.57 & -18.23 & 8.03 & $* * *$ & 11.05 & $* *$ & -5.54 & & -34.24 & 5.93 & $* * *$ & 14.72 & $* *$ & 26.16 & $* * *$ & -32.15 & \\
\hline 9 & 0.2172 & -3.0178 & 0.38 & -17.87 & 7.87 & $* * *$ & 15.50 & $* * *$ & -5.42 & & -36.00 & 5.55 & $* * *$ & 16.91 & $* *$ & 26.53 & $* * *$ & -25.90 & \\
\hline 10 & 0.2142 & -3.0139 & 1.12 & -22.07 & 7.51 & $* * *$ & 18.99 & $* * *$ & -7.62 & & -31.11 & 5.23 & $* * *$ & 18.70 & $* *$ & 27.65 & $* * *$ & -18.16 & \\
\hline 11 & 0.2158 & -3.0160 & 2.74 & -30.52 & 7.06 & $* * *$ & 22.55 & $* * *$ & -11.24 & & -23.16 & 4.96 & $* * *$ & 20.78 & $* * *$ & 28.35 & $* * *$ & -14.26 & \\
\hline 12 & 0.2151 & -3.0150 & 3.32 & -34.80 & 6.45 & $* * *$ & 24.71 & $* * *$ & -14.49 & & -17.34 & 4.69 & $* *$ & 21.63 & $* * *$ & 28.48 & $* * *$ & -11.31 & \\
\hline
\end{tabular}

Note: This table presents the results of model (5)'s time-series regressions on equal-weighted excess returns and illiquidity measures for a time lag of three months and 12 rolling averages for the identified sub-periods. It includes the coefficients of expected and unexpected illiquidity with their respective significance levels, the adjusted R-squares, and the Schwarz information criteria (SIC), based on the market's excess returns (dependent variable). However, the intercept is not reported. $* * *, * *$ and $*$ denote the test statistics of the coefficients at the 1\%,5\% and $10 \%$ levels, respectively. The heteroscedasticity and autocorrelation consistent covariance matrix is based on a quadratic kernel with automatic bandwidth selection with an AR(1) approximation, as suggested by Andrews (1991), and Andrews and Monahan (1992). The residuals are pre-whitened using VAR(1). The sub-periods are defined as follows: (1) July 1999 to March 2003; (2) April 2003 to March 2007; (3) April 2007 to February 2009; (4) March 2009 to November 2016; and (5) December 2016 to June 2019. The illiquidity measures are winsorized at the 10\% and 90\% levels for each month. The data include CDAX stocks from July 1999 to June 2019. 
Table 11: Regression results with fix breaks - value-weighted

\begin{tabular}{|c|c|c|c|c|c|c|c|c|c|c|c|c|c|c|c|c|c|}
\hline & & & \multicolumn{2}{|c|}{ Period 1} & \multicolumn{4}{|c|}{ Period 2} & \multicolumn{4}{|c|}{ Period 3} & \multicolumn{2}{|r|}{ Period 4} & \multicolumn{3}{|c|}{ Period 5} \\
\hline \multirow{2}{*}{$\begin{array}{l}\text { averaged } \\
\text { across } m \\
\text { months }\end{array}$} & \multirow[b]{2}{*}{ Adj. $\mathrm{R}^{2}$} & \multirow[b]{2}{*}{ SIC } & \multicolumn{2}{|c|}{ Illiquidity } & \multicolumn{4}{|c|}{ Illiquidity } & \multicolumn{4}{|c|}{ Illiquidity } & \multicolumn{2}{|r|}{ Illiquidity } & \multicolumn{3}{|c|}{ Illiquidity } \\
\hline & & & Exp. & Unexp. & Exp. & & Unex & & Exp. & & Unexp. & & Exp. & Unexp. & Exp & & Unexp. \\
\hline 1 & 0.1382 & -2.7801 & 2.20 & -143.02 & 93.09 & $* * *$ & 33.05 & & -124.97 & $* *$ & -71.58 & & 39.22 & -56.23 & 66.55 & & -231.49 \\
\hline 2 & 0.1068 & -2.7443 & -13.47 & -95.73 & 87.77 & $* * *$ & 85.02 & & -53.01 & & -168.67 & & 53.44 & -9.72 & 31.98 & & -178.59 \\
\hline 3 & 0.1108 & -2.7488 & -18.28 & -108.80 & 83.78 & $* * *$ & 110.20 & & -27.23 & & -243.88 & & 59.93 & -3.05 & 82.34 & & -175.22 \\
\hline 4 & 0.1099 & -2.7477 & -15.25 & -104.27 & 83.59 & $* * *$ & 133.36 & & 30.42 & & -350.73 & & 61.57 & 7.87 & 107.98 & & -135.87 \\
\hline 5 & 0.1064 & -2.7439 & -13.46 & -116.88 & 79.74 & $* * *$ & 173.18 & & -71.78 & & -262.60 & & 54.28 & 30.10 & 147.34 & & -198.04 \\
\hline 6 & 0.1043 & -2.7415 & -3.21 & -126.72 & 74.92 & $* * *$ & 174.87 & & -66.48 & & -295.70 & & 53.69 & 45.54 & 194.10 & * & -128.27 \\
\hline 7 & 0.1073 & -2.7449 & -8.12 & -118.92 & 70.02 & $* * *$ & 196.07 & * & 34.82 & & -448.11 & & 49.99 & 64.62 & 224.48 & ** & -99.49 \\
\hline 8 & 0.1096 & -2.7474 & -5.45 & -131.91 & 59.78 & $* *$ & 212.76 & $* *$ & 62.95 & & -509.43 & * & 47.15 & 50.12 & 271.34 & ** & -78.33 \\
\hline 9 & 0.1101 & -2.7479 & -10.13 & -118.77 & 55.13 & $* *$ & 228.70 & $* * *$ & 45.84 & & -512.21 & * & 43.29 & 62.45 & 314.53 & $* * *$ & -71.88 \\
\hline 10 & 0.1098 & -2.7477 & -4.25 & -137.83 & 48.45 & ** & 252.24 & $* * *$ & -3.92 & & -470.57 & & 35.58 & 85.33 & 349.78 & $* * *$ & -8.94 \\
\hline 11 & 0.1048 & -2.7421 & 5.71 & -151.13 & 42.18 & * & 229.35 & $* * *$ & -30.56 & & -455.22 & & 31.18 & 106.40 & 373.49 & $* * *$ & 45.81 \\
\hline 12 & 0.0988 & -2.7353 & 7.94 & -161.54 & 39.22 & & 181.80 & $* * *$ & -29.77 & & -474.47 & & 28.12 & 110.78 & 395.19 & $* * *$ & 95.63 \\
\hline
\end{tabular}

Note: This table presents the results of model (5)'s time-series regressions on value-weighted excess returns and illiquidity measures for a time lag of three months and 12 rolling averages for the identified sub-periods. It includes the coefficients of expected and unexpected illiquidity with their respective significance levels, the adjusted R-squares, and the Schwarz information criteria (SIC), based on the market's excess returns (dependent variable). However, the intercept is not reported. $* * *, * *$ and $*$ denote the test statistics of the coefficients at the $1 \%, 5 \%$ and $10 \%$ levels, respectively. The heteroscedasticity and autocorrelation consistent covariance matrix is based on a quadratic kernel with automatic bandwidth selection with an AR(1) approximation, as suggested by Andrews (1991), and Andrews and Monahan (1992). The residuals are pre-whitened using VAR(1). The sub-periods are defined as follows: (1) July 1999 to March 2003; (2) April 2003 to March 2007; (3) April 2007 to February 2009; (4) March 2009 to November 2016; and (5) December 2016 to June 2019. The illiquidity measures are winsorized at the 5\% and 95\% levels for each month. The data include CDAX stocks from July 1999 to June 2019. 
Table 12: Calculating ILLIQ-Alphas - equal-weighted, different rolling periods

\begin{tabular}{|c|c|c|c|c|c|c|c|c|c|c|c|c|}
\hline Portfolio & $\begin{array}{c}\text { averaged } \\
\text { across } m \\
\text { months }\end{array}$ & adj. R2 & SIC & $\begin{array}{l}\text { Durban- } \\
\text { Watson }\end{array}$ & F-Test & \multicolumn{2}{|c|}{ constant } & \multicolumn{2}{|c|}{ SMB } & HML & CMA & RMW \\
\hline TOTAL & $\begin{array}{r}1 \\
2 \\
3 \\
4 \\
5 \\
6 \\
7 \\
8 \\
9 \\
10 \\
11 \\
12 \\
\end{array}$ & $\begin{array}{r}0.0020 \\
-0.0052 \\
-0.0035 \\
-0.0003 \\
0.0045 \\
0.0083 \\
0.0101 \\
0.0126 \\
0.0126 \\
0.0123 \\
0.0136 \\
0.0137 \\
\end{array}$ & $\begin{array}{l}0.2637 \\
0.2353 \\
0.2090 \\
0.1850 \\
0.1609 \\
0.1415 \\
0.1246 \\
0.1056 \\
0.0891 \\
0.0724 \\
0.0541 \\
0.0381 \\
\end{array}$ & $\begin{array}{l}0.1738 \\
0.0941 \\
0.0723 \\
0.0684 \\
0.0710 \\
0.0749 \\
0.0779 \\
0.0788 \\
0.0793 \\
0.0799 \\
0.0787 \\
0.0790 \\
\end{array}$ & $\begin{array}{l}1.1161 \\
0.6996 \\
0.7962 \\
0.9847 \\
1.2623 \\
1.4853 \\
1.5900 \\
1.7343 \\
1.7378 \\
1.7191 \\
1.7966 \\
1.8023 \\
\end{array}$ & $\begin{array}{l}0.5831 \\
0.5801 \\
0.5783 \\
0.5767 \\
0.5744 \\
0.5724 \\
0.5709 \\
0.5696 \\
0.5687 \\
0.5676 \\
0.5666 \\
0.5662 \\
\end{array}$ & $\begin{array}{l}* * * \\
* * * \\
* * * \\
* * * \\
* * * \\
* * * \\
* * * \\
* * * \\
* * * \\
* * * \\
* * * \\
* * *\end{array}$ & $\begin{array}{l}0.7090 \\
0.7569 \\
0.8455 \\
0.9700 \\
1.1337 \\
1.2173 \\
1.2553 \\
1.3174 \\
1.3117 \\
1.2984 \\
1.3266 \\
1.3341 \\
\end{array}$ & $\begin{array}{l}* * * \\
* * * \\
* * * \\
* * * \\
* * *\end{array}$ & $\begin{array}{l}0.0613 \\
0.2890 \\
0.4515 \\
0.5191 \\
0.6006 \\
0.6892 \\
0.7173 \\
0.6927 \\
0.6812 \\
0.6780 \\
0.6861 \\
0.6546 \\
\end{array}$ & $\begin{array}{r}0.6095 \\
0.1656 \\
-0.0554 \\
-0.1584 \\
-0.2334 \\
-0.2747 \\
-0.2921 \\
-0.2530 \\
-0.2509 \\
-0.2643 \\
-0.2996 \\
-0.3249 \\
\end{array}$ & $\begin{array}{c}-0.6563 \\
-0.2995 \\
-0.2586 \\
-0.2331 \\
-0.1070 \\
-0.0291 \\
0.0233 \\
0.0482 \\
0.0501 \\
0.0722 \\
0.0978 \\
0.0790 \\
\end{array}$ \\
\hline $\begin{array}{r}2 \\
4 \\
6 \\
8 \\
10 \\
\text { TOTAL }\end{array}$ & 12 & $\begin{array}{r}0.0164 \\
0.0061 \\
-0.0016 \\
0.0104 \\
0.0217 \\
0.0137\end{array}$ & $\begin{array}{r}0.8938 \\
0.6717 \\
-0.2787 \\
-2.2880 \\
-4.5488 \\
0.0381\end{array}$ & $\begin{array}{l}0.0913 \\
0.0758 \\
0.0811 \\
0.1607 \\
0.2850 \\
0.0790\end{array}$ & $\begin{array}{l}1.9604 \\
1.3520 \\
0.9080 \\
1.6082 \\
2.2780 \\
1.8023\end{array}$ & $\begin{array}{l}1.0704 \\
0.6478 \\
0.3437 \\
0.1035 \\
0.0250 \\
0.5662\end{array}$ & $\begin{array}{l}* * * \\
* * * \\
* * * \\
* * * \\
* * * \\
* * *\end{array}$ & $\begin{array}{l}.0713 \\
1.4137 \\
0.6336 \\
0.2624 \\
0.0797 \\
1.3341\end{array}$ & $* * *$ & $\begin{array}{l}0.4544 \\
0.8189 \\
0.5914 \\
0.1002 \\
0.0945 \\
0.6546\end{array}$ & $\begin{array}{r}-0.4473 \\
-0.3773 \\
-0.1542 \\
0.1913 \\
-0.0517 \\
-0.3249\end{array}$ & $\begin{array}{r}-0.7092 \\
-0.4850 \\
0.3848 \\
0.2019 \\
0.1706 \\
0.0790\end{array}$ \\
\hline
\end{tabular}

Note: This table presents the results of model (6)'s time-series regressions on equal-weighted excess returns and illiquidity measures using four factors to explain expected illiquidity for several portfolios and rolling averages over $m$ months. It includes the coefficients of $S M B$ (small minus big - the size factor), $H M L$ (high minus low Book-to-

Market Ratio - the value factor), $R M W$ (robust minus weak operating profitability - the profitability factor), and $C M A$ (conservative minus aggressive investment firms - the investment factor) (see Fama and French 2015) with their respective significance levels, an adjusted R-square, Schwarz Information Criteria (SIC), Durban-Watson statistic, and the result of the F-Test based on portfolio resp. market excess returns (dependent variable). ***, ** and * denote the test statistics of the coefficients at the $1 \%, 5 \%$, and $10 \%$ levels, respectively. The illiquidity measures are winsorized at the 5\% and 95\% levels for each month. The data include CDAX stocks from July 1999 to June 2019. 
Table 13: Calculating ILLIQ-Alphas - equal-weighted, adjusted for inflation

\begin{tabular}{|c|c|c|c|c|c|c|c|c|c|c|c|c|}
\hline Portfolio & $\begin{array}{c}\text { averaged } \\
\text { across } m \\
\text { months }\end{array}$ & adj. R2 & SIC & $\begin{array}{l}\text { Durban- } \\
\text { Watson }\end{array}$ & F-Test & \multicolumn{2}{|c|}{ constant } & \multicolumn{2}{|c|}{ SMB } & HML & CMA & RMW \\
\hline TOTAL & $\begin{array}{r}1 \\
2 \\
3 \\
4 \\
5 \\
6 \\
7 \\
8 \\
9 \\
10 \\
11 \\
12 \\
\end{array}$ & $\begin{array}{r}0.0002 \\
-0.0062 \\
-0.0040 \\
-0.0002 \\
0.0049 \\
0.0085 \\
0.0104 \\
0.0130 \\
0.0131 \\
0.0129 \\
0.0145 \\
0.0150 \\
\end{array}$ & $\begin{array}{l}0.3401 \\
0.3122 \\
0.2872 \\
0.2649 \\
0.2428 \\
0.2258 \\
0.2112 \\
0.1945 \\
0.1802 \\
0.1657 \\
0.1495 \\
0.1353 \\
\end{array}$ & $\begin{array}{l}0.1808 \\
0.0974 \\
0.0750 \\
0.0711 \\
0.0738 \\
0.0781 \\
0.0809 \\
0.0820 \\
0.0827 \\
0.0835 \\
0.0828 \\
0.0835 \\
\end{array}$ & $\begin{array}{l}1.0090 \\
0.6420 \\
0.7713 \\
0.9886 \\
1.2821 \\
1.4976 \\
1.6070 \\
1.7600 \\
1.7692 \\
1.7563 \\
1.8480 \\
1.8793 \\
\end{array}$ & $\begin{array}{l}0.6540 \\
0.6509 \\
0.6492 \\
0.6476 \\
0.6453 \\
0.6433 \\
0.6418 \\
0.6405 \\
0.6396 \\
0.6386 \\
0.6376 \\
0.6374 \\
\end{array}$ & $\begin{array}{l}* * * \\
* * * \\
* * * \\
* * * \\
* * * \\
* * * \\
* * * \\
* * * \\
* * * \\
* * * \\
* * * \\
* * * \\
\end{array}$ & $\begin{array}{l}0.7840 \\
0.8272 \\
0.9242 \\
1.0580 \\
1.2338 \\
1.3250 \\
1.3688 \\
1.4387 \\
1.4352 \\
1.4233 \\
1.4543 \\
1.4628 \\
\end{array}$ & $\begin{array}{l}* * * \\
* * * \\
* * * \\
* * * \\
* * * \\
* * * \\
\end{array}$ & $\begin{array}{r}-0.0118 \\
0.2282 \\
0.4004 \\
0.4728 \\
0.5577 \\
0.6524 \\
0.6840 \\
0.6597 \\
0.6475 \\
0.6442 \\
0.6526 \\
0.6192 \\
\end{array}$ & $\begin{array}{r}0.4801 \\
0.0169 \\
-0.2127 \\
-0.3211 \\
-0.3992 \\
-0.4432 \\
-0.4626 \\
-0.4218 \\
-0.4188 \\
-0.4322 \\
-0.4689 \\
-0.4946 \\
\end{array}$ & $\begin{array}{r}-0.7447 \\
-0.3633 \\
-0.3224 \\
-0.2964 \\
-0.1651 \\
-0.0829 \\
-0.0284 \\
-0.0024 \\
-0.0014 \\
0.0214 \\
0.0479 \\
0.0271 \\
\end{array}$ \\
\hline $\begin{array}{r}2 \\
4 \\
6 \\
8 \\
10 \\
\text { TOTAL }\end{array}$ & 12 & $\begin{array}{r}0.0202 \\
0.0064 \\
-0.0033 \\
0.0103 \\
0.0187 \\
0.0150\end{array}$ & $\begin{array}{r}0.9821 \\
0.7351 \\
-0.1354 \\
-2.2198 \\
-4.2245 \\
0.1353\end{array}$ & $\begin{array}{l}0.0992 \\
0.0817 \\
0.0803 \\
0.1764 \\
0.2697 \\
0.0835\end{array}$ & $\begin{array}{l}2.1928 \\
1.3696 \\
0.8102 \\
1.5983 \\
2.1026 \\
1.8793 \\
\end{array}$ & $\begin{array}{l}1.1801 \\
0.7217 \\
0.3876 \\
0.1170 \\
0.0291 \\
0.6374\end{array}$ & $\begin{array}{l}* * * \\
* * * \\
* * * \\
* * * \\
* * * \\
* * *\end{array}$ & $\begin{array}{l}2.2317 \\
1.5025 \\
0.6926 \\
0.2993 \\
0.0885 \\
1.4628\end{array}$ & **** & $\begin{array}{l}0.3400 \\
0.7952 \\
0.5987 \\
0.0980 \\
0.1025 \\
0.6192\end{array}$ & $\begin{array}{r}-0.7071 \\
-0.5545 \\
-0.2517 \\
0.1755 \\
-0.0658 \\
-0.4946\end{array}$ & $\begin{array}{r}-0.8699 \\
-0.5568 \\
0.3985 \\
0.2140 \\
0.1975 \\
0.0271\end{array}$ \\
\hline
\end{tabular}

Note: This table presents the results of model (6)'s time-series regressions on equal-weighted illiquidity measures using four factors to explain expected illiquidity for several portfolios and rolling averages over $m$ months. It includes the coefficients of SMB (small minus big - the size factor), $H M L$ (high minus low Book-to-Market Ratio - the value factor), $R M W$ (robust minus weak operating profitability - the profitability factor), and CMA (conservative minus aggressive investment firms - the investment factor) (see Fama and French 2015) with their respective significance levels, an adjusted R-square, Schwarz Information Criteria (SIC), Durban-Watson statistic, and the result of the F-Test based on portfolio resp. market excess returns (dependent variable). $* * *, * *$ and $*$ denote the test statistics of the coefficients at the $1 \%, 5 \%$, and $10 \%$ levels, respectively. The illiquidity measures are winsorized at the $5 \%$ and $95 \%$ levels for each month. The data include CDAX stocks from July 1999 to June 2019. 
Table 14: Calculating ILLIQ-Alphas - equal-weighted, winsorizing level $0.5 \%$ and $99.5 \%$

\begin{tabular}{|c|c|c|c|c|c|c|c|c|c|c|c|c|}
\hline Portfolio & $\begin{array}{c}\text { averaged } \\
\text { across } m \\
\text { months }\end{array}$ & adj. R2 & SIC & $\begin{array}{l}\text { Durban- } \\
\text { Watson }\end{array}$ & F-Test & \multicolumn{2}{|c|}{ constant } & \multicolumn{2}{|c|}{ SMB } & HML & CMA & RMW \\
\hline TOTAL & $\begin{array}{r}1 \\
2 \\
3 \\
4 \\
5 \\
6 \\
7 \\
8 \\
9 \\
10 \\
11 \\
12 \\
\end{array}$ & $\begin{array}{r}0.0000 \\
-0.0049 \\
-0.0016 \\
0.0029 \\
0.0077 \\
0.0117 \\
0.0132 \\
0.0157 \\
0.0157 \\
0.0159 \\
0.0168 \\
0.0173 \\
\end{array}$ & $\begin{array}{l}0.3663 \\
0.3231 \\
0.2974 \\
0.2797 \\
0.2614 \\
0.2469 \\
0.2361 \\
0.2235 \\
0.2100 \\
0.1967 \\
0.1844 \\
0.1748 \\
\end{array}$ & $\begin{array}{l}0.2110 \\
0.1099 \\
0.0911 \\
0.0870 \\
0.0927 \\
0.0948 \\
0.0984 \\
0.0988 \\
0.0999 \\
0.1001 \\
0.0994 \\
0.0996 \\
\end{array}$ & $\begin{array}{l}1.0016 \\
0.7190 \\
0.9094 \\
1.1704 \\
1.4464 \\
1.6845 \\
1.7736 \\
1.9188 \\
1.9212 \\
1.9357 \\
1.9887 \\
2.0141 \\
\end{array}$ & $\begin{array}{l}0.7463 \\
0.7433 \\
0.7398 \\
0.7377 \\
0.7346 \\
0.7316 \\
0.7293 \\
0.7274 \\
0.7258 \\
0.7241 \\
0.7229 \\
0.7225 \\
\end{array}$ & $\begin{array}{l}* * * \\
* * * \\
* * * \\
* * * \\
* * * \\
* * * \\
* * * \\
* * * \\
* * * \\
* * * \\
* * * \\
* * * \\
\end{array}$ & $\begin{array}{l}0.8322 \\
0.8344 \\
0.9401 \\
1.0934 \\
1.2705 \\
1.3731 \\
1.4113 \\
1.4704 \\
1.4675 \\
1.4647 \\
1.4860 \\
1.4970 \\
\end{array}$ & $\begin{array}{l}* * * \\
* * * \\
* * * \\
* * * \\
* * * \\
* * * \\
* * * \\
\end{array}$ & $\begin{array}{l}0.0517 \\
0.2846 \\
0.4717 \\
0.5592 \\
0.6387 \\
0.7398 \\
0.7517 \\
0.7330 \\
0.7339 \\
0.7454 \\
0.7381 \\
0.7037 \\
\end{array}$ & $\begin{array}{r}0.4348 \\
-0.0759 \\
-0.3078 \\
-0.3943 \\
-0.4420 \\
-0.4842 \\
-0.4681 \\
-0.4268 \\
-0.4246 \\
-0.4464 \\
-0.4813 \\
-0.5201 \\
\end{array}$ & $\begin{array}{r}-0.7013 \\
-0.5180 \\
-0.5006 \\
-0.4659 \\
-0.3135 \\
-0.2181 \\
-0.1810 \\
-0.1914 \\
-0.1553 \\
-0.1362 \\
-0.1290 \\
-0.1577 \\
\end{array}$ \\
\hline $\begin{array}{r}2 \\
4 \\
6 \\
8 \\
10 \\
\text { TOTAL } \\
\end{array}$ & 12 & $\begin{array}{r}0.0142 \\
0.0077 \\
-0.0018 \\
0.0088 \\
0.0202 \\
0.0173 \\
\end{array}$ & $\begin{array}{r}1.0479 \\
0.8167 \\
-0.0933 \\
-2.1782 \\
-4.5097 \\
0.1748 \\
\end{array}$ & $\begin{array}{l}0.1240 \\
0.1051 \\
0.1025 \\
0.1977 \\
0.2915 \\
0.0996 \\
\end{array}$ & $\begin{array}{l}1.8294 \\
1.4509 \\
0.8991 \\
1.5110 \\
2.1879 \\
2.0141 \\
\end{array}$ & $\begin{array}{l}1.2826 \\
0.7151 \\
0.3633 \\
0.1070 \\
0.0254 \\
0.7225 \\
\end{array}$ & $\begin{array}{l}* * * \\
* * * \\
* * * \\
* * * \\
* * * \\
* * *\end{array}$ & $\begin{array}{l}2.1257 \\
1.4332 \\
0.6221 \\
0.2035 \\
0.0732 \\
1.4970 \\
\end{array}$ & *** & $\begin{array}{l}0.6326 \\
0.9592 \\
0.6736 \\
0.0612 \\
0.0969 \\
0.7037 \\
\end{array}$ & $\begin{array}{r}-0.5349 \\
-0.3492 \\
-0.1491 \\
0.2469 \\
-0.0548 \\
-0.5201 \\
\end{array}$ & $\begin{array}{r}-0.8097 \\
-0.7262 \\
0.4664 \\
0.2714 \\
0.1718 \\
-0.1577 \\
\end{array}$ \\
\hline
\end{tabular}

Note: This table presents the results of model (6)'s time-series regressions on value-weighted illiquidity measures using four factors to explain expected illiquidity for several portfolios and rolling averages over $m$ months. It includes the coefficients of SMB (small minus big - the size factor), $H M L$ (high minus low Book-to-Market Ratio - the value factor), $R M W$ (robust minus weak operating profitability - the profitability factor), and CMA (conservative minus aggressive investment firms - the investment factor) (see Fama and French 2015) with their respective significance levels, an adjusted R-square, Schwarz Information Criteria (SIC), Durban-Watson statistic, and the result of the F-Test based on portfolio resp. market excess returns (dependent variable). $* * *, * *$ and $*$ denote the test statistics of the coefficients at the $1 \%, 5 \%$, and $10 \%$ levels, respectively. The illiquidity measures are winsorized at the $0.5 \%$ and $99.5 \%$ levels for each month. The data include CDAX stocks from July 1999 to June 2019. 
Table 15: Calculating ILLIQ-Alphas - equal-weighted, winsorizing level 10\% and 90\%

\begin{tabular}{|c|c|c|c|c|c|c|c|c|c|c|c|c|}
\hline Portfolio & $\begin{array}{l}\text { averaged } \\
\text { across } m \\
\text { months }\end{array}$ & adj. R2 & SIC & $\begin{array}{l}\text { Durban- } \\
\text { Watson }\end{array}$ & F-Test & \multicolumn{2}{|c|}{ constant } & \multicolumn{2}{|c|}{ SMB } & HML & CMA & RMW \\
\hline TOTAL & $\begin{array}{r}1 \\
2 \\
3 \\
4 \\
5 \\
6 \\
7 \\
8 \\
9 \\
10 \\
11 \\
12 \\
\end{array}$ & $\begin{array}{r}0.0002 \\
-0.0062 \\
-0.0040 \\
-0.0002 \\
0.0049 \\
0.0085 \\
0.0104 \\
0.0130 \\
0.0131 \\
0.0129 \\
0.0145 \\
0.0150 \\
\end{array}$ & $\begin{array}{l}0.3401 \\
0.3122 \\
0.2872 \\
0.2649 \\
0.2428 \\
0.2258 \\
0.2112 \\
0.1945 \\
0.1802 \\
0.1657 \\
0.1495 \\
0.1353 \\
\end{array}$ & $\begin{array}{l}0.1808 \\
0.0974 \\
0.0750 \\
0.0711 \\
0.0738 \\
0.0781 \\
0.0809 \\
0.0820 \\
0.0827 \\
0.0835 \\
0.0828 \\
0.0835 \\
\end{array}$ & $\begin{array}{l}1.0090 \\
0.6420 \\
0.7713 \\
0.9886 \\
1.2821 \\
1.4976 \\
1.6070 \\
1.7600 \\
1.7692 \\
1.7563 \\
1.8480 \\
1.8793 \\
\end{array}$ & $\begin{array}{l}0.6540 \\
0.6509 \\
0.6492 \\
0.6476 \\
0.6453 \\
0.6433 \\
0.6418 \\
0.6405 \\
0.6396 \\
0.6386 \\
0.6376 \\
0.6374 \\
\end{array}$ & $\begin{array}{l}* * * \\
* * * \\
* * * \\
* * * \\
* * * \\
* * * \\
* * * \\
* * * \\
* * * \\
* * * \\
* * * \\
* * * \\
\end{array}$ & $\begin{array}{l}0.7840 \\
0.8272 \\
0.9242 \\
1.0580 \\
1.2338 \\
1.3250 \\
1.3688 \\
1.4387 \\
1.4352 \\
1.4233 \\
1.4543 \\
1.4628 \\
\end{array}$ & $\begin{array}{l}* * * \\
* * * \\
* * * \\
* * * \\
* * * \\
* * * \\
\end{array}$ & $\begin{array}{r}-0.0118 \\
0.2282 \\
0.4004 \\
0.4728 \\
0.5577 \\
0.6524 \\
0.6840 \\
0.6597 \\
0.6475 \\
0.6442 \\
0.6526 \\
0.6192 \\
\end{array}$ & $\begin{array}{r}0.4801 \\
0.0169 \\
-0.2127 \\
-0.3211 \\
-0.3992 \\
-0.4432 \\
-0.4626 \\
-0.4218 \\
-0.4188 \\
-0.4322 \\
-0.4689 \\
-0.4946 \\
\end{array}$ & $\begin{array}{c}-0.7447 \\
-0.3633 \\
-0.3224 \\
-0.2964 \\
-0.1651 \\
-0.0829 \\
-0.0284 \\
-0.0024 \\
-0.0014 \\
0.0214 \\
0.0479 \\
0.0271 \\
\end{array}$ \\
\hline $\begin{array}{r}2 \\
4 \\
6 \\
8 \\
10 \\
\text { TOTAL } \\
\end{array}$ & 12 & $\begin{array}{r}0.0202 \\
0.0064 \\
-0.0033 \\
0.0103 \\
0.0187 \\
0.0150 \\
\end{array}$ & $\begin{array}{r}0.9821 \\
0.7351 \\
-0.1354 \\
-2.2198 \\
-4.2245 \\
0.1353 \\
\end{array}$ & $\begin{array}{l}0.0992 \\
0.0817 \\
0.0803 \\
0.1764 \\
0.2697 \\
0.0835 \\
\end{array}$ & $\begin{array}{l}2.1928 \\
1.3696 \\
0.8102 \\
1.5983 \\
2.1026 \\
1.8793 \\
\end{array}$ & $\begin{array}{l}1.1801 \\
0.7217 \\
0.3876 \\
0.1170 \\
0.0291 \\
0.6374 \\
\end{array}$ & $\begin{array}{l}* * * \\
* * * \\
* * * \\
* * * \\
* * * \\
* * * \\
\end{array}$ & $\begin{array}{l}2.2317 \\
1.5025 \\
0.6926 \\
0.2993 \\
0.0885 \\
1.4628 \\
\end{array}$ & $* * *$ & $\begin{array}{l}0.3400 \\
0.7952 \\
0.5987 \\
0.0980 \\
0.1025 \\
0.6192 \\
\end{array}$ & $\begin{array}{r}-0.7071 \\
-0.5545 \\
-0.2517 \\
0.1755 \\
-0.0658 \\
-0.4946 \\
\end{array}$ & $\begin{array}{r}-0.8699 \\
-0.5568 \\
0.3985 \\
0.2140 \\
0.1975 \\
0.0271 \\
\end{array}$ \\
\hline
\end{tabular}

Note: This table presents the results of model (6)'s time-series regressions on value-weighted illiquidity measures using four factors to explain expected illiquidity for several portfolios and rolling averages over $m$ months. It includes the coefficients of SMB (small minus big - the size factor), $H M L$ (high minus low Book-to-Market Ratio - the value factor), $R M W$ (robust minus weak operating profitability - the profitability factor), and CMA (conservative minus aggressive investment firms - the investment factor) (see Fama and French 2015) with their respective significance levels, an adjusted R-square, Schwarz Information Criteria (SIC), Durban-Watson statistic, and the result of the F-Test based on portfolio resp. market excess returns (dependent variable). $* * *, * *$ and $*$ denote the test statistics of the coefficients at the $1 \%, 5 \%$, and $10 \%$ levels, respectively. The illiquidity measures are winsorized at the $10 \%$ and $90 \%$ levels for each month. The data include CDAX stocks from July 1999 to June 2019. 
Table 16: Calculating ILLIQ-Alphas - value-weighted

\begin{tabular}{|c|c|c|c|c|c|c|c|c|c|c|c|}
\hline Portfolio & $\begin{array}{c}\text { averaged } \\
\text { across } m \\
\text { months }\end{array}$ & adj. R2 & SIC & $\begin{array}{l}\text { Durban- } \\
\text { Watson }\end{array}$ & F-Test & \multicolumn{2}{|c|}{ constant } & SMB & HML & CMA & RMW \\
\hline \multirow{12}{*}{ TOTAL } & 1 & 0.0056 & 0.0214 & 0.5637 & -0.0517 & 0.0338 & $* * *$ & 0.0214 & -0.0517 & 0.0945 & -0.0171 \\
\hline & 2 & -0.0117 & 0.0187 & 0.4785 & -0.0148 & 0.0334 & $* * *$ & 0.0187 & -0.0148 & 0.0396 & 0.0134 \\
\hline & 3 & -0.0139 & 0.0247 & 0.6763 & 0.0105 & 0.0331 & $* * *$ & 0.0247 & 0.0105 & 0.0092 & 0.0251 \\
\hline & 4 & -0.0133 & 0.0327 & 0.9429 & 0.0178 & 0.0329 & $* * *$ & 0.0327 & 0.0178 & -0.0057 & 0.0213 \\
\hline & 5 & -0.0099 & 0.0421 & 1.2773 & 0.0253 & 0.0327 & $* * *$ & 0.0421 & 0.0253 & -0.0126 & 0.0320 \\
\hline & 6 & -0.0077 & 0.0446 & 1.3879 & 0.0333 & 0.0325 & $* * *$ & 0.0446 & 0.0333 & -0.0149 & 0.0333 \\
\hline & 7 & -0.0052 & 0.0460 & 1.4884 & 0.0380 & 0.0323 & $* * *$ & 0.0460 & 0.0380 & -0.0140 & 0.0396 \\
\hline & 8 & 0.0009 & 0.0578 & 1.8365 & 0.0414 & 0.0321 & $* * *$ & 0.0578 & 0.0414 & -0.0103 & 0.0450 \\
\hline & 9 & 0.0003 & 0.0559 & 1.8151 & 0.0394 & 0.0320 & $* * *$ & 0.0559 & 0.0394 & -0.0064 & 0.0418 \\
\hline & 10 & 0.0016 & 0.0573 & 1.8616 & 0.0405 & 0.0320 & $* * *$ & 0.0573 & 0.0405 & -0.0060 & 0.0418 \\
\hline & 11 & 0.0041 & 0.0615 & 2.0119 & 0.0419 & 0.0319 & $* * *$ & 0.0615 & 0.0419 & -0.0081 & 0.0444 \\
\hline & 12 & 0.0029 & 0.0610 & 2.0335 & 0.0389 & 0.0319 & $* * *$ & 0.0610 & 0.0389 & -0.0080 & 0.0415 \\
\hline 2 & & 0.0170 & 0.6608 & 0.1151 & 1.9964 & 0.9172 & $* * * *$ & 1.9263 & 0.6490 & -0.4490 & -0.3133 \\
\hline 4 & & 0.0061 & 0.5076 & 0.0950 & 1.3525 & 0.5829 & $* * *$ & 1.2745 & 0.7141 & -0.1955 & -0.4665 \\
\hline 6 & & 0.0000 & -0.5755 & 0.0915 & 1.0004 & 0.3066 & $* * *$ & 0.5746 & 0.4946 & -0.0559 & 0.3120 \\
\hline 8 & 12 & 0.0127 & -2.6270 & 0.1892 & 1.7457 & 0.0921 & $* * *$ & 0.2297 & 0.0512 & 0.1905 & 0.1893 \\
\hline 10 & & -0.0034 & -7.0089 & 0.2326 & 0.8054 & 0.0089 & $* * *$ & 0.0198 & 0.0168 & -0.0177 & 0.0225 \\
\hline TOTAL & & 0.0029 & -5.4582 & 0.1161 & 1.1691 & 0.0319 & $* * *$ & 0.0610 & 0.0389 & -0.0080 & 0.0415 \\
\hline
\end{tabular}

Note: This table presents the results of model (6)'s time-series regressions on value-weighted illiquidity measures using four factors to explain expected illiquidity for several portfolios and rolling averages over $m$ months. It includes the coefficients of $S M B$ (small minus big - the size factor), $H M L$ (high minus low Book-to-Market Ratio - the value factor), $R M W$ (robust minus weak operating profitability - the profitability factor), and $C M A$ (conservative minus aggressive investment firms - the investment factor) (see Fama and French 2015) with their respective significance levels, an adjusted R-square, Schwarz Information Criteria (SIC), Durban-Watson statistic, and the result of the F-Test based on portfolio resp. market excess returns (dependent variable). $* * * * *$ and $*$ denote the test statistics of the coefficients at the $1 \%, 5 \%$, and $10 \%$ levels, respectively. The illiquidity measures are winsorized at the 5\% and 95\% levels for each month. The data include CDAX stocks from July 1999 to June 2019. 
Table 17: Regression results with orthogonalized LIQ and Fama-French factors without breaks and with fix breaks - equal-weighted, adjusted for inflation

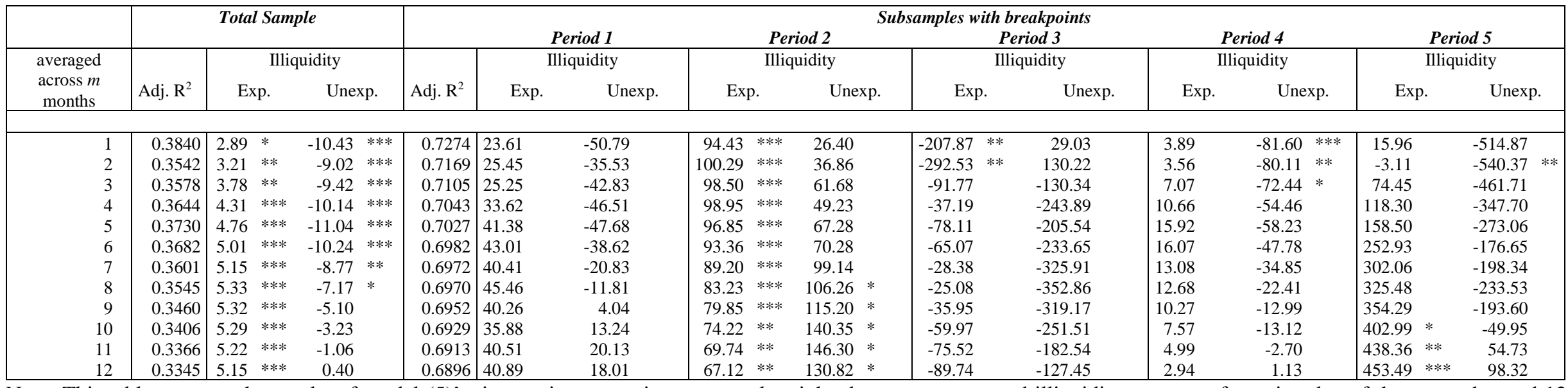

Note: This table presents the results of model (5)'s time-series regressions on equal-weighted excess returns and illiquidity measures for a time lag of three months, and 12 rolling averages for the total period, without breaks, and identified sub-periods. It includes the coefficients of expected and unexpected illiquidity with their respective significance levels, and the adjusted R-squares, based on the market's excess returns (dependent variable). The illiquidity measures are adjusted for inflation (EUR-turnover adjusted by consumer price index, Germany). However, the intercept is not reported. ***,** and * denote the test statistics of the coefficients at the $1 \%, 5 \%$, and $10 \%$ levels, respectively. The $O L I Q$, which represents the orthogonalized $L I Q$, is the illiquidity measure. This orthogonalized $L I Q$ is risk-adjusted for the four Fama-French factors (see Table 13). The heteroscedasticity and autocorrelation consistent covariance matrix is based on a quadratic kernel with automatic bandwidth selection with an AR(1) approximation, as suggested by Andrews (1991), and Andrews and Monahan (1992). The residuals are pre-whitened using VAR(1). The sub-periods are defined as follows: (1) July 1999 to March 2003; (2) April 2003 to March 2007; (3) April 2007 to February 2009; (4) March 2009 to November 2016; and (5) December 2016 to October 2018. The illiquidity measures are winsorized at the 5\% and 95\% levels for each month. The data include CDAX stocks from July 1999 to October 2018. 
Table 18: Regression results with orthogonalized LIQ and Fama-French factors without breaks and with fix breaks - equal-weighted, winsorizing level at 0.5\% and 99.5\%

\begin{tabular}{|c|c|c|c|c|c|c|c|c|c|c|c|c|c|c|c|c|c|c|c|c|c|}
\hline \multirow{4}{*}{$\begin{array}{c}\text { averaged } \\
\text { across } m \\
\text { months }\end{array}$} & \multirow{2}{*}{\multicolumn{5}{|c|}{ Total Sample }} & \multicolumn{16}{|c|}{ Subsamples with breakpoints } \\
\hline & & & & & & \multirow{2}{*}{\multicolumn{3}{|c|}{$\begin{array}{c}\text { Period 1 } \\
\text { Illiquidity }\end{array}$}} & \multirow{2}{*}{\multicolumn{4}{|c|}{$\begin{array}{c}\text { Period 2 } \\
\text { Illiquidity }\end{array}$}} & \multicolumn{2}{|c|}{ Period 3} & \multirow{2}{*}{\multicolumn{4}{|c|}{$\begin{array}{c}\text { Period 4 } \\
\text { Illiquidity }\end{array}$}} & \multirow{2}{*}{\multicolumn{3}{|c|}{$\begin{array}{c}\text { Period } 5 \\
\text { Illiquidity }\end{array}$}} \\
\hline & \multirow[b]{2}{*}{ Adj. $\mathrm{R}^{2}$} & \multicolumn{4}{|c|}{ Illiquidity } & & & & & & & & & idity & & & & & & & \\
\hline & & \multicolumn{2}{|c|}{ Exp. } & \multicolumn{2}{|c|}{ Unexp. } & Adj. $\mathrm{R}^{2}$ & Exp. & Unexp. & \multicolumn{2}{|l|}{ Exp. } & \multicolumn{2}{|c|}{ Unexp. } & Exp. & Unexp. & \multicolumn{2}{|c|}{ Exp. } & \multicolumn{2}{|c|}{ Unexp. } & \multicolumn{2}{|c|}{ Exp. } & Unexp. \\
\hline 1 & 0.3716 & 2.96 & $*$ & -9.54 & **** & 0.6245 & -1.66 & -3.03 & 8.13 & **** & -1.34 & & $-13.95 *$ & -3.90 & 2.77 & & -5.97 & & 12.45 & & -6.74 \\
\hline 2 & 0.3472 & 3.34 & $* *$ & -8.58 & $* * *$ & 0.6174 & -1.81 & -3.13 & 8.82 & $* * *$ & 0.64 & & -13.07 & -4.22 & 3.25 & & -1.96 & & 14.76 & $* * *$ & $-17.01 * *$ \\
\hline 3 & 0.3482 & 3.98 & $* *$ & -8.33 & ** & 0.6210 & -1.29 & -5.81 & 8.99 & $* * *$ & 2.47 & & -13.06 & -6.11 & 3.84 & $* *$ & 1.80 & & 16.35 & $* * *$ & -17.72 \\
\hline 4 & 0.3496 & 4.52 & $* * *$ & -7.83 & ** & 0.6290 & -0.67 & $-7.80 *$ & 9.05 & $* * *$ & 2.32 & & -14.11 & -6.80 & 4.12 & $* *$ & 4.58 & & 17.46 & $* * *$ & -18.60 \\
\hline 5 & 0.3580 & 4.99 & $* * *$ & -8.20 & ** & 0.6287 & -0.09 & $-9.27 * *$ & 8.92 & $* * *$ & 1.94 & & -15.26 & -4.22 & 4.19 & $* *$ & 4.40 & & 18.69 & $* * *$ & -11.68 \\
\hline 6 & 0.3564 & 5.27 & $* * *$ & -7.15 & ** & 0.6272 & 0.09 & $-9.48 * *$ & 8.80 & $* * *$ & 2.08 & & -15.38 & -5.33 & 4.14 & $* *$ & 5.28 & & 19.70 & $* * *$ & -7.86 \\
\hline 7 & 0.3500 & 5.39 & $* * *$ & -5.28 & & 0.6265 & -0.07 & $-8.85 *$ & 8.53 & $* * *$ & 5.49 & & -14.51 & -8.53 & 3.88 & $* *$ & 7.05 & $* *$ & 20.26 & $* * *$ & -8.37 \\
\hline 8 & 0.3481 & 5.56 & $* * *$ & -3.79 & & 0.6270 & 0.13 & $-9.00 *$ & $8.26=$ & $* * *$ & 7.24 & $*$ & -13.79 & -11.82 & 3.77 & $* *$ & 8.07 & $* *$ & 20.77 & $* * *$ & -6.28 \\
\hline 9 & 0.3428 & 5.52 & $* * *$ & -1.63 & & 0.6252 & -0.19 & $-8.30 *$ & 7.89 & $* * *$ & 9.50 & $* *$ & -12.21 & -12.87 & 3.58 & $* *$ & 8.74 & $* * *$ & 21.14 & $* * *$ & -5.34 \\
\hline 10 & 0.3402 & 5.44 & $* * *$ & 0.08 & & 0.6210 & -0.60 & -7.85 & 7.52 & $* * *$ & 10.30 & $* *$ & -11.35 & -12.42 & 3.45 & $* *$ & 8.83 & $* * *$ & 21.79 & $* * *$ & -2.84 \\
\hline 11 & 0.3393 & 5.33 & $* * *$ & 2.27 & & 0.6204 & -0.73 & -7.83 & 7.18 & $* * *$ & 11.69 & $* * *$ & -10.06 & -4.00 & 3.34 & $* *$ & 9.43 & $* * *$ & 22.56 & $* * *$ & -2.22 \\
\hline 12 & 0.3392 & 5.23 & $* * *$ & 3.56 & & 0.6190 & -0.87 & -8.10 & 6.77 & $* * *$ & 12.12 & $*:$ & -8.19 & 2.24 & 3.20 & $* *$ & 9.70 & $* * *$ & 22.49 & ** & 2.51 \\
\hline
\end{tabular}

Note: This table presents the results of model (5)'s time-series regressions on equal-weighted excess returns and illiquidity measures for a time lag of three months, and 12 rolling averages for the total period, without breaks, and identified sub-periods. It includes the coefficients of expected and unexpected illiquidity with their respective significance levels, and the adjusted R-squares, based on the market's excess returns (dependent variable). However, the intercept is not reported. ***, ** and * denote the test statistics of the coefficients at the $1 \%, 5 \%$, and $10 \%$ levels, respectively. The $O L I Q$, which represents the orthogonalized $L I Q$, is the illiquidity measure. This orthogonalized $L I Q$ is risk-adjusted for the four Fama-French factors (see Table 14). The heteroscedasticity and autocorrelation consistent covariance matrix is based on a quadratic kernel with automatic bandwidth selection with an AR(1) approximation, as suggested by Andrews (1991), and Andrews and Monahan (1992). The residuals are pre-whitened using VAR(1). The sub-periods are defined as follows: (1) July 1999 to March 2003; (2) April 2003 to March 2007; (3) April 2007 to February 2009; (4) March 2009 to November 2016; and (5) December 2016 to October 2018. The illiquidity measures are winsorized at the $0.5 \%$ and $99.5 \%$ levels for each month. The data include CDAX stocks from July 1999 to October 2018. 
Table 19: Regression results with orthogonalized LIQ and Fama-French factors without breaks and with fix breaks - equal-weighted, winsorizing level at 10\% and 90\%

\begin{tabular}{|c|c|c|c|c|c|c|c|c|c|c|c|c|c|c|c|c|c|c|c|}
\hline \multirow{4}{*}{$\begin{array}{c}\text { averaged } \\
\text { across } m \\
\text { months }\end{array}$} & \multirow{2}{*}{\multicolumn{5}{|c|}{ Total Sample }} & \multicolumn{14}{|c|}{ Subsamples with breakpoints } \\
\hline & & & & & & \multirow{2}{*}{\multicolumn{3}{|c|}{$\begin{array}{c}\text { Period 1 } \\
\text { Illiquidity }\end{array}$}} & \multirow{2}{*}{\multicolumn{4}{|c|}{$\begin{array}{c}\text { Period 2 } \\
\text { Illiquidity }\end{array}$}} & \multirow{2}{*}{\multicolumn{2}{|c|}{$\begin{array}{c}\text { Period } 3 \\
\text { Illiquidity }\end{array}$}} & \multirow{2}{*}{\multicolumn{2}{|c|}{$\begin{array}{c}\text { Period } 4 \\
\text { Illiquidity }\end{array}$}} & & & \\
\hline & \multirow[b]{2}{*}{ Adj. $\mathrm{R}^{2}$} & \multicolumn{4}{|c|}{ Illiquidity } & & & & & & & & & & & & \multicolumn{3}{|c|}{$\begin{array}{c}\text { Period } 5 \\
\text { Illiquidity }\end{array}$} \\
\hline & & \multicolumn{2}{|c|}{ Exp. } & \multicolumn{2}{|c|}{ Unexp. } & Adj. $R^{2}$ & Exp. & Unexp. & \multicolumn{2}{|c|}{ Exp. } & \multicolumn{2}{|c|}{ Unexp. } & Exp. & Unexp. & Exp. & Unexp. & \multicolumn{2}{|c|}{ Exp. } & Unexp. \\
\hline 1 & 0.4086 & 3.13 & $*$ & -13.35 & **** & 0.6454 & -1.67 & -2.67 & 8.38 & **** & -5.72 & $*$ & $-15.19 *$ & -1.84 & 1.74 & $-8.87 * *$ & 0.37 & & -51.65 \\
\hline 2 & 0.3639 & 3.36 & $* *$ & -11.14 & $* * *$ & 0.6253 & -1.67 & -3.15 & 9.25 & $* * *$ & 0.12 & & -15.28 & 0.25 & 2.08 & -5.94 & 6.38 & & -50.73 \\
\hline 3 & 0.3677 & 3.93 & $* *$ & -11.95 & $* * *$ & 0.6255 & -1.40 & -5.79 & 9.42 & $* * *$ & 1.20 & & -15.30 & -1.29 & 2.63 & -3.55 & 6.64 & & -63.26 \\
\hline 4 & 0.3758 & 4.53 & $* * *$ & -13.23 & $* * *$ & 0.6273 & -0.79 & $-8.51 *$ & 9.51 & $* * *$ & 2.28 & & -15.02 & -9.14 & 3.17 & -1.50 & 6.49 & & $-72.39 *$ \\
\hline 5 & 0.3875 & 5.05 & $* * *$ & -14.85 & $* * *$ & 0.6254 & -0.11 & $-10.54 * *$ & 9.39 & $* * *$ & 2.37 & & -15.59 & -8.85 & $3.36 *$ & -2.19 & 14.28 & & -58.38 \\
\hline 6 & 0.3838 & 5.34 & $* * *$ & -14.63 & $* * *$ & 0.6207 & 0.00 & $-10.67 * *$ & 9.33 & $* * *$ & 2.42 & & -15.55 & -9.85 & $3.32 *$ & -0.23 & 25.20 & $* *$ & -27.31 \\
\hline 7 & 0.3726 & 5.52 & $* * *$ & -13.20 & $* * *$ & 0.6175 & -0.04 & $-10.18 *$ & 9.14 & $* * *$ & 6.24 & & -14.97 & -13.24 & $3.19 *$ & 3.90 & 28.64 & $* * *$ & -21.38 \\
\hline 8 & 0.3644 & 5.74 & $* * *$ & -11.59 & $* * *$ & 0.6169 & 0.02 & $-9.87 *$ & 8.94 & $* * *$ & 8.41 & & -14.38 & -16.46 & $3.07 *$ & 6.68 & 30.06 & $* * *$ & -14.55 \\
\hline 9 & 0.3525 & 5.76 & $* * *$ & -9.37 & $*$ & 0.6168 & -0.33 & -8.98 & 8.69 & $* * *$ & 11.14 & $* *$ & -13.92 & -17.37 & $2.86 *$ & 8.06 & 31.09 & $* * *$ & -18.57 \\
\hline 10 & 0.3436 & 5.73 & $* * *$ & -7.35 & & 0.6139 & -0.78 & -8.02 & 8.33 & $* * *$ & 12.41 & $* *$ & -14.47 & -14.19 & 2.72 & 8.29 & 32.37 & $* * *$ & -21.31 \\
\hline 11 & 0.3357 & 5.66 & $* * *$ & -4.86 & & 0.6141 & -0.91 & -8.01 & 8.01 & $* * *$ & 14.18 & $* * *$ & -14.74 & -8.28 & 2.60 & $9.75 *$ & 33.80 & $* * *$ & -22.50 \\
\hline 12 & 0.3313 & 5.59 & $* * *$ & -3.17 & & 0.6136 & -1.06 & -8.53 & 7.62 & $* * *$ & 15.84 & $* * *$ & -15.10 & -2.31 & 2.48 & 10.41 & 35.32 & $* *$ & -10.14 \\
\hline
\end{tabular}

Note: This table presents the results of model (5)'s time-series regressions on equal-weighted excess returns and illiquidity measures for a time lag of three months, and 12 rolling averages for the total period, without breaks, and identified sub-periods. It includes the coefficients of expected and unexpected illiquidity with their respective significance levels, and the adjusted R-squares, based on the market's excess returns (dependent variable). However, the intercept is not reported. ***, ** and $*$ denote the test statistics of the coefficients at the $1 \%, 5 \%$, and $10 \%$ levels, respectively. The $O L I Q$, which represents the orthogonalized $L I Q$, is the illiquidity measure. This orthogonalized $L I Q$ is risk-adjusted for the four Fama-French factors (see Table 15). The heteroscedasticity and autocorrelation consistent covariance matrix is based on a quadratic kernel with automatic bandwidth selection with an AR(1) approximation, as suggested by Andrews (1991), and Andrews and Monahan (1992). The residuals are pre-whitened using VAR(1). The sub-periods are defined as follows: (1) July 1999 to March 2003; (2) April 2003 to March 2007; (3) April 2007 to February 2009; (4) March 2009 to November 2016; and (5) December 2016 to October 2018. The illiquidity measures are winsorized at the 10\% and 90\% levels for each month. The data include CDAX stocks from July 1999 to October 2018. 
Table 20: Regression results with orthogonalized LIQ and Fama-French factors without breaks and with fix breaks - value-weighted

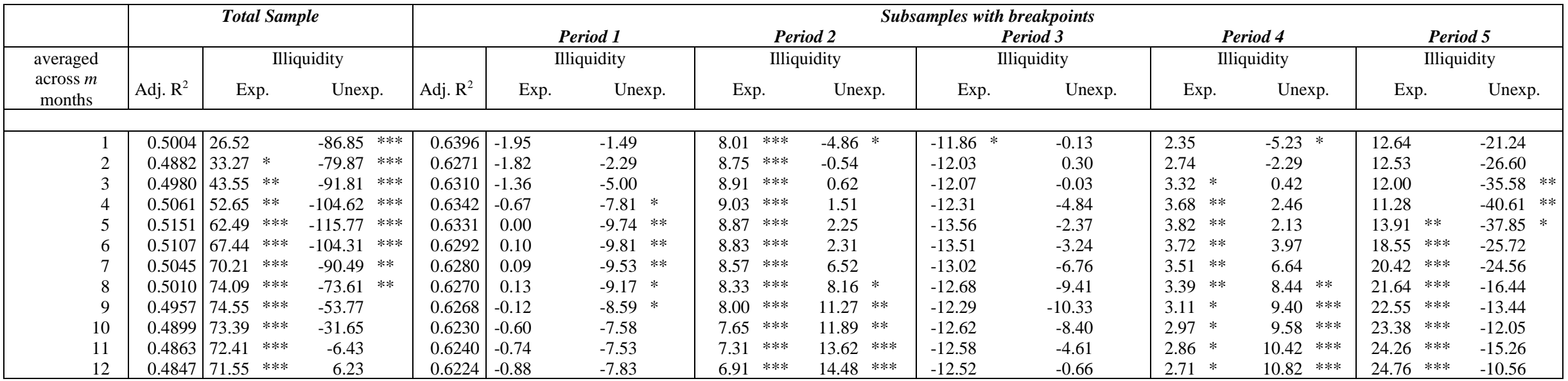

Note: This table presents the results of model (5)'s time-series regressions on value-weighted excess returns and illiquidity measures for a time lag of three months, and 12 rolling averages for the total period, without breaks, and identified sub-periods. It includes the coefficients of expected and unexpected illiquidity with their respective significance levels, and the adjusted R-squares, based on the market's excess returns (dependent variable). However, the intercept is not reported. ***, ** and * denote the test statistics of the coefficients at the $1 \%, 5 \%$, and $10 \%$ levels, respectively. The $O L I Q$, which represents the orthogonalized $L I Q$, is the illiquidity measure. This orthogonalized $L I Q$ is risk-adjusted for the four Fama-French factors (see Table 16). The heteroscedasticity and autocorrelation consistent covariance matrix is based on a quadratic kernel with automatic bandwidth selection with an AR(1) approximation, as suggested by Andrews (1991), and Andrews and Monahan (1992). The residuals are pre-whitened using VAR(1). The sub-periods are defined as follows: (1) July 1999 to March 2003; (2) April 2003 to March 2007; (3) April 2007 to February 2009; (4) March 2009 to November 2016; and (5) December 2016 to October 2018. The illiquidity measures are winsorized at the 5\% and 95\% levels for each month. The data include CDAX stocks from July 1999 to October 2018. 
Table 21: Regression results without breaks and with fix breaks on size-based portfolios - equal-weighted, adjusted for inflation

\begin{tabular}{|c|c|c|c|c|c|c|c|c|c|c|c|c|c|c|c|c|c|c|c|c|}
\hline & \multirow{2}{*}{\multicolumn{4}{|c|}{ Total Sample }} & \multicolumn{16}{|c|}{ Subsamples with breakpoints } \\
\hline & & & & & \multirow{2}{*}{\multicolumn{3}{|c|}{$\frac{\text { Period 1 }}{\text { Illiquidity }}$}} & \multirow{2}{*}{\multicolumn{4}{|c|}{$\frac{\text { Period } 2}{\text { Illiquidity }}$}} & \multicolumn{2}{|c|}{ Period 3} & \multirow{2}{*}{\multicolumn{4}{|c|}{$\frac{\text { Period 4 }}{\text { Illiquidity }}$}} & \multirow{2}{*}{\multicolumn{3}{|c|}{$\begin{array}{l}\text { Period } 5 \\
\text { Illiquidity }\end{array}$}} \\
\hline \multirow{2}{*}{\begin{tabular}{|c|} 
Size- \\
Portfolios
\end{tabular}} & & \multicolumn{3}{|c|}{ Illiquidity } & & & & & & & & \multicolumn{2}{|r|}{ Illiquidity } & & & & & Illiquidity & & \\
\hline & Adj. $R^{2}$ & Exp & & Unexp. & \multirow[t]{2}{*}{ Adj. $\mathrm{R}^{2}$} & \multirow{2}{*}{ Exp. } & \multirow{2}{*}{ Unexp. } & \multicolumn{4}{|c|}{\begin{tabular}{l}
\multicolumn{2}{c}{ Illiquidity } \\
Exp.
\end{tabular}} & Exp. & Unexp. & & xp. & Unexp & & Exp & & Unexp. \\
\hline \multicolumn{18}{|c|}{ Averaged across 1 month } & & & \\
\hline 2 & 0.1647 & 3.42 & ** & $-13.87 * * *$ & 0.2443 & -0.08 & $-8.34 *$ & 7.39 & $* * *$ & -13.23 & **** & -3.01 & -11.81 & 6.83 & & -1.62 & & 5.34 & & $-18.06 *$ \\
\hline 4 & 0.1352 & 1.88 & & $-14.12 * * *$ & 0.2466 & -2.15 & -6.81 & 6.99 & $* * *$ & -8.47 & $* *$ & -6.36 & -13.08 & 5.31 & $* *$ & -3.11 & & 6.77 & & -13.53 \\
\hline 6 & 0.1331 & 2.34 & & $-14.50 * * *$ & 0.2080 & 1.06 & -10.00 & 4.81 & $* * *$ & -7.19 & $* *$ & -5.13 & -19.33 & 4.26 & $*$ & -5.36 & $*$ & 6.66 & & -14.38 \\
\hline 8 & 0.1038 & 2.85 & & $-12.75 * * *$ & 0.1786 & 1.18 & -7.31 & 6.04 & $* * *$ & -4.53 & & -8.59 & -12.28 & 7.98 & $* * *$ & -2.83 & & 2.22 & & -20.87 \\
\hline 10 & 0.0780 & 0.19 & & $-11.15 * * *$ & 0.1761 & -3.51 & $-10.34 *$ & 4.87 & **** & 2.30 & & $-11.96 *$ & $-15.39 *$ & 6.65 & $* *$ & -1.90 & & 10.51 & $* *$ & $-11.68 *$ \\
\hline TOTAL & 0.1395 & 2.22 & & $-13.32 * * *$ & 0.2325 & -0.73 & -8.92 & 6.83 & $* * *$ & -6.12 & * & -6.72 & -15.07 & 5.91 & $* *$ & -2.79 & & 8.40 & & -15.24 \\
\hline \multicolumn{21}{|c|}{ Averaged across 6 months } \\
\hline 2 & 0.0768 & 4.80 & $* * *$ & -9.96 & \begin{tabular}{l|l}
0.2066 \\
\end{tabular} & -0.20 & -8.95 & 9.14 & $* * *$ & 3.46 & $* * *$ & -5.76 & -7.59 & 7.20 & $* *$ & 10.47 & $* * *$ & 17.65 & $* * *$ & -26.23 \\
\hline 4 & 0.0776 & 3.86 & $* *$ & -13.74 & 0.2375 & -2.28 & -9.15 & 8.55 & $* * *$ & 1.73 & $* * *$ & -9.83 & -8.33 & 6.32 & $* * *$ & 7.73 & $* * *$ & 20.73 & $* * *$ & -20.90 \\
\hline 6 & 0.0638 & 4.08 & $* *$ & -12.32 & 0.1876 & 2.35 & -16.08 & 6.07 & $* * *$ & 2.20 & $* * *$ & -10.16 & -8.01 & 5.11 & $* *$ & 8.38 & $* * *$ & 15.18 & $* *$ & -30.23 \\
\hline 8 & 0.0510 & 4.46 & $* *$ & -9.50 & 0.1749 & 5.16 & -22.83 & 6.17 & $* * *$ & 7.53 & $* * *$ & -10.92 & -8.54 & 8.18 & $* * *$ & 12.32 & $* * *$ & 11.65 & $*$ & -37.78 \\
\hline 10 & 0.0133 & 1.29 & & -7.88 & 0.1605 & -2.64 & -17.37 & 4.12 & $* *$ & 8.37 & $* * *$ & $-18.15 *$ & -8.38 & 6.36 & $* * *$ & 12.94 & $* * *$ & 12.98 & $* * *$ & -16.81 \\
\hline TOTAL & 0.0617 & 3.77 & $* *$ & -10.56 & 0.2126 & -0.13 & -12.74 & 7.62 & $* * *$ & 5.27 & & -10.24 & -10.40 & 6.38 & $* * *$ & 9.95 & & 17.21 & $* * *$ & -25.37 \\
\hline \multicolumn{21}{|c|}{ Averaged across 12 months } \\
\hline 2 & 0.0568 & 5.46 & $* * *$ & -2.37 & 0.2117 & 3.27 & -26.98 & 6.92 & $* *$ & 24.23 & $* * *$ & -5.91 & -16.53 & 4.99 & $* * *$ & 18.94 & *** & 21.55 & $* * *$ & 0.28 \\
\hline 4 & 0.0488 & 4.98 & $* * *$ & -6.35 & 0.2442 & 1.71 & -30.03 & 6.38 & $* *$ & 22.53 & $* * *$ & -13.42 & -12.64 & 4.66 & $* * *$ & 17.17 & $* * *$ & 24.17 & $* * *$ & 6.45 \\
\hline 6 & 0.0460 & 5.11 & $* * *$ & -6.35 & 0.1907 & 5.37 & -29.68 & 4.29 & ** & 18.43 & $* * *$ & -12.26 & -16.73 & 3.23 & & 16.76 & **** & 18.04 & ** & -11.01 \\
\hline 8 & 0.0378 & 5.17 & $* * *$ & -2.24 & 0.1643 & 7.55 & -30.57 & 4.10 & $*$ & 18.45 & $* * *$ & $-18.03 *$ & -2.33 & 5.45 & $* * *$ & 22.02 & $* * *$ & 16.04 & $*$ & -12.76 \\
\hline 10 & 0.0031 & 1.98 & & -4.24 & 0.1535 & -3.88 & -19.13 & 2.16 & & 17.07 & $* * *$ & $-23.55 *$ & -19.97 & 3.84 & & 19.43 & $* * *$ & 12.28 & $* *$ & -6.27 \\
\hline TOTAL & 0.0427 & 4.63 & $* * *$ & -4.08 & 0.2148 & 2.71 & -27.77 & 5.41 & $* *$ & 22.28 & $* * *$ & -13.34 & -15.22 & 4.36 & $* * *$ & 17.93 & $* * *$ & 19.59 & $* * *$ & -3.51 \\
\hline
\end{tabular}

Note: This table presents the results of model (5)'s time-series regressions on equal-weighted excess returns and illiquidity measures for a time lag of three months and different rolling averages of the selected size portfolios, as well as the total market for the total period, without breaks, and the identified sub-periods. It includes the coefficients of expected and unexpected illiquidity with their respective significance levels and the adjusted R-squares, based on the market's excess returns (dependent variable). The illiquidity measures are adjusted for inflation (EUR-turnover adjusted by consumer price index, Germany). However, the intercept is not reported. ***, ** and * denote the test statistics of the coefficients at the $1 \%, 5 \%$, and $10 \%$ levels, respectively. The heteroscedasticity and autocorrelation consistent covariance matrix is based on a quadratic kernel with automatic bandwidth selection with an AR(1) approximation, as suggested by Andrews (1991), and Andrews and Monahan (1992). The residuals are pre-whitened using VAR(1). All stocks in the sample are sorted at the year-end into one of 10 portfolios, based on their respective market capitalization. The sub-periods are defined as follows: (1) July 1999 to March 2003; (2) April 2003 to March 2007; (3) April 2007 to February 2009; (4) March 2009 to November 2016; and (5) December 2016 to June 2019. The illiquidity measures are winsorized at the $5 \%$ and $95 \%$ levels for each month. The data include CDAX stocks from July 1999 to June 2019 
Table 22: Regression results without breaks and with fix breaks on size-based portfolios - equal-weighted, winsorizing level at a $0.5 \%$ and $99.5 \%$

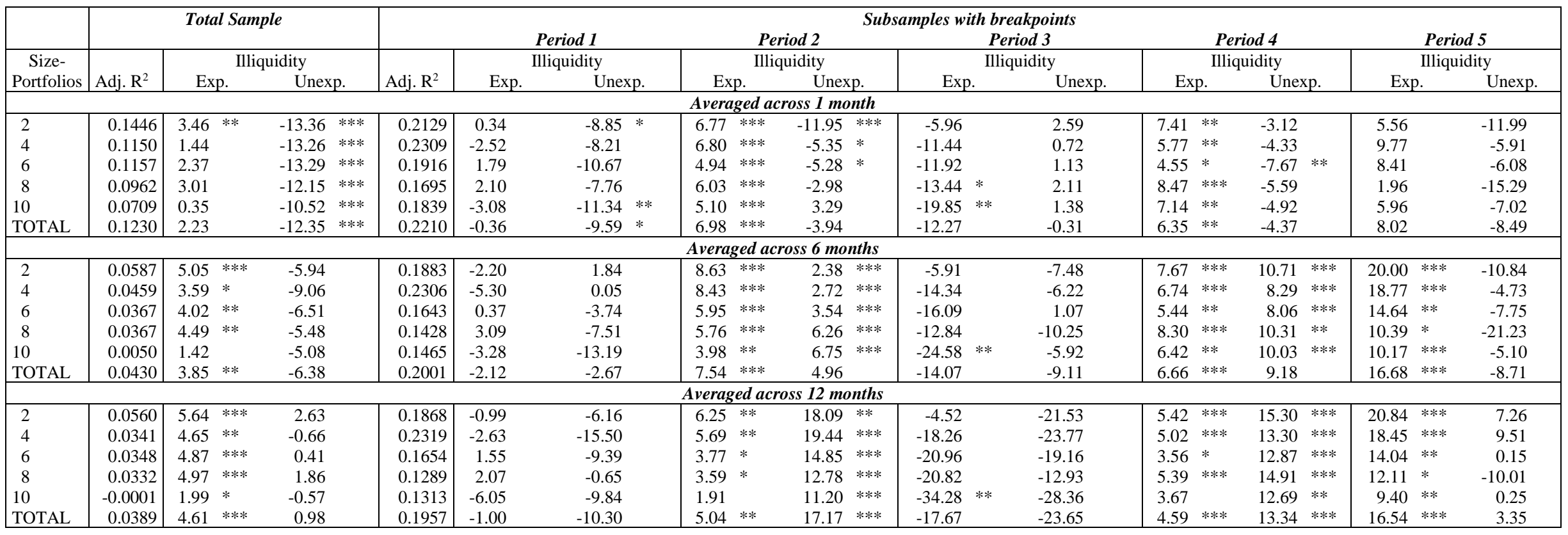

Note: This table presents the results of model (5)'s time-series regressions on equal-weighted excess returns and illiquidity measures for a time lag of three months and different rolling averages of the selected size portfolios, as well as the total market for the total period, without breaks, and the identified sub-periods. It includes the coefficients of expected and unexpected illiquidity with their respective significance levels and the adjusted R-squares, based on the market's excess returns (dependent variable). However, the intercept is not reported. $* * *, * *$ and $*$ denote the test statistics of the coefficients at the $1 \%, 5 \%$, and $10 \%$ levels, respectively. The heteroscedasticity and autocorrelation consistent covariance matrix is based on a quadratic kernel with automatic bandwidth selection with an AR(1) approximation, as suggested by Andrews (1991), and Andrews and Monahan (1992). The residuals are pre-whitened using VAR(1). All stocks in the sample are sorted at the year-end into one of 10 portfolios, based on their respective market capitalization. The sub-periods are defined as follows: (1) July 1999 to March 2003; (2) April 2003 to March 2007; (3) April 2007 to February 2009; (4) March 2009 to November 2016; and (5) December 2016 to June 2019. The illiquidity measures are winsorized at the $0.5 \%$ and $99.5 \%$ levels for each month. The data include CDAX stocks from July 1999 to June 2019 
Table 23: Regression results without breaks and with fix breaks on size-based portfolios-equal-weighted, winsorizing level at a 10\% and $90 \%$

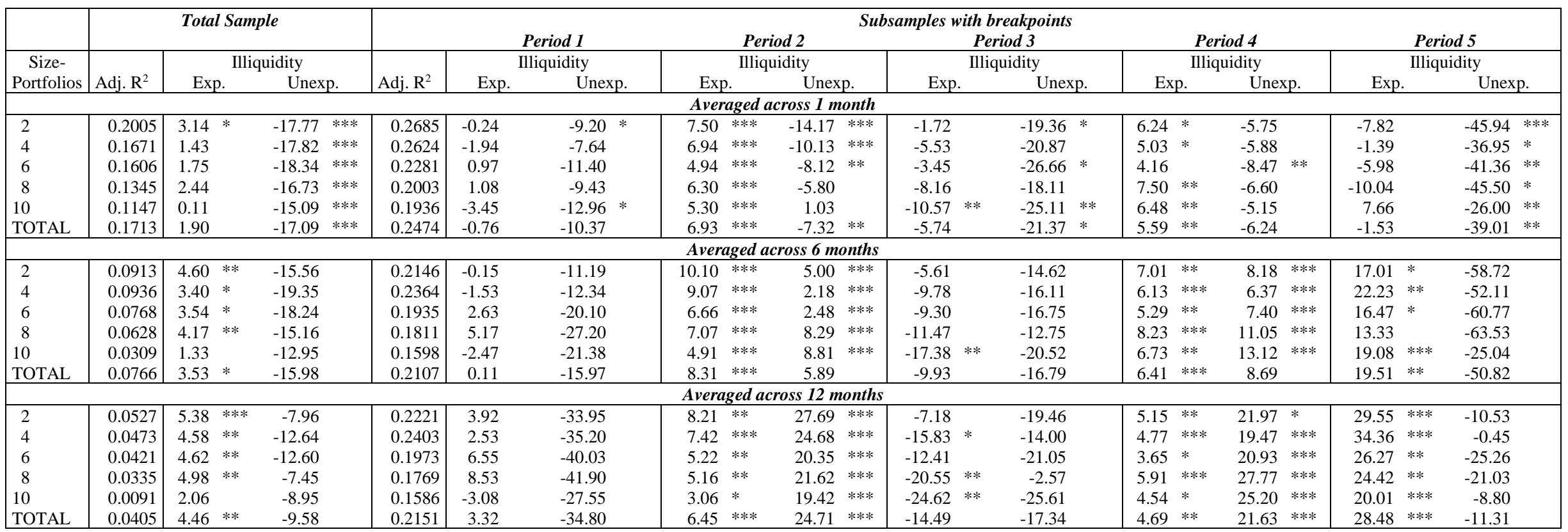

Note: This table presents the results of model (5)'s time-series regressions on equal-weighted excess returns and illiquidity measures for a time lag of three months and different rolling averages of the selected size portfolios, as well as the total market for the total period, without breaks, and the identified sub-periods. It includes the coefficients of expected and unexpected illiquidity with their respective significance levels and the adjusted R-squares, based on the market's excess returns (dependent variable). However, the intercept is not reported. $* * *, * *$ and $*$ denote the test statistics of the coefficients at the $1 \%, 5 \%$, and $10 \%$ levels, respectively. The heteroscedasticity and autocorrelation consistent covariance matrix is based on a quadratic kernel with automatic bandwidth selection with an AR(1) approximation, as suggested by Andrews (1991), and Andrews and Monahan (1992). The residuals are pre-whitened using VAR(1). All stocks in the sample are sorted at the year-end into one of 10 portfolios, based on their respective market capitalization. The sub-periods are defined as follows: (1) July 1999 to March 2003; (2) April 2003 to March 2007; (3) April 2007 to February 2009; (4) March 2009 to November 2016; and (5) December 2016 to June 2019. The illiquidity measures are winsorized at the 10\% and 90\% levels for each month. The data include CDAX stocks from July 1999 to June 2019 
Table 24: Regression results without breaks and with fix breaks on size-based portfolios - value-weighted

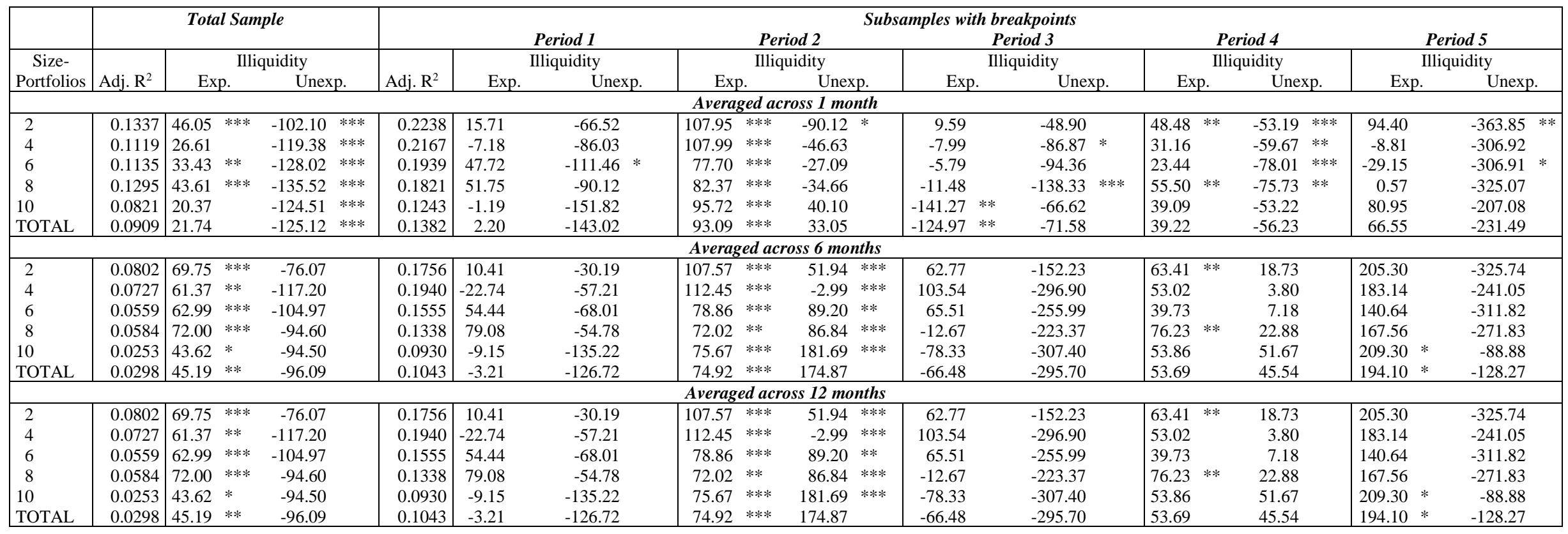

Note: This table presents the results of model (5)'s time-series regressions on value-weighted excess returns and illiquidity measures for a time lag of three months and different rolling averages of the selected size portfolios, as well as the total market for the total period, without breaks, and the identified sub-periods. It includes the coefficients of expected and unexpected illiquidity with their respective significance levels and the adjusted R-squares, based on the market's excess returns (dependent variable). However, the intercept is not reported. $* * *, * *$ and $*$ denote the test statistics of the coefficients at the $1 \%, 5 \%$, and $10 \%$ levels, respectively. The heteroscedasticity and autocorrelation consistent covariance matrix is based on a quadratic kernel with automatic bandwidth selection with an AR(1) approximation, as suggested by Andrews (1991), and Andrews and Monahan (1992). The residuals are pre-whitened using VAR(1). All stocks in the sample are sorted at the year-end into one of 10 portfolios, based on their respective market capitalization. The sub-periods are defined as follows: (1) July 1999 to March 2003; (2) April 2003 to March 2007; (3) April 2007 to February 2009; (4) March 2009 to November 2016; and (5) December 2016 to June 2019. The illiquidity measures are winsorized at the 5\% and 95\% levels for each month. The data include CDAX stocks from July 1999 to June 2019. 
Table 25: Economic value of illiquidity

\begin{tabular}{|c|c|c|c|c|c|c|c|c|c|c|c|c|c|c|c|c|}
\hline \multirow[b]{3}{*}{$\begin{array}{c}\text { Size- } \\
\text { Portfolios }\end{array}$} & \multicolumn{4}{|c|}{ Return } & \multicolumn{12}{|c|}{ Return contribution of illiquidity } \\
\hline & & & & & \multicolumn{6}{|c|}{$\begin{array}{r}\text { Impact of market illiquidity } \\
\text { With breaks }\end{array}$} & \multicolumn{6}{|c|}{$\begin{array}{r}\text { Impact of portfolio illiquidity } \\
\text { With breaks }\end{array}$} \\
\hline & $\begin{array}{c}\text { Total } \\
\text { period }\end{array}$ & $\begin{array}{l}\text { Non- } \\
\text { crisis } \\
\text { period }\end{array}$ & \multicolumn{2}{|l|}{$\begin{array}{l}\text { Crisis } \\
\text { period }\end{array}$} & $\begin{array}{c}\text { Without } \\
\text { breaks- } \\
\text { Total period }\end{array}$ & $\begin{array}{c}\text { Total } \\
\text { period }\end{array}$ & $\begin{array}{l}\text { Non- } \\
\text { crisis } \\
\text { period }\end{array}$ & $\begin{array}{l}\text { Crisis } \\
\text { period }\end{array}$ & \multicolumn{2}{|c|}{$\begin{array}{l}\text { Difference between } \\
\text { non-crisis periods } \\
\text { (with vs. w/o } \\
\text { breaks) }\end{array}$} & \multirow[t]{2}{*}{$\begin{array}{c}\text { Without } \\
\text { breaks- } \\
\text { Total } \\
\text { period } \\
\end{array}$} & \multirow[t]{2}{*}{$\begin{array}{l}\text { Total } \\
\text { period }\end{array}$} & \multirow[t]{2}{*}{$\begin{array}{l}\text { Non- } \\
\text { crisis } \\
\text { period }\end{array}$} & \multirow[t]{2}{*}{$\begin{array}{l}\text { Crisis } \\
\text { period }\end{array}$} & \multicolumn{2}{|c|}{$\begin{array}{l}\text { Difference betweer } \\
\text { non-crisis periods } \\
\text { (with vs. w/o } \\
\text { breaks) }\end{array}$} \\
\hline \multicolumn{13}{|c|}{ Averaged across 1 month } & & & & \\
\hline 1 & 1.02 & 2.05 & -1.57 & *** & 2.86 & 3.75 & 5.41 & -0.43 & 2.25 & $* * * *$ & 3.50 & 9.26 & 13.15 & -0.57 & 9.39 & $* * * *$ \\
\hline 2 & 0.27 & 1.57 & -3.00 & $* * *$ & 2.16 & 2.45 & 3.77 & -0.87 & 1.24 & $* * *$ & 2.71 & 4.58 & 6.92 & -1.35 & 3.88 & $* * *$ \\
\hline 4 & 0.09 & 1.64 & -3.81 & $* * *$ & 1.35 & 2.07 & 3.29 & -1.01 & 1.55 & $* * *$ & 1.08 & 2.46 & 3.94 & -1.28 & 2.45 & $* * *$ \\
\hline 6 & 0.07 & 1.62 & -3.82 & $* * *$ & 1.57 & 1.70 & 2.36 & 0.03 & 0.41 & $* *$ & 0.76 & 1.00 & 1.44 & -0.11 & 0.49 & $* * *$ \\
\hline 8 & 0.34 & 1.72 & -3.15 & $* * *$ & 2.20 & 2.88 & 3.47 & 1.40 & 0.96 & $* * *$ & 0.50 & 0.52 & 0.65 & 0.19 & -0.03 & \\
\hline 10 & 0.38 & 1.39 & -2.17 & $* *$ & 1.12 & 1.67 & 2.13 & 0.49 & 0.70 & $* * *$ & 0.33 & 0.07 & 0.11 & -0.05 & -0.30 & $* * *$ \\
\hline TOTAL & 0.33 & 1.65 & -3.00 & $* * *$ & 1.70 & 2.34 & 3.27 & -0.03 & 1.22 & $* * *$ & 1.70 & 2.34 & 3.27 & -0.03 & 1.22 & $* * * *$ \\
\hline \multicolumn{17}{|c|}{ Averaged across 6 months } \\
\hline 1 & 1.02 & 2.05 & -1.57 & *** & 3.79 & 4.27 & 6.16 & -0.51 & 2.11 & $* * * *$ & 4.98 & 10.92 & 15.64 & -0.99 & 10.21 & $* * * *$ \\
\hline 2 & 0.27 & 1.57 & -3.00 & $* * *$ & 3.20 & 3.46 & 4.94 & -0.28 & 1.40 & $* * *$ & 3.83 & 6.80 & 9.58 & -0.22 & 5.43 & $* * *$ \\
\hline 4 & 0.09 & 1.64 & -3.81 & $* * *$ & 2.89 & 3.04 & 4.39 & -0.35 & 1.07 & $* * *$ & 2.25 & 3.41 & 5.01 & -0.63 & 2.37 & $* * *$ \\
\hline 6 & 0.07 & 1.62 & -3.82 & $* * *$ & 2.85 & 2.42 & 3.16 & 0.56 & -0.06 & & 1.31 & 1.30 & 1.71 & 0.27 & 0.25 & $*$ \\
\hline 8 & 0.34 & 1.72 & -3.15 & $* * *$ & 3.48 & 3.48 & 4.01 & 2.16 & 0.18 & & 1.34 & 0.58 & 0.65 & 0.40 & -0.72 & $* * *$ \\
\hline 10 & 0.38 & 1.39 & -2.17 & *** & 2.13 & 2.35 & 2.86 & 1.08 & 0.44 & $* *$ & 0.75 & 0.09 & 0.13 & -0.01 & -0.77 & $* * *$ \\
\hline TOTAL & 0.33 & 1.65 & -3.00 & $* * *$ & 2.92 & 3.08 & 4.11 & 0.48 & 0.84 & $* * *$ & 2.92 & 3.08 & 4.11 & 0.48 & 0.84 & $* * * *$ \\
\hline \multicolumn{17}{|c|}{ Averaged across 12 months } \\
\hline 1 & 1.02 & 2.05 & -1.57 & *** & 3.72 & 3.74 & 5.55 & -0.85 & 1.66 & $* * *$ & 5.62 & 9.83 & 14.50 & -1.93 & 8.42 & **** \\
\hline 2 & 0.27 & 1.57 & -3.00 & $* * *$ & 3.20 & 3.14 & 4.57 & -0.46 & 1.16 & $* * *$ & 3.98 & 6.34 & 9.12 & -0.67 & 4.85 & $* * *$ \\
\hline 4 & 0.09 & 1.64 & -3.81 & $* * *$ & 3.13 & 2.79 & 4.03 & -0.35 & 0.63 & $* *$ & 2.37 & 2.88 & 4.26 & -0.62 & 1.62 & $* * *$ \\
\hline 6 & 0.07 & 1.62 & -3.82 & $* * *$ & 3.00 & 1.96 & 2.73 & 0.04 & -0.49 & & 1.42 & 0.99 & 1.39 & -0.03 & -0.12 & \\
\hline 8 & 0.34 & 1.72 & -3.15 & $* * *$ & 3.42 & 3.05 & 3.54 & 1.82 & -0.09 & & 1.33 & 0.50 & 0.54 & 0.39 & -0.74 & $* * *$ \\
\hline 10 & 0.38 & 1.39 & -2.17 & $* *$ & 2.16 & 2.02 & 2.56 & 0.64 & 0.26 & & 0.86 & 0.07 & 0.10 & 0.00 & -0.88 & $* * *$ \\
\hline TOTAL & 0.33 & 1.65 & -3.00 & $* * *$ & 3.00 & 2.66 & 3.68 & 0.11 & 0.47 & & 3.00 & 2.66 & 3.68 & 0.11 & 0.47 & \\
\hline
\end{tabular}

Note: This table presents the means of the excess returns (left panel), the return impact of orthogonalized market illiquidity (middle panel), and the return impact of orthogonalized portfolio specific illiquidity (right panel) for the total period ( 229 months), non-crisis period (164 months), and crisis period (65 months). These are presented in percentage points per month for portfolios of different sizes, with a time lag of three months, and rolling averaged across one, six, and 12 months. In addition, we compare the difference between illiquidity's impact in non-crisis periods from the model with and without structural breaks by testing a t-statistic to determine whether the difference is equal to zero. The illiquidity measures are winsorized at the 5\% and 95\% levels for each month. The data include CDAX stocks from July 1999 to October 2018. 


\section{References}

Andrews, Donald W. K. 1991. "Heteroskedasticity and Autocorrelation Consistent Covariance Matrix Estimation.” Econometrica 59 (3): 817-58.

Andrews, Donald W. K., and J. C. Monahan. 1992. "An Improved Heteroskedasticity and Autocorrelation Consistent Covariance Matrix Estimator." Econometrica 60 (4): 953-66.

Bai, Jushan, and Pierre Perron. 2003. "Computation and analysis of multiple structural change models." Journal of Applied Econometrics 18 (1): 1-22.

Fama, Eugene F., and Kenneth R. French. 2015. "A five-factor asset pricing model." Journal of financial economics 116 (1): 1-22. doi:10.1016/j.jfineco.2014.10.010. 